$$
\begin{aligned}
& \text { DOE/PC/91154-.TB } \\
& M 96050309 .
\end{aligned}
$$

\title{
DEVELOPMENT OF A HIGH-PERFORMANCE \\ COAL-FIRED POWER GENERATING SYSTEM WITH \\ PYROLYSIS GAS AND CHAR-FIRED \\ HIGH-TEMPERATURE FURNACE (HITAF)
}

\section{DE-AC22-91PC91154}

FINAL REPORT

Volume III

\author{
Prepared for \\ Department of Energy \\ Pittsburgh Energy Technology Center \\ Pittsburgh, Pennsylvania
}

FWDC Project 9-41-3492

May 1996

FOSTER WHEELER DEVELOPMENT CORPORATION

12 Peach Tree Hill Road, Livingston, New Jersey 07039

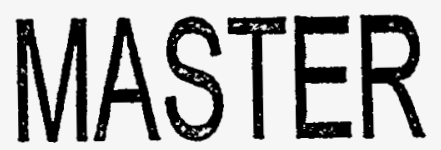




\section{DISCLAIMER}

Portions of this document may be illegible in electronic image products. Images are produced from the best available original document. 
APPENDIX F: PYROLYZER TESTING

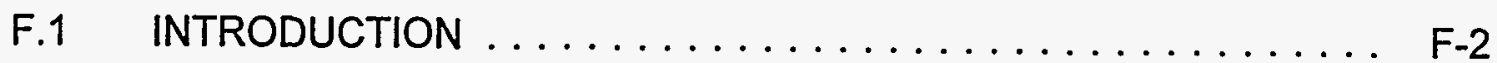

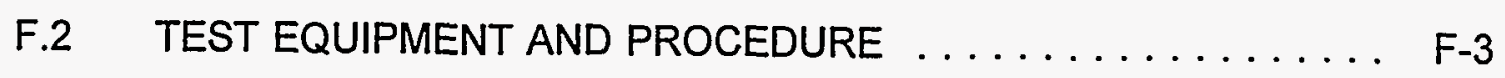

F.3 RESULTS $\ldots \ldots \ldots \ldots \ldots \ldots \ldots \ldots \ldots \ldots \ldots \ldots \ldots$ F-9

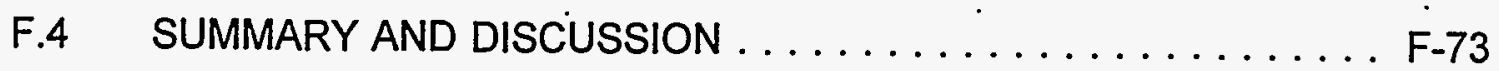

F.5 TABLES OF EXPERIMENTAL DATA VALUES . . . . . . . . F-77

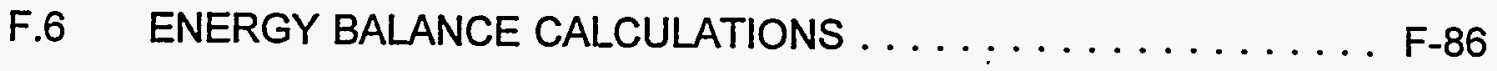

\section{DISCLAIMER}

This report was prepared as an account of work sponsored by an agency of the United States Government. Neither the United States Government nor any agency thereof, nor any of their employees, makes any warranty, express or implied, or assumes any legal liability or responsibility for the accuracy, completeness, or usefulness of any information, apparatus, product, or process disclosed, or represents that its use would not infringe privately owned rights. Reference herein to any specific commercial product, process, or service by trade name, trademark, manufacturer, or otherwise does not necessarily constitute or imply its endorsement, recomI mendation, or favoring by the United States Government or any agency thereof. The views and opinions of authors expressed herein do not necessarily state or reflect those of the United States Government ơ any agency thereof."- 


\section{APPENDIX F}

PYROLYZER TESTING 


\section{F.1 INTRODUCTION}

Testing of an atmospheric circulating bed pyrolyzer was done at Southern Illinois University. A variety of experiments have been conducted in a laboratory scale pyrolyzer with coal input flow rates from 2 to $6 \mathrm{lb} / \mathrm{h}$. Three feed coal particle sizes, corresponding to a nominal -40 mesh, -30 mesh and -18 mesh were used. The limestone used in the tests was a Genstar limestone. Parameters investigated in the tests include the influence of superficial velocity, temperature and coal-air mass ratios. Char particle size distributions under various test conditions have been measured and the char composition determined. Fuel gas composition, yields and heating values have been investigated. Char morphology has been studied using scanning electron microscopy. Char reactivity for selected samples has been measured, and the influence of feed coal size, bed temperature and superficial velocity has been determined.

Material balance calculations have been performed and found to be in very good agreement. Energy audit calculations for the process have been made to investigate the flow of energy and to estimate the losses during the process. Full details of the data, results obtained and conclusions drawn are presented. 


\section{F.2 TEST EQUIPMENT AND PROCEDURE}

\section{F.2.1 Pyrolyzer Description}

As shown in Figures F-1 and F-2, the CFB pyrolyzer used in the present experiments is divided into two sections each $3 \mathrm{ft}$. long. A blower supplies fluidizing air that is metered by a nozzle and passes through an air preheater before it enters the main dense phase section of the fluidized bed. Coal and limestone are fed from separate hoppers to the bed. Water flow to the pyrolyzer is measured with a rotameter, converted to steam at $350-400^{\circ} \mathrm{F}$ and introduced into the combustor. Char and limestone solids elutriated from the bed are captured by primary and secondary cyclones. Solids passing through the primary cyclone are collected in a recycle hopper. Part of the primary cyclone catch is recycled back into the bottom portion of the main bed. Solids captured by the secondary cyclone are not recycled. A portion of the gases exiting this secondary cyclone is filtered and conveyed through heated lines to a bank of analyzers. At the bottom of the recycle hopper is a drain auger through which char may be withdrawn. The CFB unit is instrumented with thermocouples at various points. Also, the main pyrolyzer column and primary hot cyclone are equipped with electrical heaters that are used to reduce heat losses from the pyrolyzer.

To ensure that the particle size of the collected char from the primary cyclone is not altered, the drain auger at the bottom of the recycle hopper is not used when char samples are collected for analysis. Instead, a gated side discharge port in the downcomer from the primary cyclone is utilized to collect char-limestone particles for determining the particle size. To withdraw product char from the pyrolyzer, the drain auger is used. The downcomer from the primary cyclone also has a short section of see-through quartz glass tubing. By measuring the time necessary to build up a specified column length of char in this see-through section, the recycle ratio is calculated. Details are given elsewhere. 


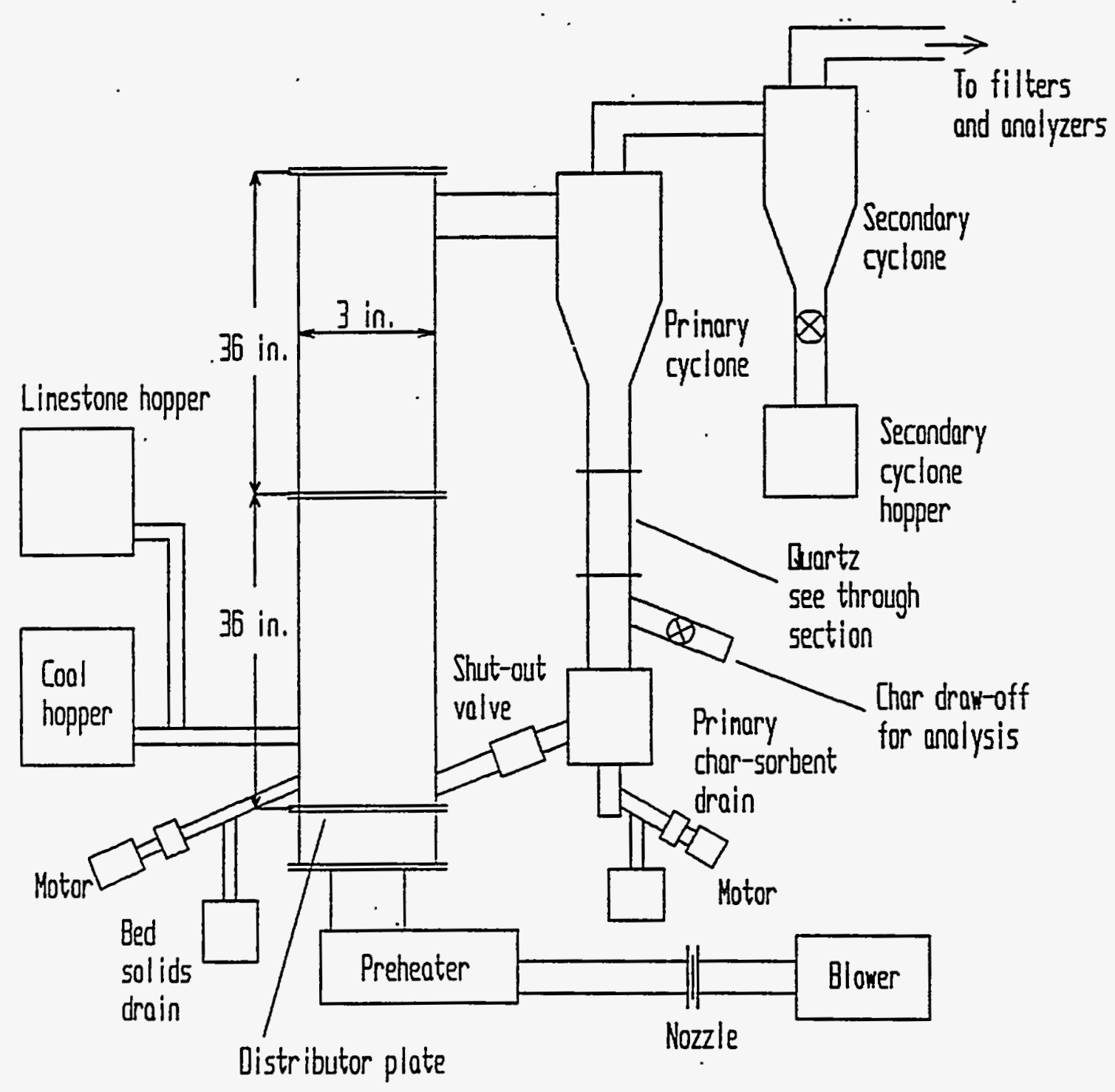

Figure F-1 Schematic of $10 \mathrm{lbs} / \mathrm{hr}$ Circulating Fluidized Bed Pyrolyzer 


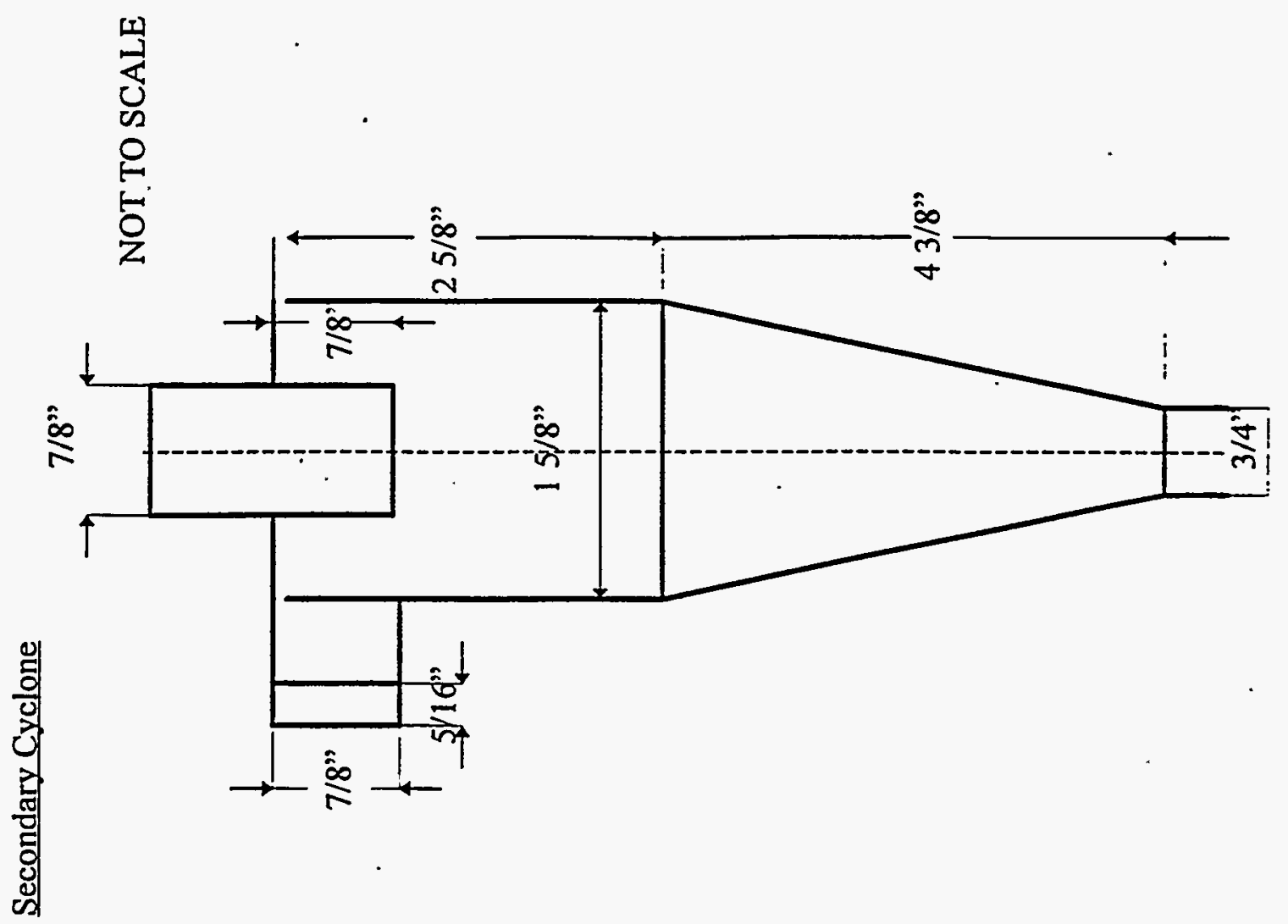

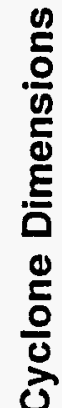

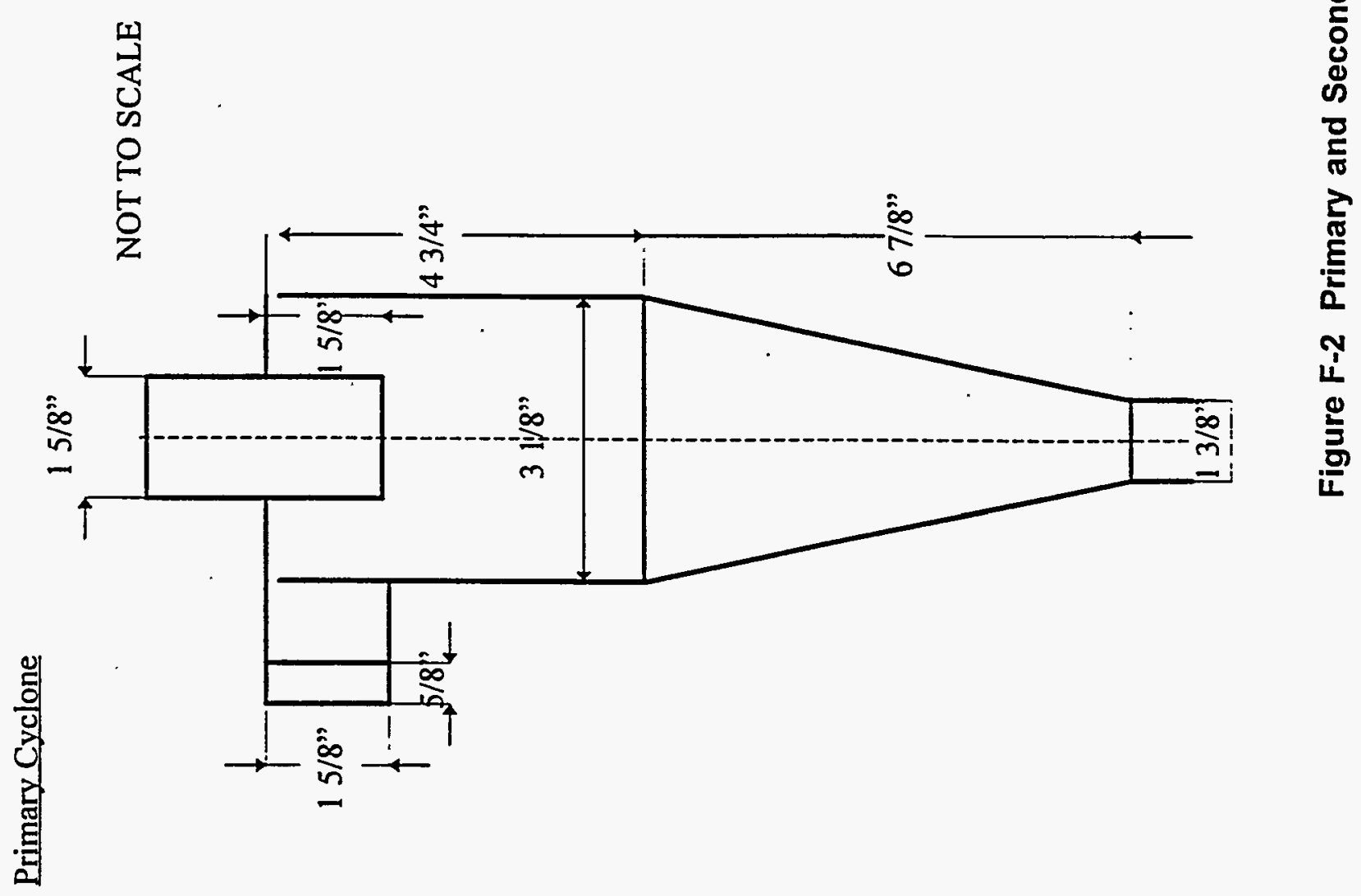




\section{F.2.2 Variables Measured}

The variables measured and the equipment used to measure these items are given in Table F-1. The gas samples are monitored continuously during a test, with the appropriate instruments.

\section{F.2.3 Experimental Procedure}

The pyrolyzer was initially heated using electric air preheat. At temperatures of about $1000^{\circ} \mathrm{F}$, coal feed is initiated and the unit brought up to temperatures of about $1600^{\circ} \mathrm{F}$ as a combustor operating in the lean regime at the fluidization velocity of the test. It is allowed to operate under these conditions for several hours so that the temperatures at various parts of the CFB pyrolyzer reach steady state values. Air preheat is then reduced such that the air entering the pyrolyzer is $100-150^{\circ} \mathrm{F}$ or is turned off.

At this point, coal feed is gradually increased so that the oxygen concentration in the flue gas is reduced to zero, and the pyrolyzer is operating in the rich stoichiometric regime (substoichiometric conditions). At a given test condition, the air, coal, limestone and water feed rates were kept constant. In addition, the amount of recycle char was kept constant at the maximum capacity of the recycle apparatus. This maximum recycle capacity was limited because of the frequency of the shut-out valve employed to isolate the bed from the recycle hopper. This shut-out valve had a maximum frequency of four cycles per minute. The calcium/sulfur mole ratio for all the experiments was $2: 1$. It was kept constant.

After the pyrolyzer had stabilized at a given test condition, a sample of fuel gas was taken from the exit of the secondary cyclone through heated lines to a bank of continuous monitoring analyzers as listed in Table F-1. The $\mathrm{CO}, \mathrm{CO}_{2}, \mathrm{O}_{2}, \mathrm{H}_{2} \mathrm{~S}$ and $\mathrm{NH}_{3}$ concentrations in the fuel gas were measured. At least two readings were taken for a given test. The coal, water and limestone feed rates are measured. Char samples coming down the primary cyclone downcomer were collected for particle size analysis. The time for a specified height of char to collect in the see-through portion of the primary cyclone downcomer was measured. This time was used to calculate the char production or char yield rate as described in the Results section. The particle size analysis of these chars was performed after the completion of the test. In addition, the amount of the smaller char particles collected by the secondary cyclone in a given time was measured. 
Table F-1 Parameters Measured and Equipment Used

\begin{tabular}{|l|l|}
\hline Variable Measured & Equipment Used \\
\hline Pyrolyzer & calibrated screw feeder \\
coal mass flow rate & calibrated screw feeder \\
limestone mass flow rate & weight scales .. \\
char mass collected & nozzle pressure drop \\
fluidizing air mass flow & rotameters \\
injection air mass flows & pressure transducer \\
pressure at various points & Type K thermocouples \\
temperature at various points & Beckman 864 IR analyzer \\
\hline Gas and Particulate Analysis & Beckman 864 IR analyzer \\
\hline Carbon monoxide & Beckman 755 Paramagnetic Analyzer \\
Carbon dioxide & Beckman 400 HC Analyzer \\
Oxygen & Anarad IR Analyzer \\
Hydrocarbons. & Rosemount IR Analyzer \\
Ammonia & Rosemount thermal conductivity analyzer \\
Hydrogen & Ultrasonic sieve analysis \\
\hline Charlparticle size analyses & Leeds and Northrop Microtrak \\
& Laser particle size analyzer \\
\hline char morphology & Scanning Electron microscopy \\
\hline char reactivity & TGA \\
\hline
\end{tabular}

Experiments were conducted to study the influence of the following parameters:

(1) Feed coal particle size (-18, -30 and -40 mesh)

(2) Superficial velocities ( 3.5 to $10 \mathrm{ft} / \mathrm{sec}$ )

(3) Bed temperature $\left(1600-1760^{\circ} \mathrm{F}\right)$

(4) Feed coal/air ratios

(5) Recycle rates

In experiments where the effect of superficial velocity was investigated, the feed coal/air ratio was maintained constant by increasing the rates of feed of coal, air and limestone proportionately, while also keeping the temperature constant. In experiments where the bed temperature was varied, the coal-air ratio and fluidization velocity were kept constant. Temperature was changed by altering slightly the heat transfer rates from the pyrolyzer. When the effect of feed coal-air ratio was studied, the superficial velocity and temperature were maintained constant. The coal-air ratio was changed by varying only the coal feed rate. In all these experiments, the amount of char recycled was kept constant at the maximum capacity of the recycle apparatus, namely four pulses per minute. 
The surface morphology of some of the primary and secondary cyclone char samples was studied using scanning electron microscopy. The particle size distribution of the primary char was determined using an ultrasonic siever with different screens. The particle size distributions of selected secondary cyclone chars and the particulates collected by a bag filter at the exit of the secondary cyclone were analyzed using the Leeds and Northrop Microtrak Laser particle size analyzer. The reactivity of selected primary cyclone chars was determined using a Cahn thermogravimetric analyzer.

\section{F.2.4 The Test Matrix}

As mentioned above, pyrolyzer tests were conducted to study the influence of feed coal particle size, superficial velocity, bed temperature, and feed coal-air ratio and to investigate the influence of solids recycle. The influence of these variables was studied by operating the gasifier under a wide range of conditions. It involved testing over a significant period of time. A few data test points were generally recorded in the span of 2-3 days. To resume the test, the pyrolyzer would be started up again on another day and often brought to stabilize at the last test condition of the previous day's testing. Further tests would then be made.

For the sake of brevity, the test data are grouped together in tables, indicating the variable that was studied during the test. The corresponding test matrix is given in Table F-2 below.

Table F-2 Pyrolyzer Test Matrix

\begin{tabular}{|l|l|l|l|l|l|}
\hline $\begin{array}{l}\text { Test } \\
\text { No. }\end{array}$ & $\begin{array}{l}\text { Coal } \\
\text { Size }\end{array}$ & $\begin{array}{l}\text { Temperature, } \\
{ }^{\circ} \mathrm{F}\end{array}$ & $\begin{array}{l}\text { Superficial } \\
\text { Velocity, ftlsec }\end{array}$ & C/A Ratio & Recycle \\
\hline 1 & -30 Mesh & 1650 & 6.4 & Variable & Yes \\
2 & -18 Mesh & 1650 & 5.9 & Variable & Yes \\
3 & -18 Mesh & 1650 & Variable & 0.23 & Yes \\
4 & -40 Mesh & 1650 & Variable & 0.22 & Yes \\
5 & -40 Mesh & Variable & 6.4 & 0.24 & Yes \\
6 & -40 Mesh & 1650 & 6.0 & Variable & Yes \\
7 & -30 Mesh & 1650 & Variable & Variable & Yes/No \\
\hline
\end{tabular}

The tests were not conducted in the order listed. The test data are given in Section 4. In plotting the data, some common values were imported from other test numbers conducted with the same size coal. 


\section{F.3 RESULTS}

\section{F.3.1 COAL AND LIMESTONE ANALYSIS}

The coal used in the experiments is a Pittsburgh No. 8 coal supplied by Foster Wheeler Development Corporation. The limestone used is a Genstar limestone also supplied by FWDC. To investigate the influence of coal feed particle size, three size distributions corresponding to a nominal -18 mesh, -30 mesh and -40 mesh were used in the experiments. Figure F-3 shows the distribution of the three feed particle sizes. The -18 mesh has $50 \%$ less than 300 microns, the -30 mesh has $50 \%$ less than 200 microns, and the -40 mesh has $50 \%$ less than 120 microns. The elemental analysis of the test coal is given in Table F-3.

Table F-3 Analysis of Pittsburgh No. 8 Coal

\begin{tabular}{|l|l|}
\hline Component & Weight \% \\
\hline Moisture & 2.44 \\
Carbon & 70.12 \\
Hydrogen & 4.46 \\
Sulfur & 3.17 \\
Nitrogen & 1.29 \\
Oxygen & 8.25 \\
Ash & 10.27 \\
\hline Heating Value & 12,765 Btu/lb \\
\hline
\end{tabular}

The limestone particle size distribution is shown in Figure F-4. The bed material used in the tests was sand. The sand size fraction was $-18+30$ mesh, with a mean particle size of $1.18 \mathrm{~mm}$. A typical size distribution of the bed material after a test run is given in Figure F-5. No. sand was added during a test.

\section{F.3.2 EFFECT OF FEED COAL PARTICLE SIZE}

Effect on Coal Feed Particle Size on Char Particle Size. The char-limestone solids collected from the primary hot cyclone under different operating conditions, i.e., the char that is recycled back into the pyrolyzer, was analyzed using an ultrasonic sieve. Figures F-6 to F-8 show the size distributions of the char-sorbent particles collected by the primary cyclone at a fluidization velocity of $6.4 \mathrm{ft} / \mathrm{sec}$ and a feed coal-to-air (C/A) mass ratio of 0.22 . The temperature of the test was $1650^{\circ} \mathrm{F}$. Each figure compares the char size with the size distribution of the corresponding feed coal. For all three feed sizes, the primary char has reduced in size compared to the size of the feed coal. This size reduction is brought about by reaction and attrition. Once the char has formed, its density is low and it is softer in consistency than the parent coal, making it easy to 


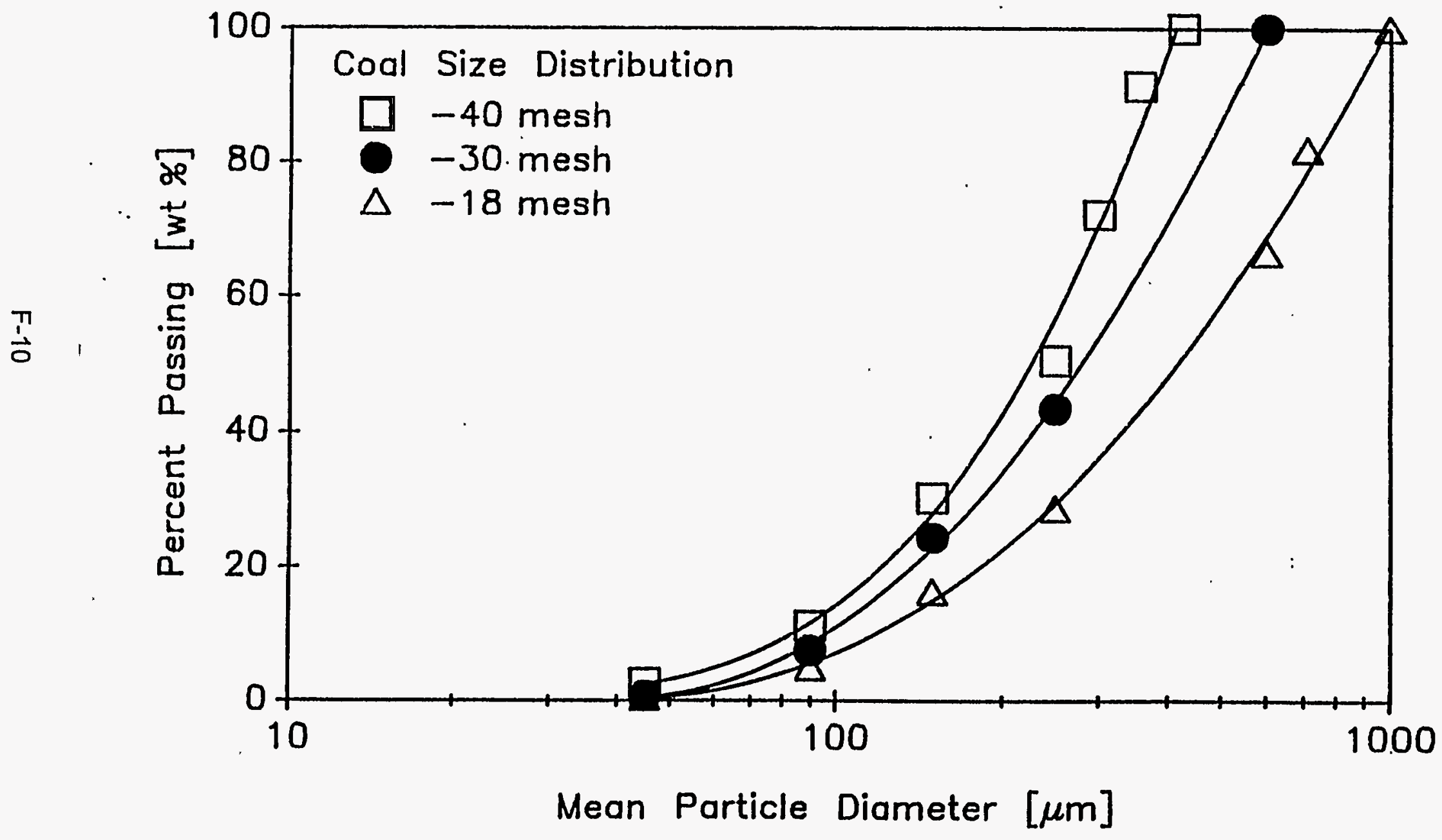

Figure F-3 Comparison of Feed Coal Particle Size Distributions 


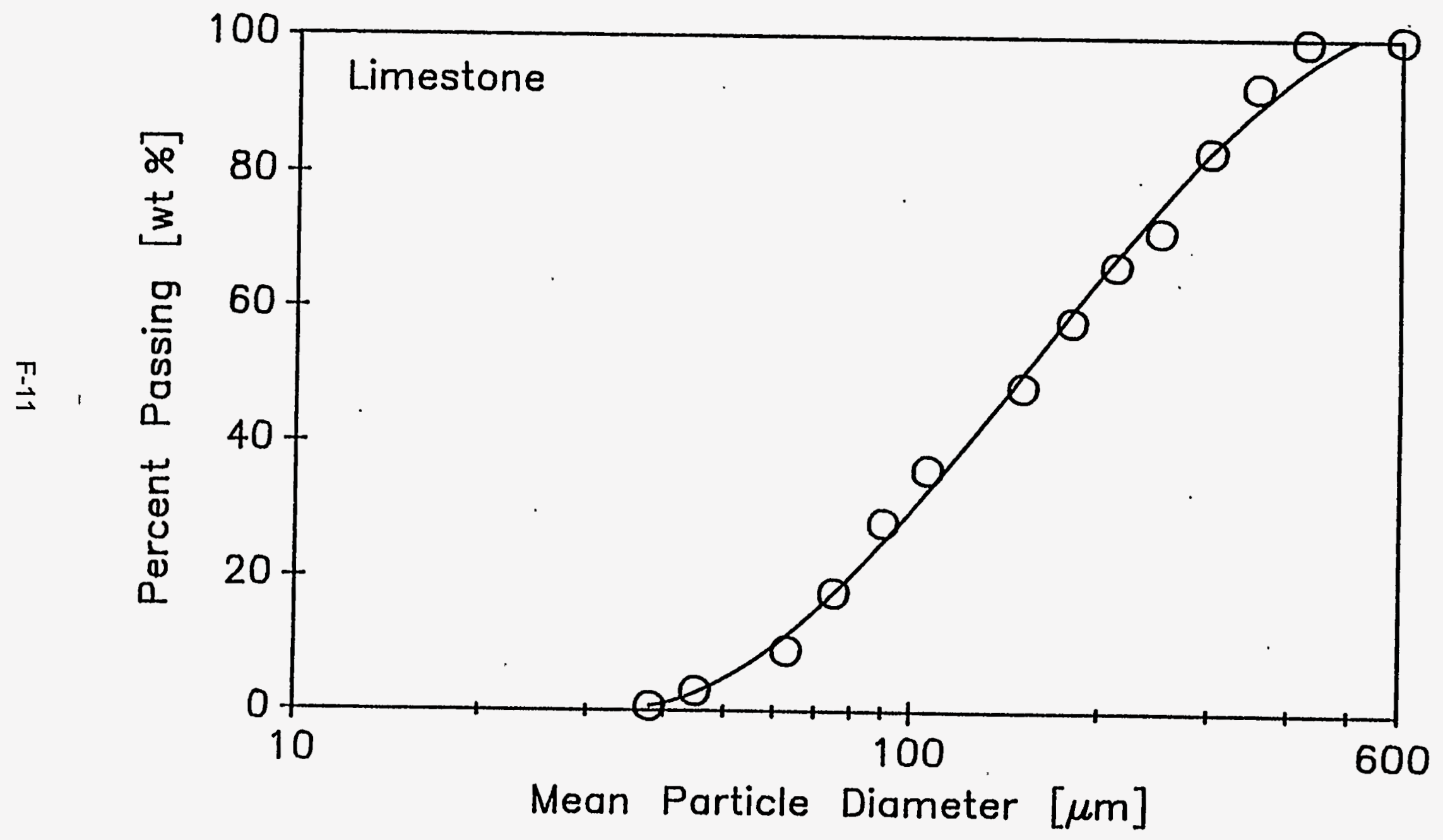

Figure F-4 Particle Size Distribution of Test Limestone 


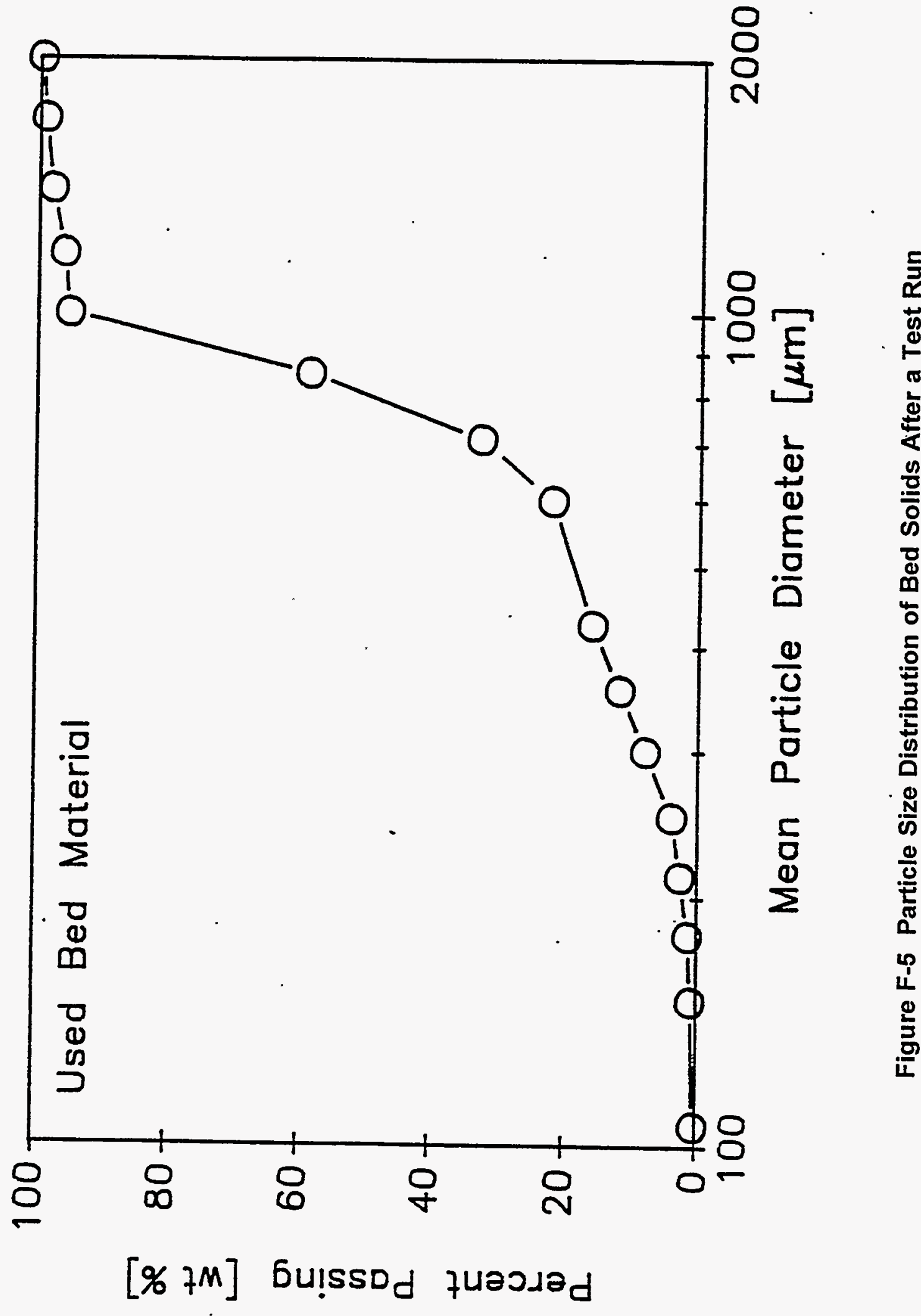




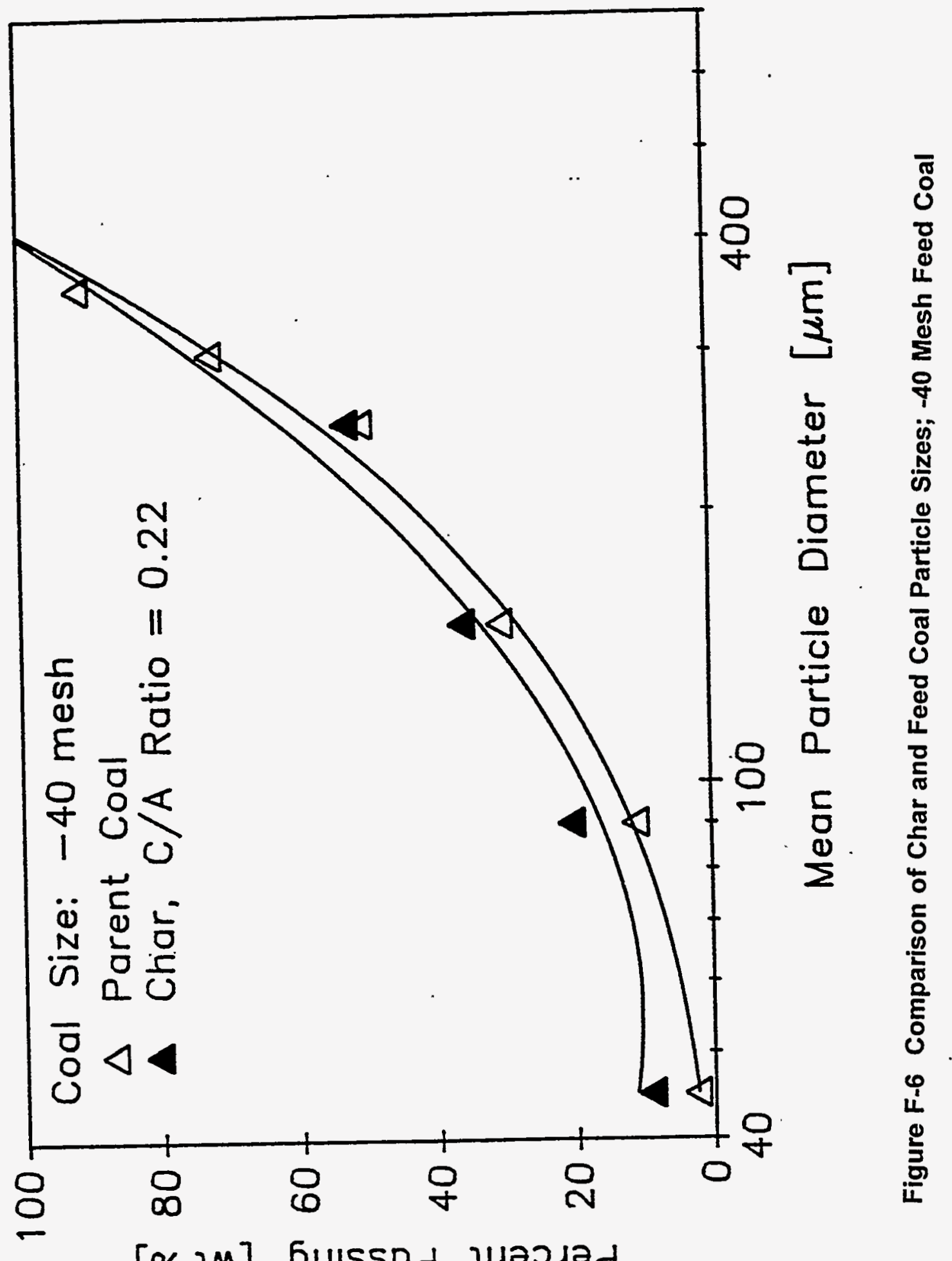

F-13 


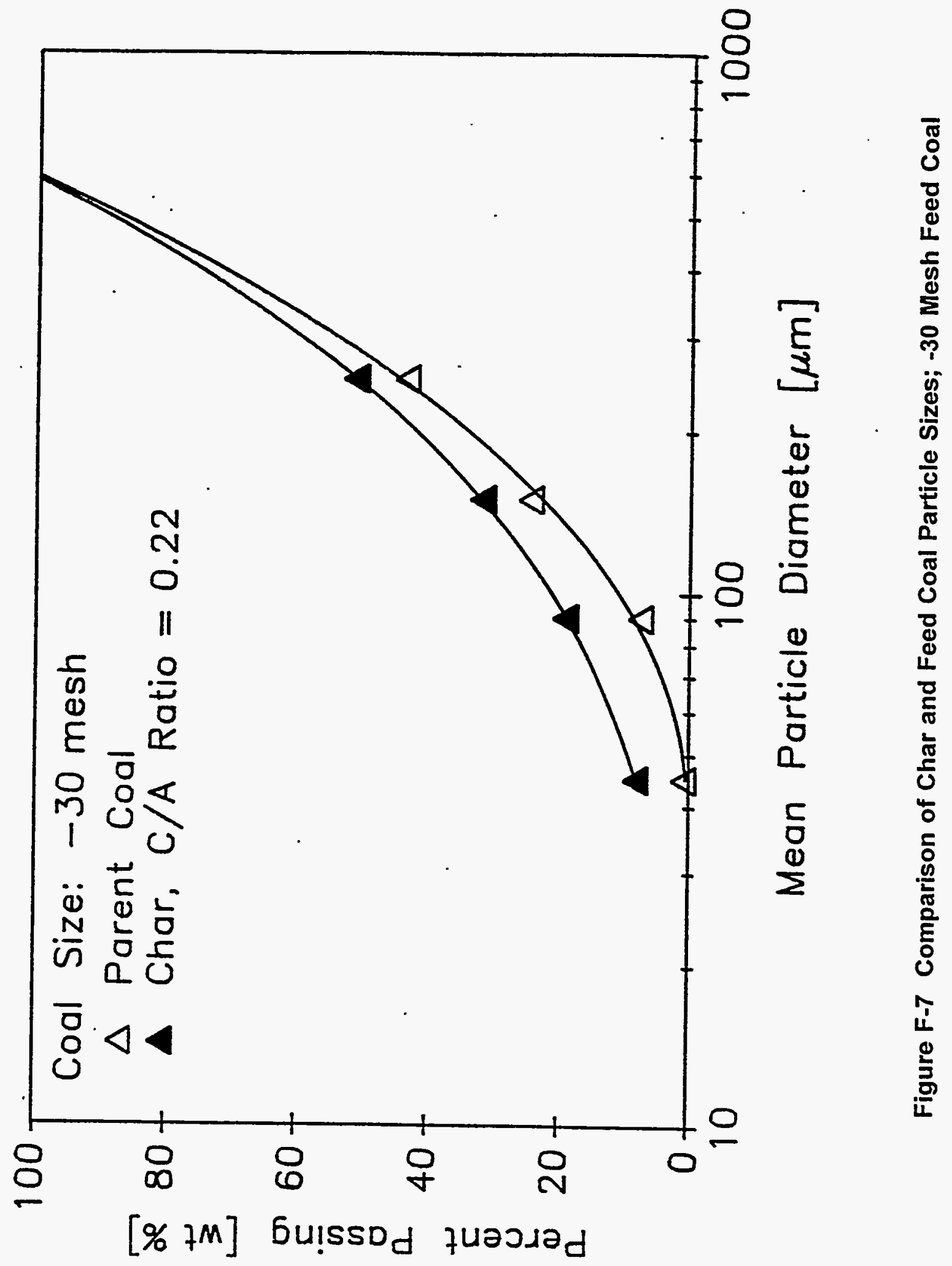




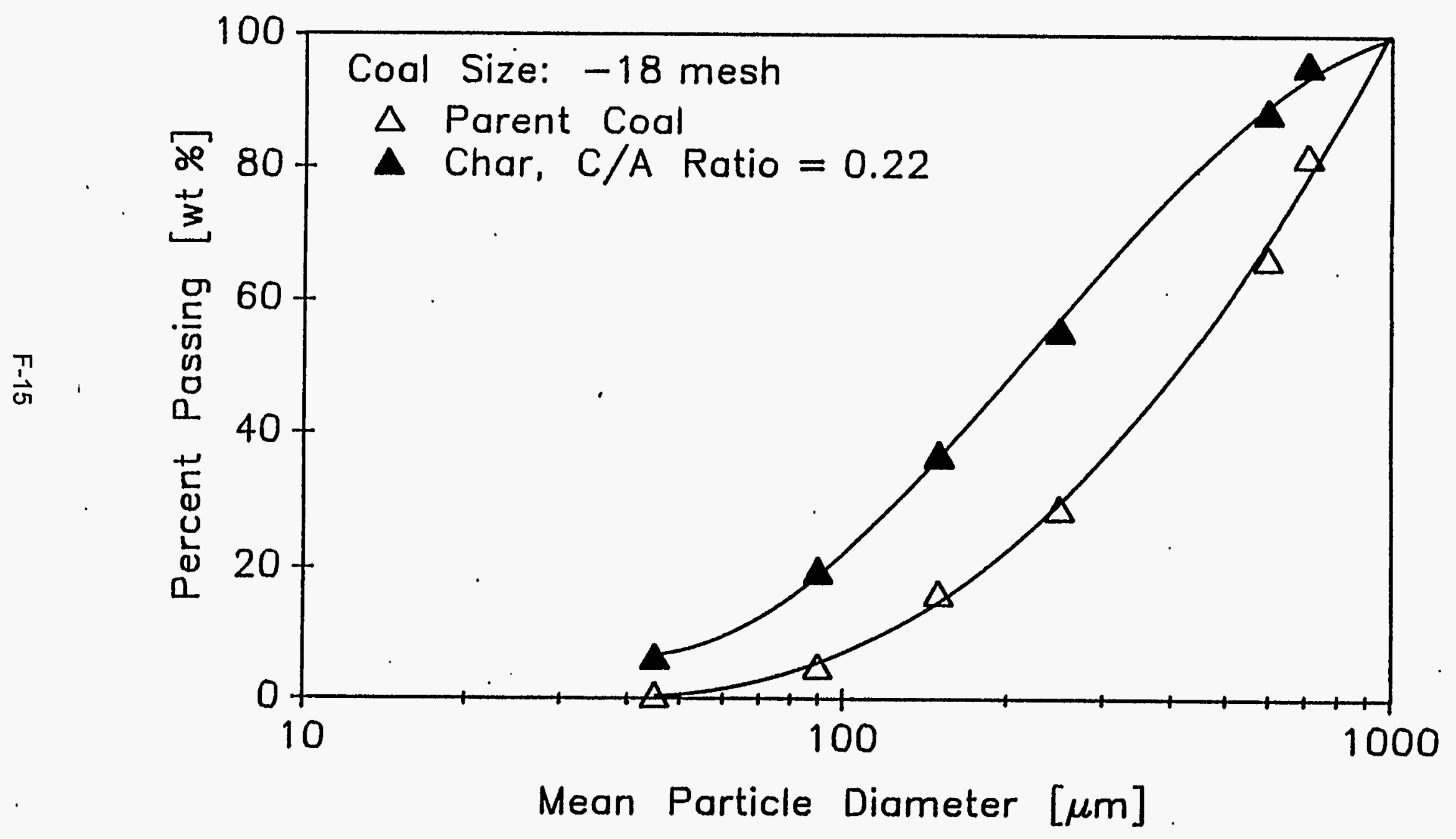

Figure F-8 Comparison of Char and Feed Coal Particle Sizes; -18 Mesh Feed Coal 
fragment with attrition. The effect of recycle is to subject the coal to more and more attrition cycles. This effect of reaction and attrition is counteracted by the coal swelling, which for this Pittsburgh coal is not sufficient to overcome the effect of the other factors.

The figures show that the reduction in char particle size is more prominent for the larger -18 mesh coal. This is seen in Figure F-8, where at a given particle size a larger percent passes through the sieve. The variation in the char particle size distribution for the smallest -40 mesh coal is least, being closest to the parent coal size distribution.

Effect of Fluidization Velocity on Char Particle Size. Experiments were conducted to investigate the influence of residence times and fluidization velocity for the three coal feed sizes. During these experiments; the coal/air mass ratio was kept constant at 0.22 and the temperature was maintained at $1650^{\circ} \mathrm{F}$. Thus, the influence of reaction rates was isolated. Fluidization velocities were varied in a limited range for each particle size.

Figures F-9 to F-11 show the influence of fluidization velocity. The effect of fluidization velocity is most pronounced with the -18 mesh coal and least with the -40 mesh coal. Increasing the fluidization velocity, while keeping all other variables constant, increases the elutriation rates from the dense portion of the bed and decreases the per pass coal residence time. The particle size at terminal velocity is increased. Therefore, as the fluidization velocity is increased for each coal size, larger particles are entering and being trapped by the primary cyclone. This is seen more strongly with the -18 mesh coal, which has a larger char size distribution at the higher fluidization velocity, (see Figure F-11).

For the -40 mesh coal, the size distribution is narrow and a larger proportion of char particles have reached their terminal velocity, even at lower fluidization velocities. This is seen in Figure F-9, where the size distribution of the primary char is not too different from the size distribution of the parent coal, while for the -18 mesh coal, there is an appreciable difference in the size distribution of the chars and the parent coal. As the fluidization velocity is increased from 6.4 to 9.7 in Figure F-11, a lesser percent passes through a given sieve size, indicating that the mean particle size of the primary char is increasing due to the larger particles reaching their terminal velocity. For the -30 mesh coal, this effect is intermediate between the -18 and -40 mesh coals. This effect of terminal velocity is counteracted by attrition and reaction as the solids are recycled through more cycles per unit time at higher velocities.

In each case, increasing the fluidization velocity is shown from the data of Figures F-9, $\mathrm{F}-10$ and $\mathrm{F}-11$ to increase the mean particle size of the primary cyclone char, the effect being stronger at higher velocities and larger initial coal feed particle sizes.

Effect of Temperature on Char Particle Size. The effect of temperature on char particle size was studied with the -40 mesh coal. For these experiments, the feed coal/air mass ratio was kept constant at 0.22 and the superficial velocity was $6.4 \mathrm{ft} / \mathrm{sec}$. 


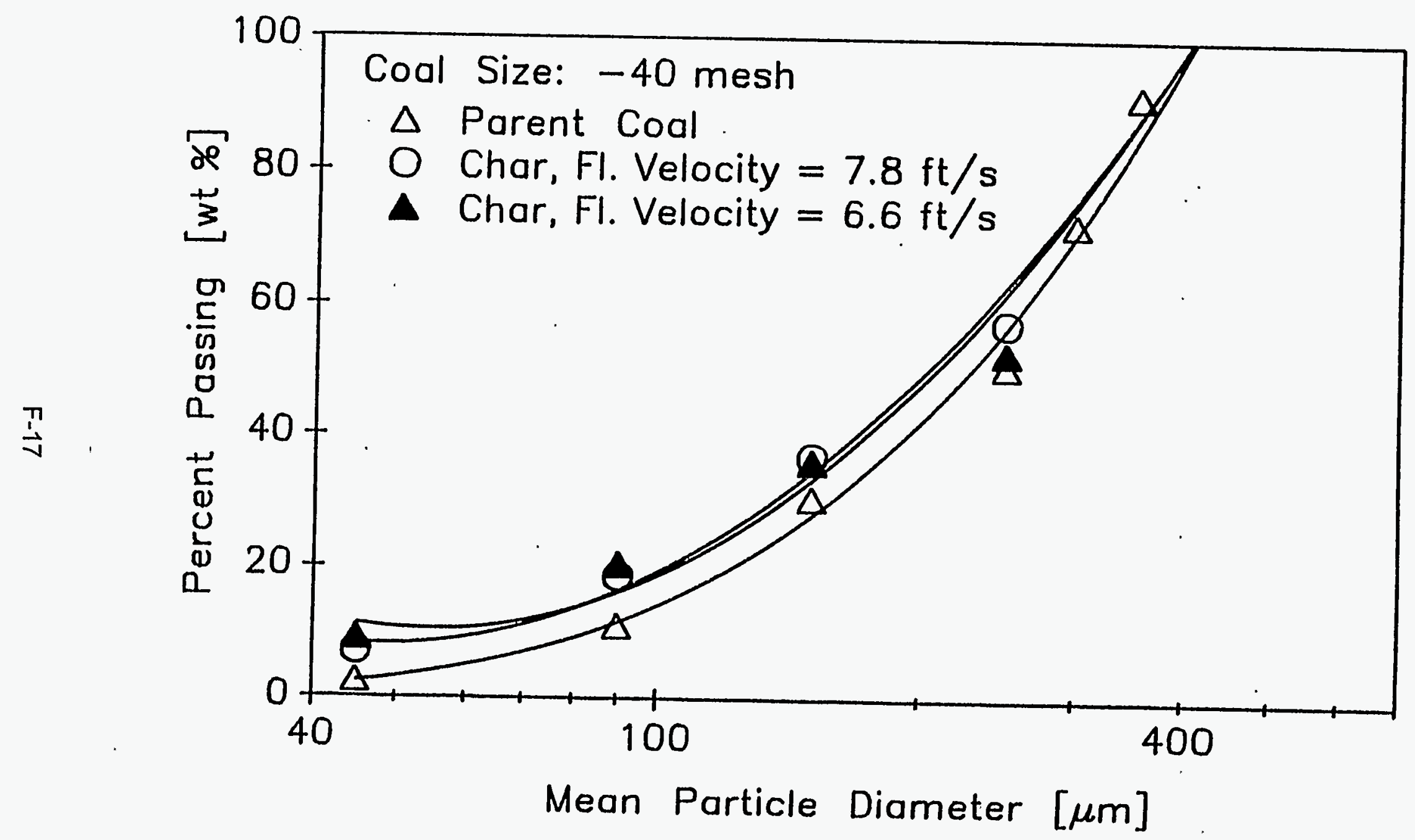

Figure F-9 Effect of Fluidization Velocity on Primary Char Particle Size; -40 Mesh Feed Coal 


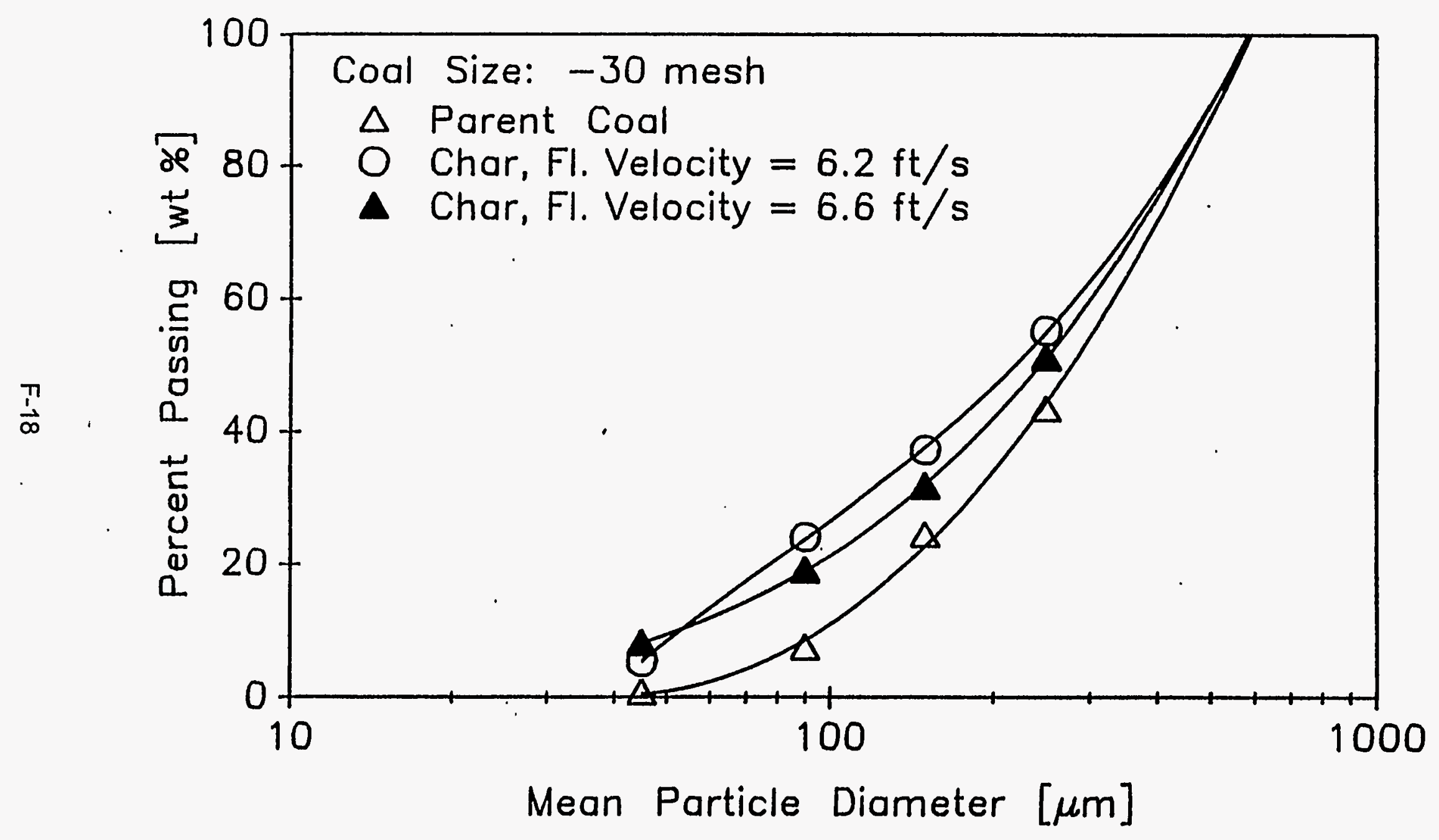

Figure F-10 Effect of Fluidization Velocity on Primary Char Particle Size; -30 Mesh Feed Coal 


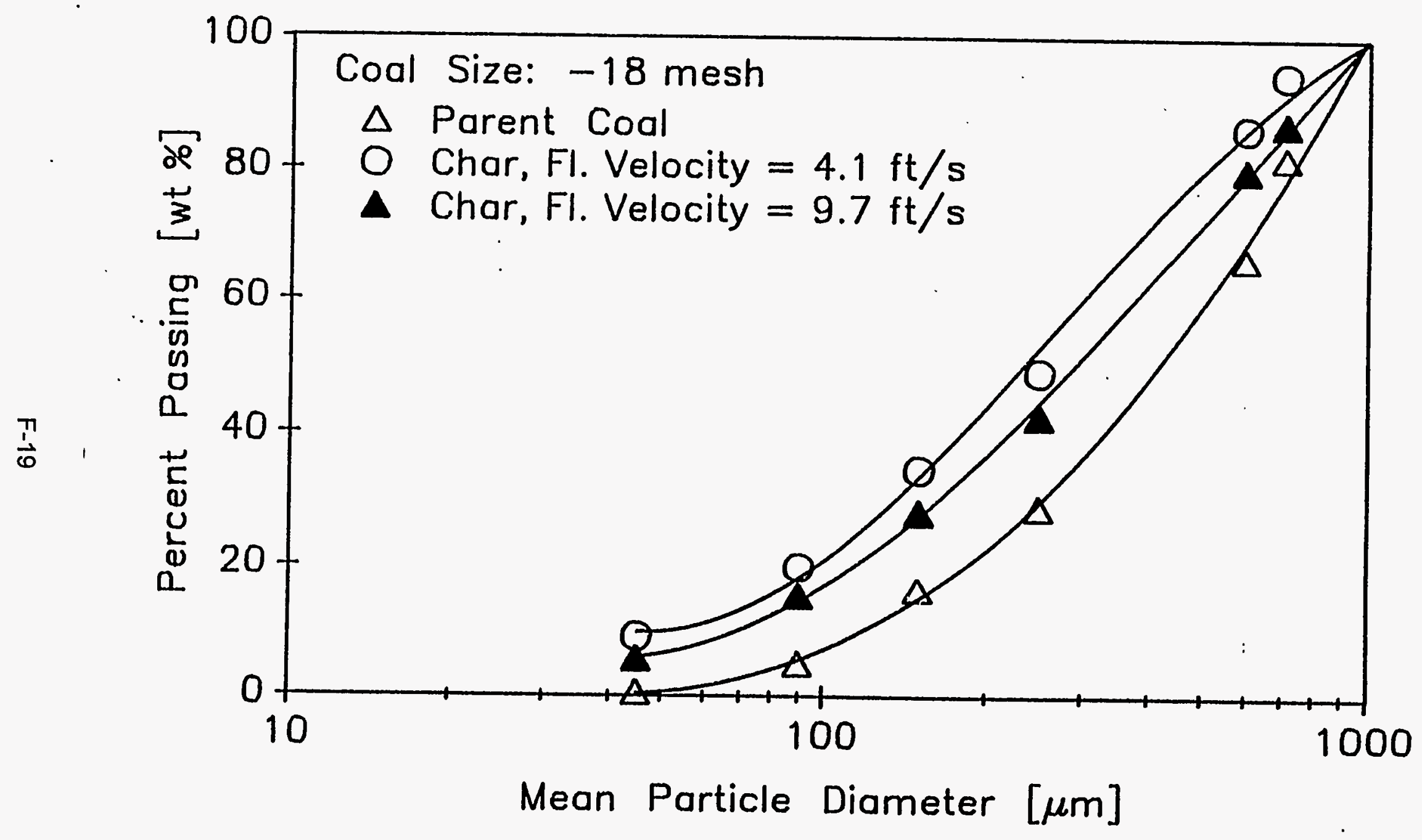

Figure F-11 Effect of Fluidization Velocity on Primary Char Particle Size; -18 Mesh Feed Coal 
Figure $\mathrm{F}-12$ shows the effect of operating temperature in the range of $1600-1740^{\circ} \mathrm{F}$. As operating temperatures are increased, keeping the effect of stoichiometry and fluidization velocity isolated, the reaction rate is expected to increase. This increase in reaction rate should reduce the char particle size. This effect can be seen from the size distribution presented in Figure F-12. As the temperature is increased from 1600 to $1740^{\circ} \mathrm{F}$, a larger fraction of the char passes through a given sieve mesh size indicating a reduction in char particle size.

Effect of Char Recycle on Particle Size. Experiments were conducted with the -30 mesh coal to investigate the influence of char recycle rates on particle size. These results are shown for a typical case where all other variables were kept constant, and the effect of recycle was studied.

Figure $\mathrm{F}-13$ is a sketch showing the arrangement used to measure the recycle ratio. For a coal feed rate of $A$, and a recycle mass rate of $D, C$ is the amount of char collected by the primary cyclone. Since $D$ is less than $C$ because of the limitation in the rate of opening and closing of the shut-out valve located between the recycle hopper and the main bed, (C-D) is the rate of accumulation of the char-sorbent mixture in the recycle leg of the pyrolyzer. This rate of accumulation of the char in the recycle leg (C$D$ ) is measured by observing the time required for a given height of char to accumulate in the see-through section of the recycle leg, as shown in the figure. Next, a given quantity of char is drawn off from the port below the see-through section using a gentle vacuum. It is allowed to $\mathrm{cool}$ and stored for later determination of particle size distribution and density. Also, the volume rate of char recycle corresponding to $D$ is measured. From these measurements, the recycle rate, as a percentage of char collected by the primary cyclone is calculated as

Primary char recycled $\%=\frac{D}{C}=\frac{D}{(C-D)+D} \times 100$

It was found that the recycling of primary cyclone solids increased bed stability and reduced bed temperature excursions, thereby preventing agglomeration. This was especially beneficial in the experiments at high C/A mass ratios and high temperatures.

Figure F-14 shows the char particle size distributions for no recycle and for the $80 \%$ recycle rate. As seen from the figure, the recycle rate by itself does not influence the char particle size very strongly. This is because the char particle size is governed by considerations of fluidization velocity, C/A ratios, temperature and attrition rates. Once a char particle has attained its terminal velocity, its presence in the dense phase bed section is no longer permitted, and it is elutriated from the bottom of the bed and enters the freeboard. If reinjected, the same process ensues. However, by repeated reinjection, the char particle has a longer residence time and has a greater time for reaction. Thus, with recycle, the char particle size distribution should tend toward smaller sizes. This is shown in Figure F-14, where the particle size of the recycled char 


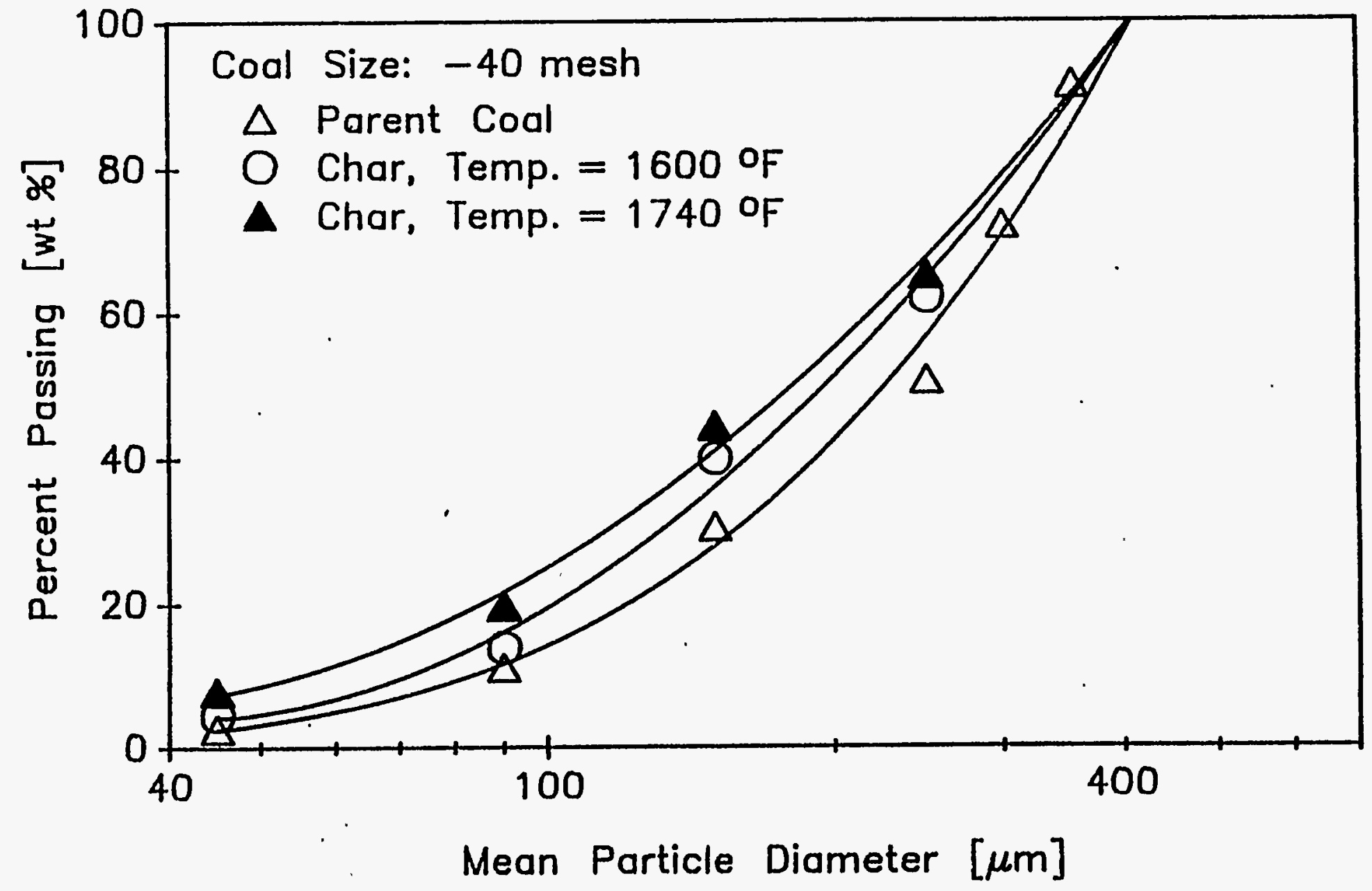

Figure F-12 Influence of Temperature on Primary Char Particle Size; -40 Mesh Feed Coal 


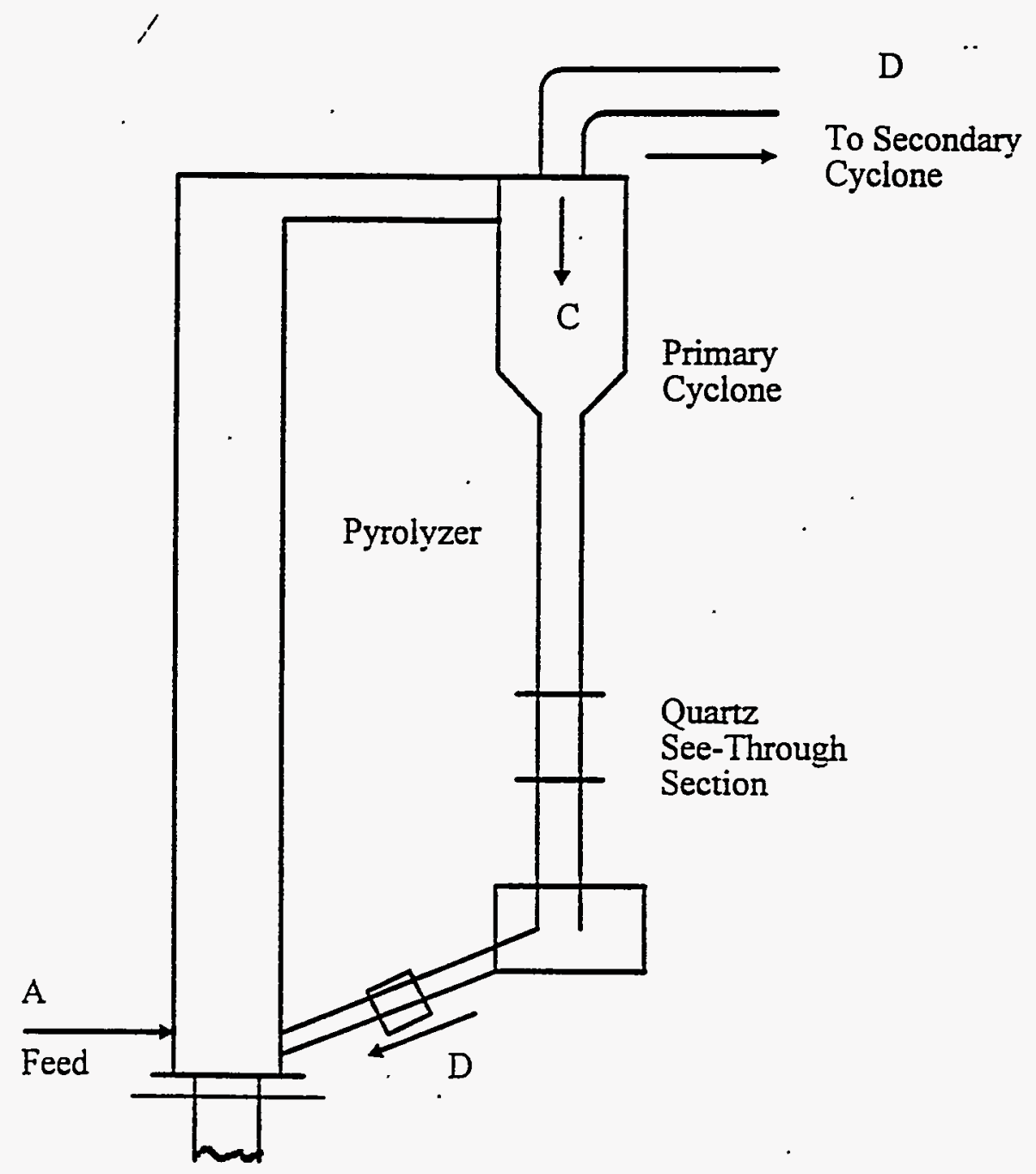

Figure F-13 Schematic of Recycle Leg of Pyrolyzer 


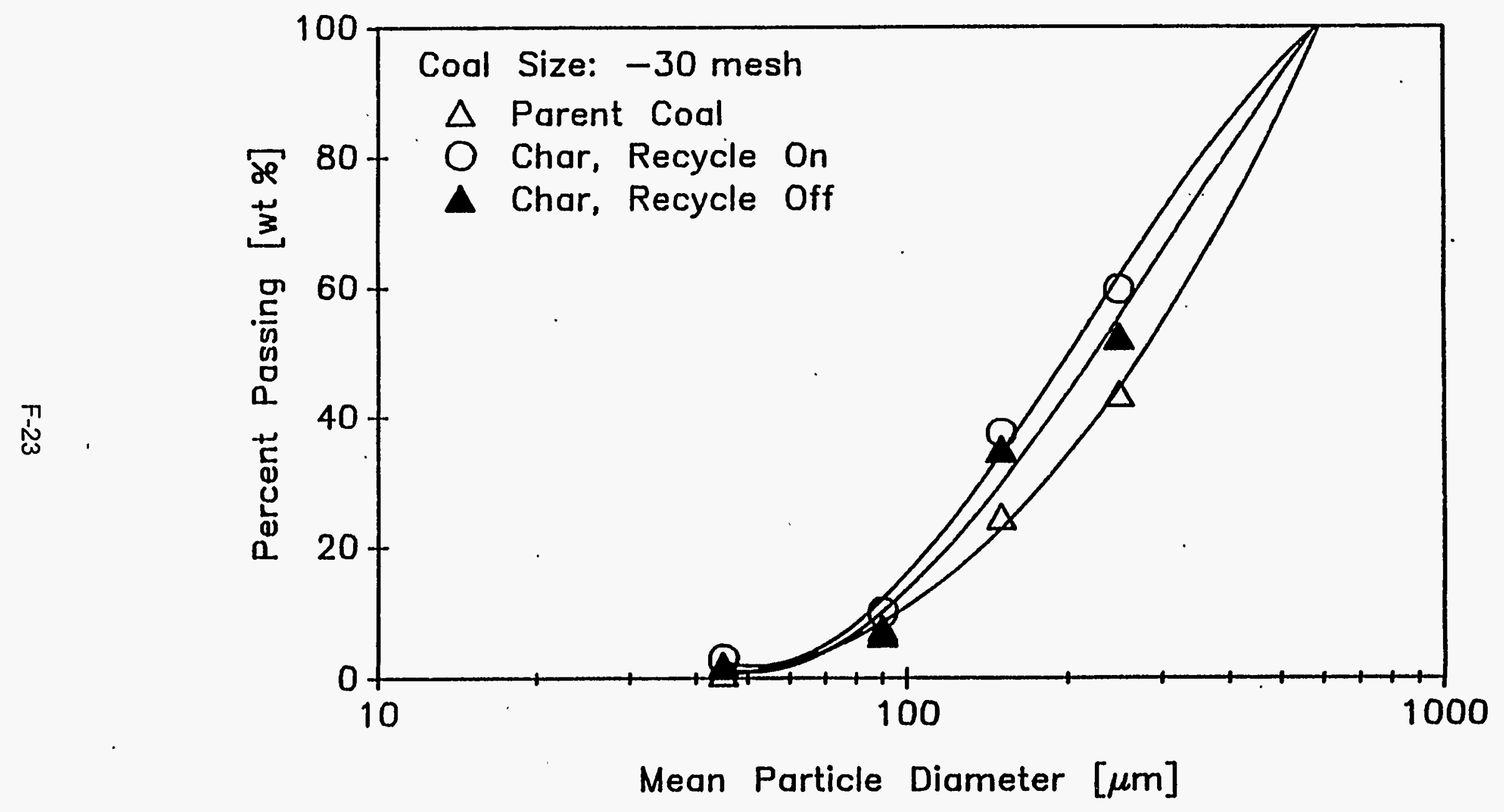

Figure F-14 Effect of Recycle on Primary Cyclone Particle Size; -30 Mesh Coal 
is indeed smaller than that of the char produced without recycle: Even so, the residence time of the recycled char in the dense portion of the bed at the bottom of the reactor is small compared to that of the fresh coal fed because of density and size factors. Reaction rates are much higher in the dense portion of the bed compared to that in the dilute phase above the bed. Hence, char particle size reduction due to continued reinjection and reaction is influenced by these factors.

In summary, char recycle has the beneficial effect of improving bed stability. It . influences fuel gas composition and results in a net reduction of char particle size.

Secondary Cyclone Chars. Figure F-15 shows the size distribution of the secondary cyclone char for the smallest -40 feed coal size. Typically, secondary cyclone chars are less than 100 microns with $50 \%$ on the order of 10 microns. The secondary cyclone catch is much smaller than the primary cyclone catch. Sometimes, a few particles on the order of 100-130 microns find their way into the secondary cyclone. Hence, the percent passing shown in Figure F-15 does not add up to $100 \%$. This is because the secondary cyclone char was analyzed with the Leeds and Northrop Laser particle size analyzer whose upper limit of detection was 125 microns. These larger particles had to be sieved off before the secondary cyclone chars could be analyzed.

Bag Filter Particulates. A bag filter was utilized to collect particulates from the fuel gas stream leaving the pyrolyzer. These particulates were analyzed using the Leeds and Northrop Laser particle size analyzer. The raw data from the analyzer is shown in Figure F-16. As seen from the data, the particles are even smaller in size than the secondary cyclone catch shown in Figure F-15 for the same -40 mesh coal feed. Ninety percent of the bag filter particulates were found to be less than 30 microns in size.

Effect of Coal/Air Mass Ratio on Char Particle Size. To investigate the influence of particle loading in the pyrolyzer on the attrition properties of the char, and the associated influence of reaction rate, the primary char mass mean particle size was measured as the coal/air mass ratio was changed. This was done by keeping the superficial velocity constant at $6.4 \mathrm{ft} / \mathrm{sec}$, but varying the coal feed mass. The temperature was also constant at $1650^{\circ} \mathrm{F}$. Varying the coal mass increases the particle loading in the pyrolyzer. Figure F-17 shows the mass mean diameter of the primary char as a function of coal/air (C/A) mass ratio. At low C/A ratios, the particle loading is low and the conversion rate is also low. Attrition in the freeboard is also low. The effect of primary cyclone recycle is a constant factor and contributes weakly to char particle size distribution. 


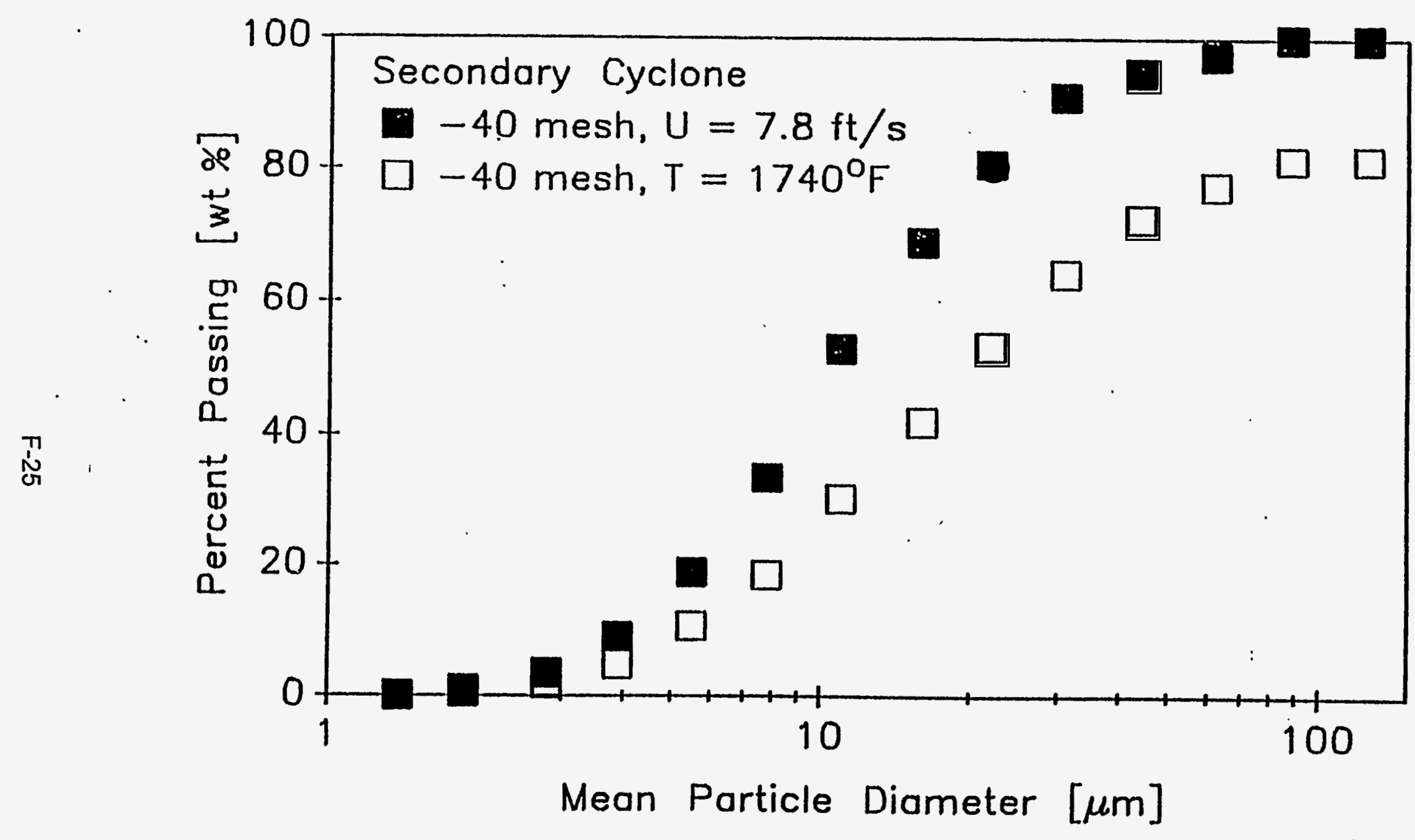

Figure F-15 Particle Size Analysis of Secondary Cyclone Char for -40 Mesh Feed Coal 

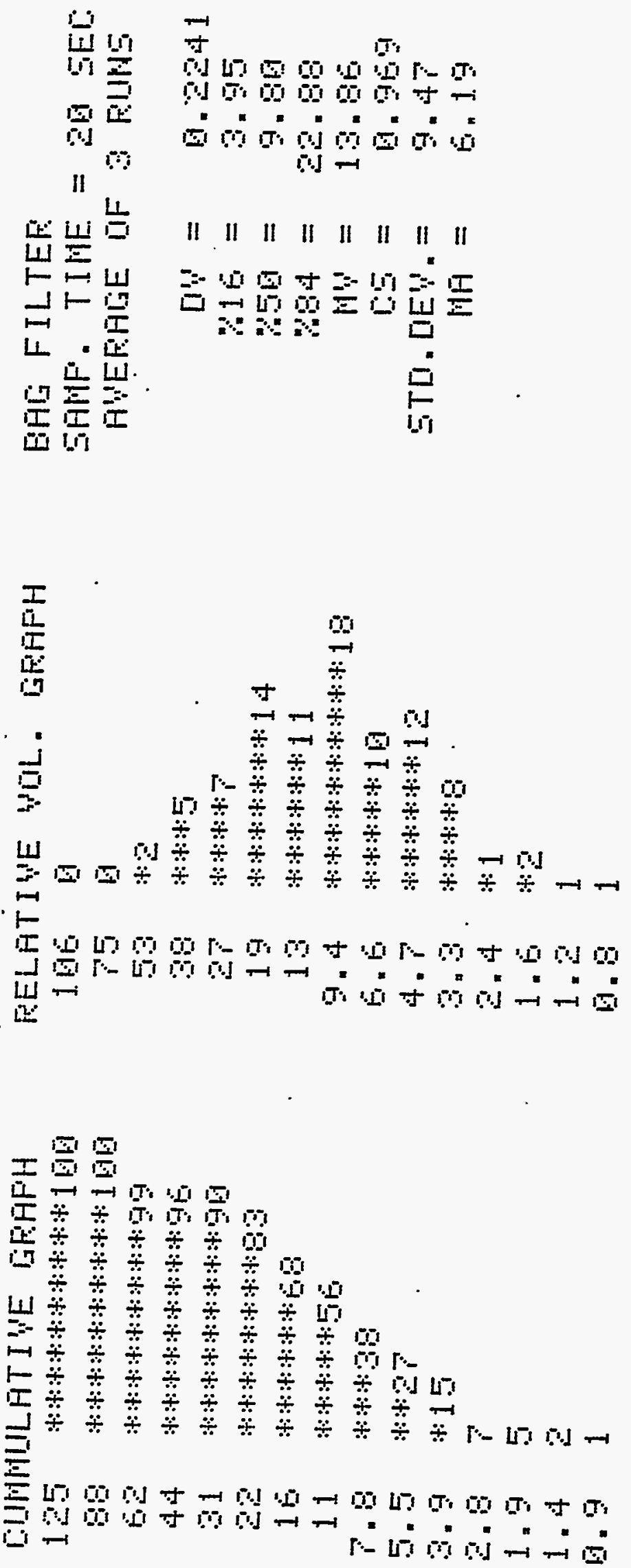


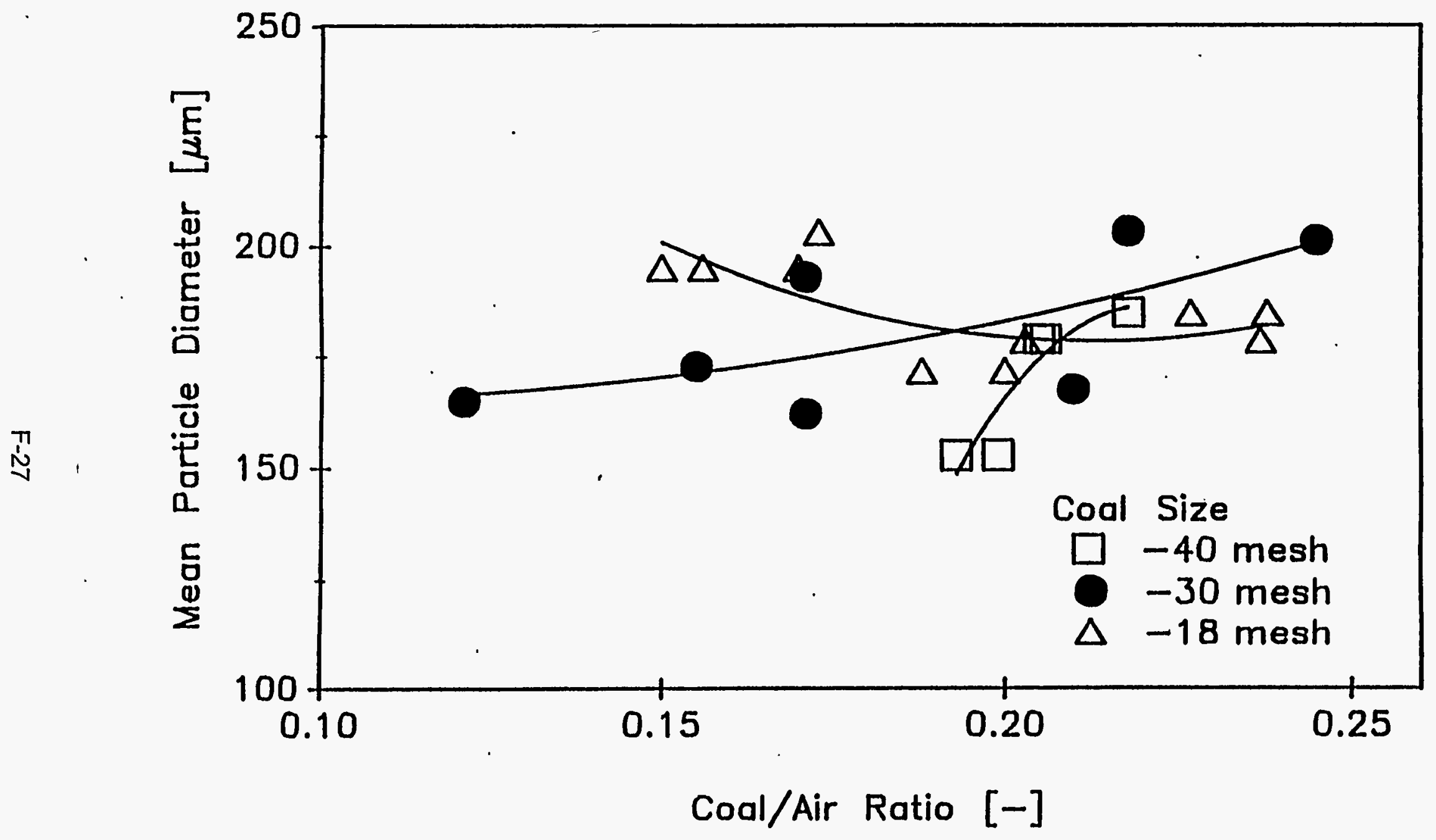

Figure F-17 Variation of Mean Primary Char Particle Sizes with Coal/Air Ratio 
At higher C/A ratios, the mean particie size of the -18 mesh coal decreases due to stronger reaction rates, while the size of the -30 mesh and -40 mesh char still continues to increase. This is reflected in the composition of the fuel gas from the -18 mesh coal. In addition, the mean particle size of the char is a function of the size distribution of the feed coal, the cyclone collection efficiency for a given particle size, and the superficial velocity, as discussed above. 


\section{F.3.3 FUEL GAS COMPOSITION}

The fuel gas composition was measured for the different experiments which investigated the influence of C/A ratio, fluidization velocity and bed temperature. The results show the influence of these variables on the various gas components that specifically exert a strong influence on fuel gas heating value. The calcium/sulfur mole ratio for all these experiments is $2: 1$.

Effect of Coal Feed Size and C/A Ratio. The effect of coal feed size on the carbon monoxide (CO), hydrogen $\left(\mathrm{H}_{2}\right)$, hydrocarbons $(\mathrm{HC})$, ammonia $\left(\mathrm{NH}_{3}\right)$ and hydrogen sulfide $\left(\mathrm{H}_{2} \mathrm{~S}\right)$ components of the fuel gas is shown in Figures $\mathrm{F}-18$ to $\mathrm{F}-22$. As the coal particle size increases from -40 mesh to -18 mesh, it was found that the $\mathrm{CO}, \mathrm{H}_{2}$ and $\mathrm{HC}$ concentrations of the fuel increased. This effect is considered to be largely the result of residence time variations caused by particle size. The larger -18 mesh coal remains a longer time in the dense phase portion of the bed where mixing and reaction rates are stronger, and hence yields higher concentrations of $\mathrm{CO}, \mathrm{H}_{2}$ and $\mathrm{HC}$.

The important reactions instrumental in determining the relative yields of the fuel gas components are given below, with the corresponding enthalpy of formation.

\section{Reaction}

$$
\mathrm{C}+\mathrm{O}_{2} \Leftrightarrow \mathrm{CO}_{2}
$$$$
\mathrm{C}+\mathrm{CO}_{2} \Leftrightarrow 2 \mathrm{CO}
$$$$
\mathrm{C}+\mathrm{H}_{2} \mathrm{O} \Leftrightarrow \mathrm{CO}+\mathrm{H}_{2}
$$$$
\mathrm{C}+2 \mathrm{H}_{2} \Leftrightarrow \mathrm{CH}_{4}
$$$$
\mathrm{C}+2 \mathrm{H}_{2} \mathrm{O} \Leftrightarrow \mathrm{CO}_{2}+2 \mathrm{H}_{2}
$$$$
\mathrm{C}+\mathrm{H}_{2} \mathrm{O} \Leftrightarrow \frac{1}{2} \mathrm{CO}_{2}+\frac{1}{2} \mathrm{CH}_{4}
$$

\section{Enthalpy of formation $\mathrm{kJ} / \mathrm{kg} \mathrm{mol}$}

$-393.5$

$+172.5$

$+131.3$

$-74.8$

90.1

Some relative gasification rates the literature at $10 \mathrm{kPa}$ and $800^{\circ} \mathrm{C}$ are as follows:

\begin{tabular}{|c|c|}
\hline Reaction & Relative Rate \\
\hline $\mathrm{C}+\mathrm{O}_{2}$ & $1 \times 10^{5}$ \\
\hline $\mathrm{C}+\mathrm{H}_{2} \mathrm{O}$ & 3 \\
\hline $\mathrm{C}+\mathrm{CO}_{2}$ & 1 \\
\hline $\mathrm{C}+\mathrm{H}_{2}$ & $1 \times 10^{-3}$ \\
\hline
\end{tabular}

Carbon monoxide is produced via reactions (2) and (3), which are strongly endothermic. These reactions are promoted by good gas-solid mixing and high heat transfer rates such as exist in the dense phase bed section. The hydrogen producing reactions (3) and (5) require similar conditions. Methane, however, is produced from reaction (4), which is exothermic and from reaction (6), which is endothermic, but which proceeds three times as fast as reaction (2) for CO production. Hence, of the three components, 


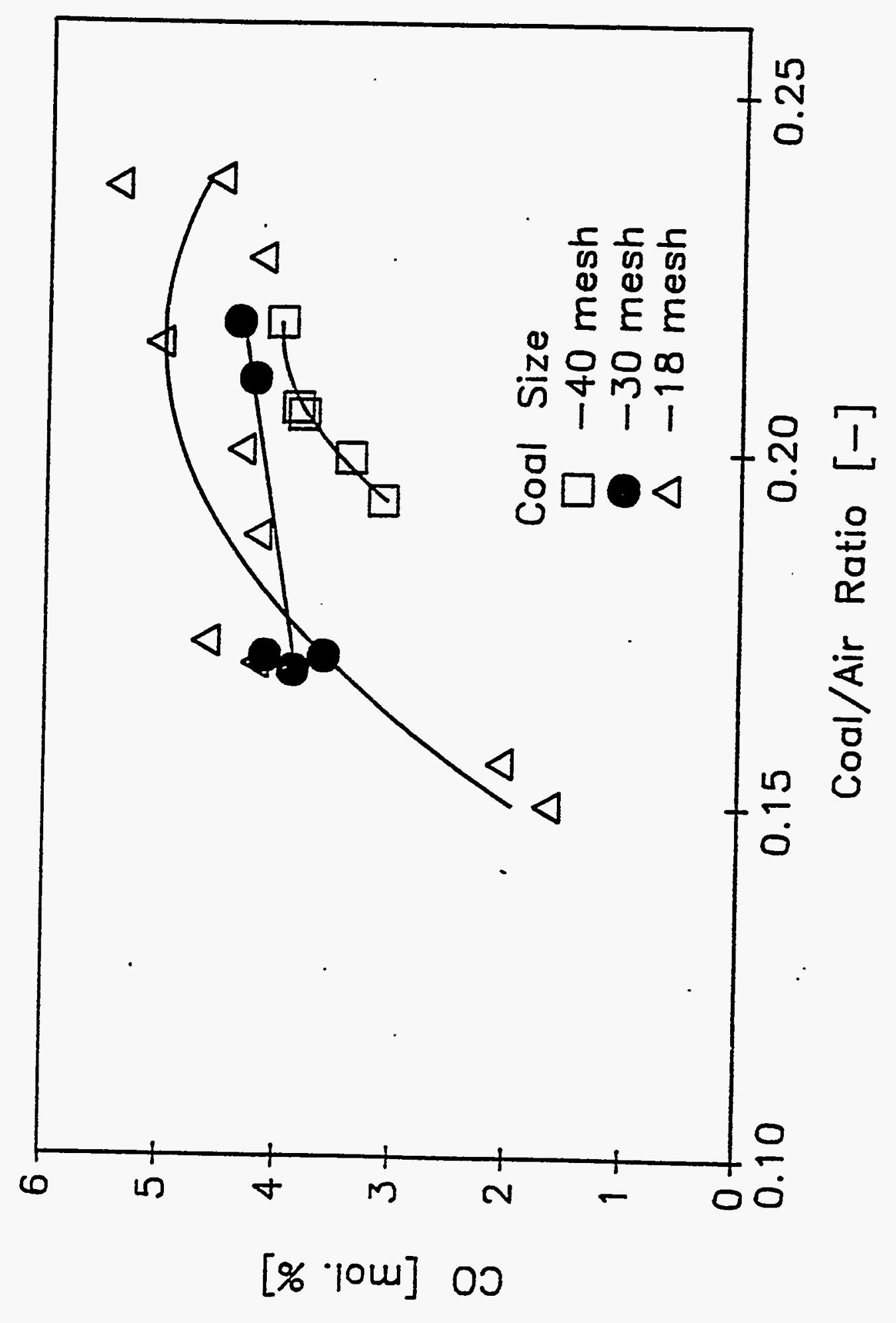

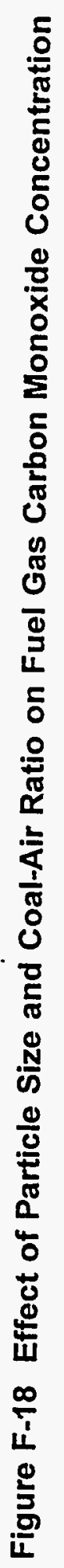

F-30 


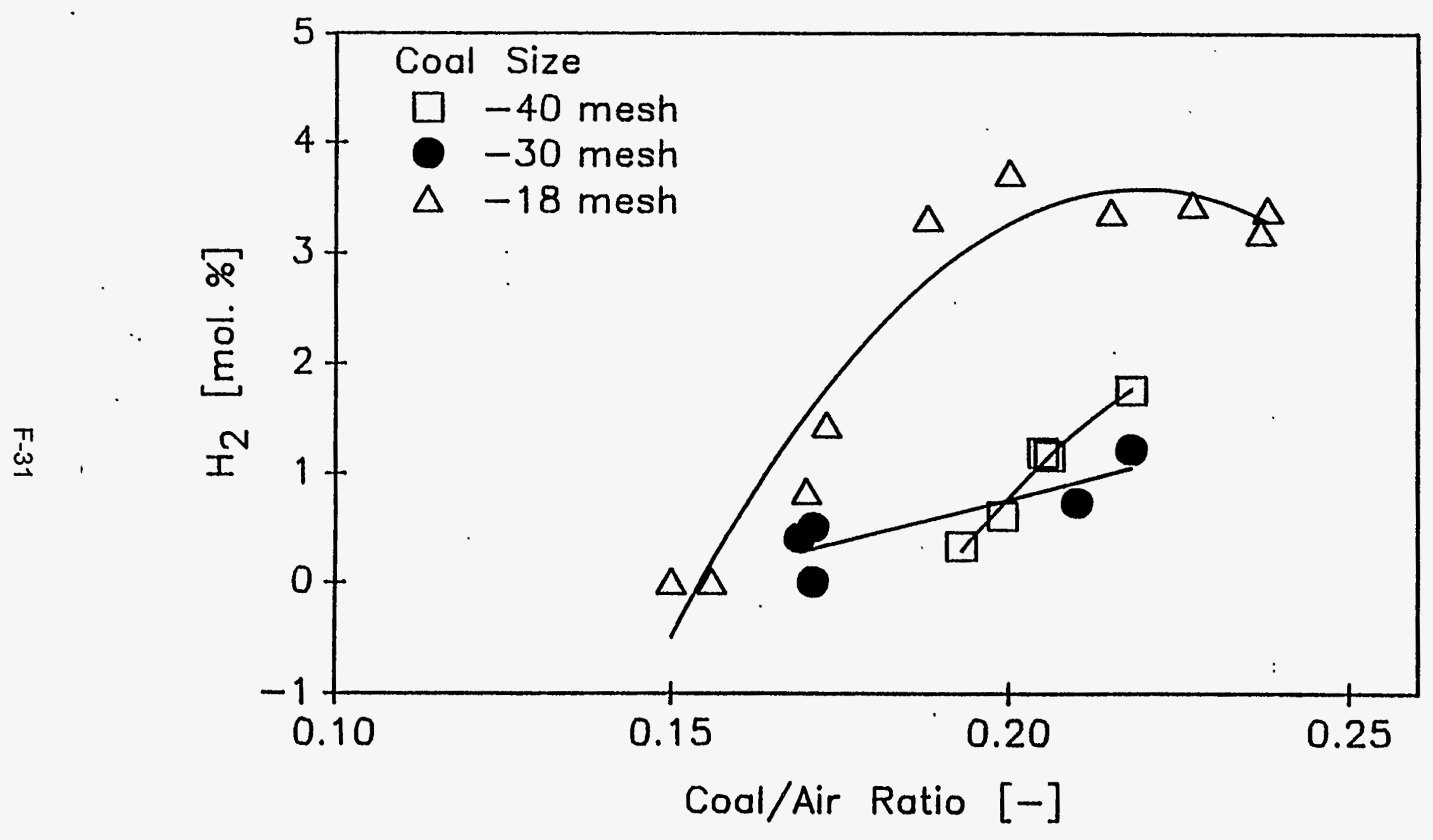

Figure F-19 Effect of Particle Size and Coal-Air Ratio on Fuel Gas Hydrogen Concentration 


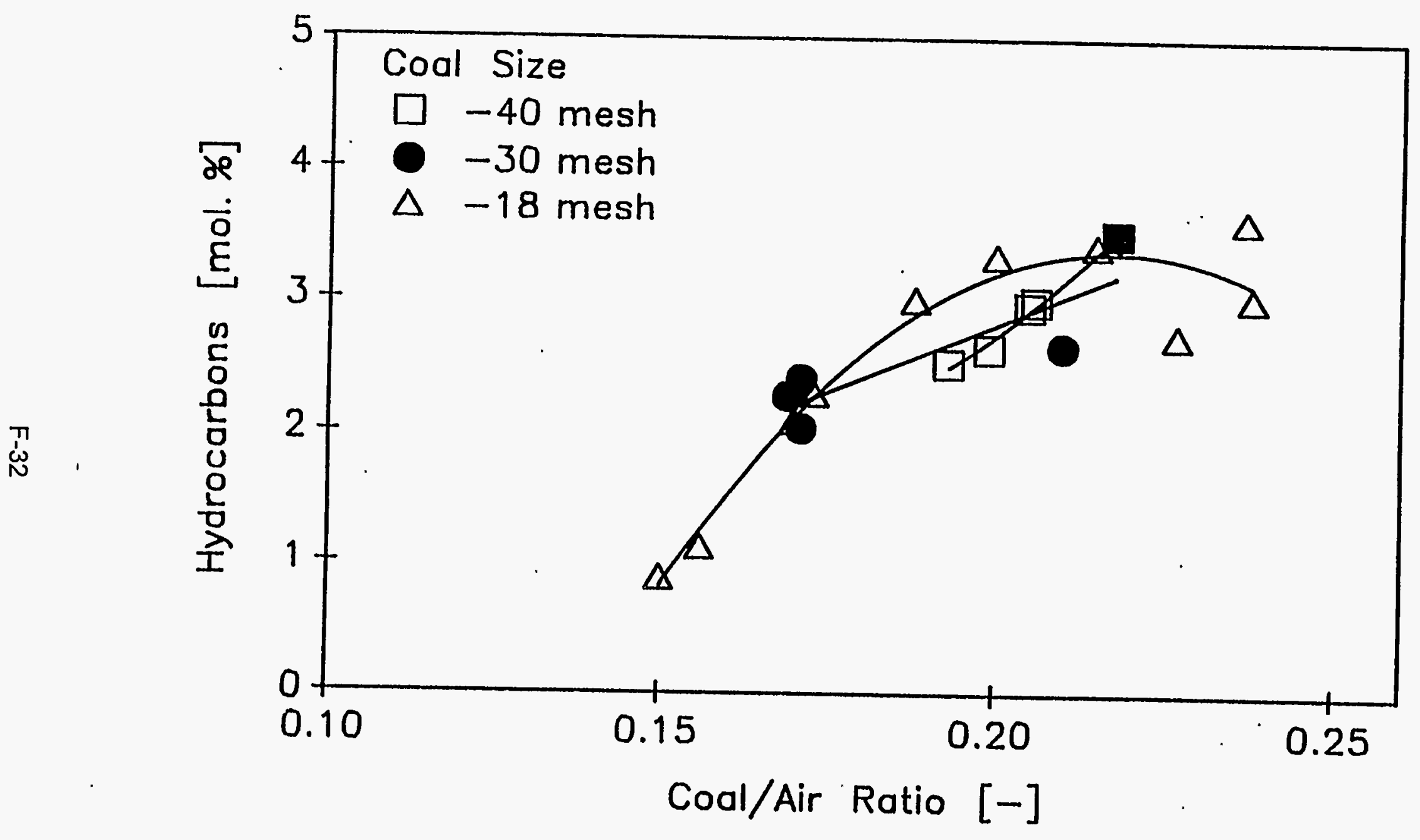

Figure F-20 Effect of Particle Size and Coal-Air Ratio on Fuel Gas Hydrocarbon Concentration 


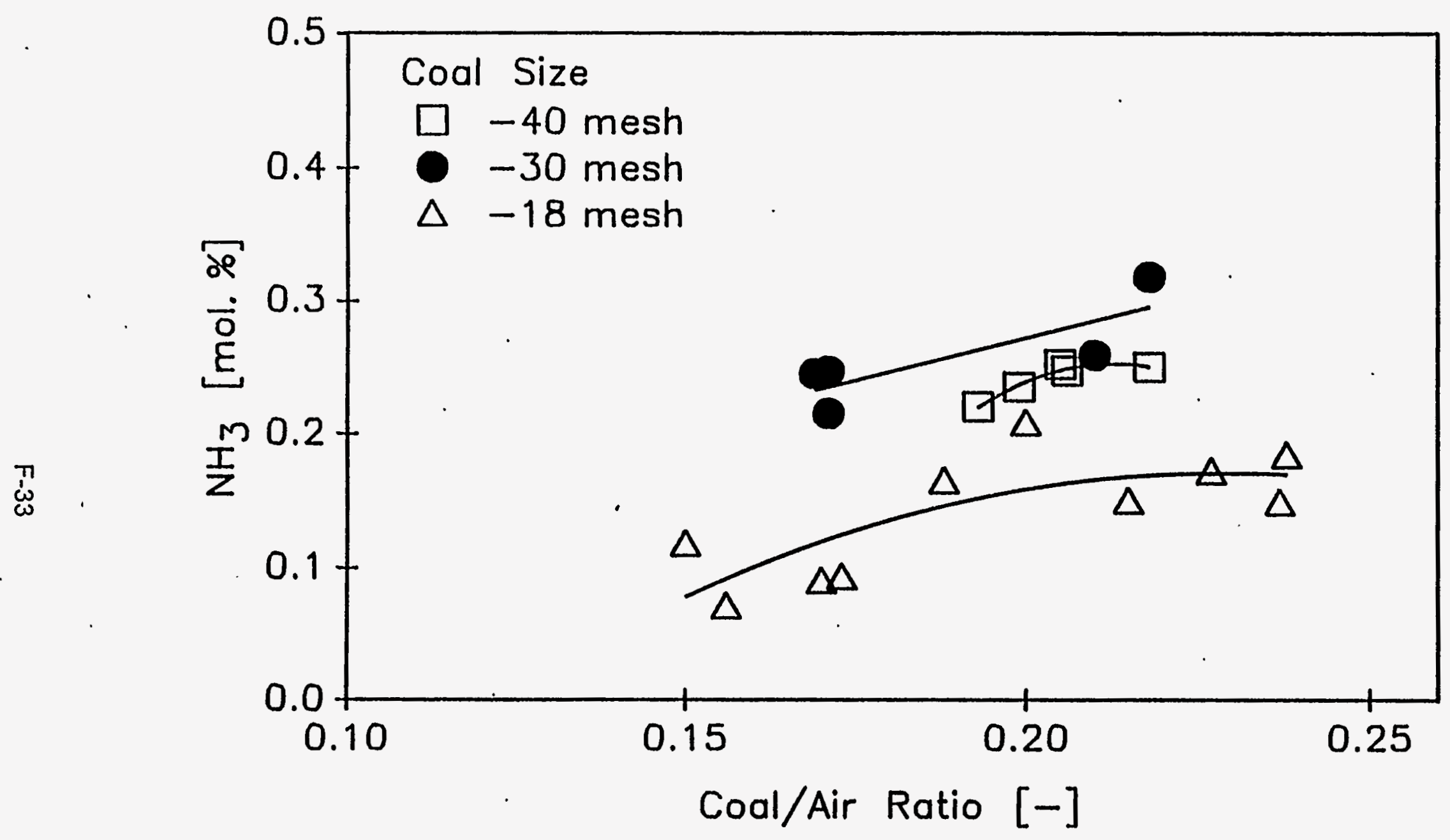

Figure F-21 Effect of Particle Size and Coal-Air Ratio on Fuel Gas Ammonia Concentration 


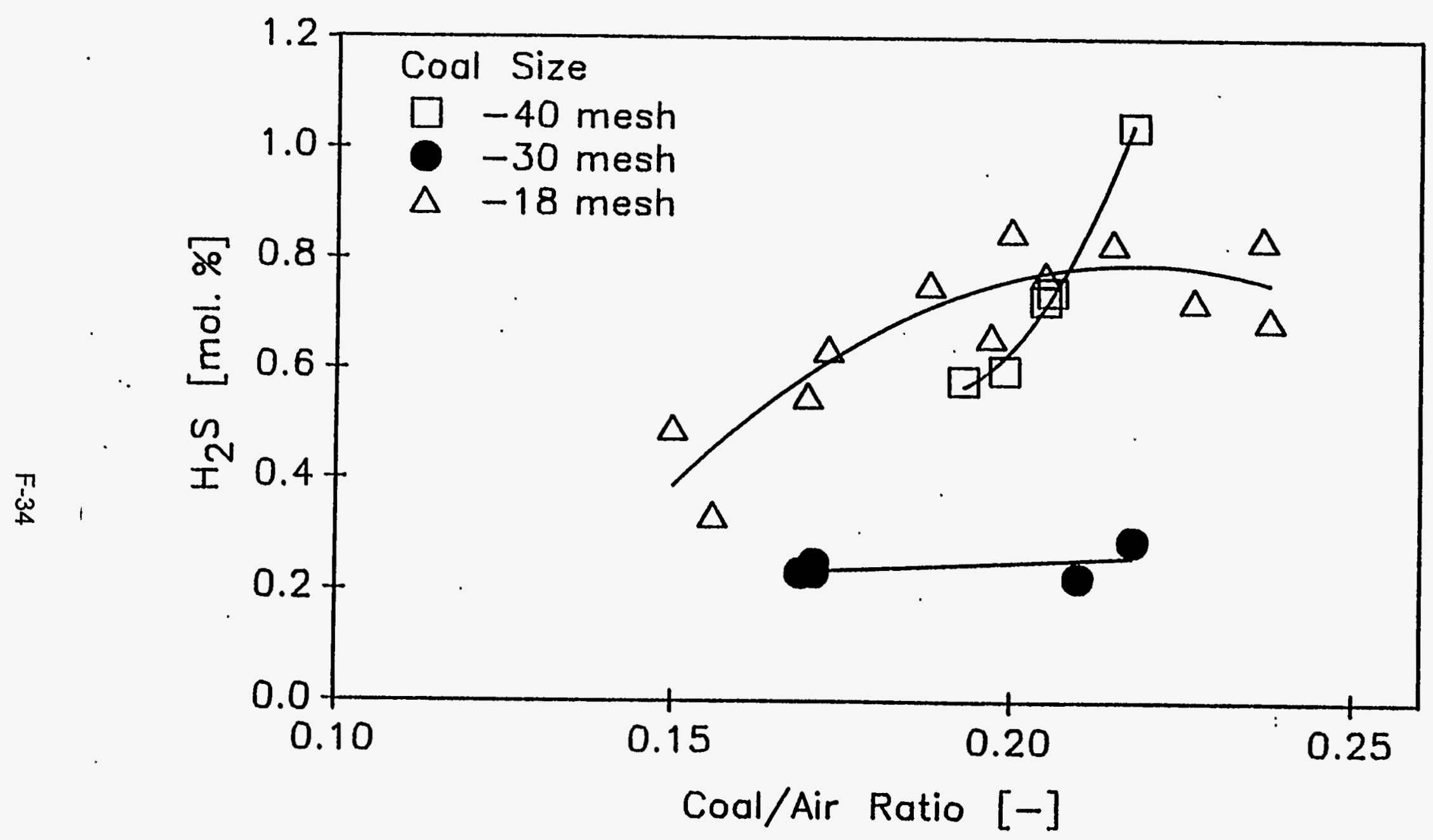

Figure F-22 Effect of Particle Size and Coal-Air Ratio on Fuel Gas Hydrogen Sulfide Concentration 
the hydrocarbons that are here measured as methane are the least influenced by the particle residence time in the dense phase. This is shown in Figure F-20 where the hydrocarbon content of the fuel gas is not strongly dependent on particle size. But the $\mathrm{CO}$ and $\mathrm{H}_{2}$ concentrations shown in Figures $\mathrm{F}-18$ and $\mathrm{F}-19$ do show that the longer residence times of the larger -18 mesh particles in the region of high mixing and heat transfer rates produces higher concentrations of these components. Even though the smaller -40 mesh particles are considered more reactive because of their smaller size, residence time and elutriation into the dilute phase region influences the composition.

These results are influenced by the scale of the pyrolyzer. In a commercial unit with a long freeboard such as that proposed to be built [1], the freeboard also would allow adequate time for reaction, although mixing, turbulence and heat transfer would be less than in the dense phase.

Figures F-21 and F-22 show the measured ammonia and hydrogen sulfide concentrations. As with the $\mathrm{CO}, \mathrm{H}_{2}$ and $\mathrm{HC}$ concentrations, the $\mathrm{NH}_{3}$ and $\mathrm{H}_{2} \mathrm{~S}$ components in the fuel gas increase with $\mathrm{C} / \mathrm{A}$ ratio. The $\mathrm{H}_{2} \mathrm{~S}$ concentration was lowest for the -30 mesh coal, but somewhat higher for the -18 and -40 mesh coals. The effect of C/A ratio on the $\mathrm{NH}_{3}$ concentrations was the opposite; it was higher for the -30 mesh coal and lowest for the -18 mesh coal.

Effect of Fluidization Velocity. The above results are for a fluidization velocity of 6.4 $\mathrm{ft} / \mathrm{sec}$. If the fluidization velocity is reduced, the concentrations of $\mathrm{H}_{2}$ and $\mathrm{HC}$ can be increased with smaller size coal. This is shown by the results of our earlier experiments with -30 mesh coal where concentrations of $\mathrm{CO}$ and $\mathrm{H}_{2}$ were measured similar to those shown in Figures F-18 and F-19 for the larger -18 mesh coal but at lower fluidization velocities.

Figures F-23 to F-27 show the influence of fluidization velocity and tend to substantiate the above observations. In the fluidization velocity range of 4.0 to $9.7 \mathrm{ft} / \mathrm{sec}, \mathrm{CO}$ and $\mathrm{H}_{2}$ levels for the larger -18 mesh coal particle size are higher, because as mentioned -above, these particles spend more time in the high mixing, high heat transfer dense phase region. On the other hand, the smaller -40 mesh particles elutriate sooner as fluidization velocity is increased, and $\mathrm{CO}$ and $\mathrm{H}_{2}$ concentrations decrease as fluidization velocity increases for this coal feed size. As before, the hydrocarbon concentrations do not appear to be strongly dependent on particle size as the fluidization velocity is varied (see Figure F-25). Both ammonia and hydrogen sulfide emissions decreased with increasing fluidization velocity.

Effect of Temperature. The effect of temperature on gas composition was studied with the -40 mesh coal. In these experiments, the C/A mass ratio was fixed at 0.22 , while the bed temperature was increased by varying the heat transfer to the bed. Thus, there is a slight variation in the fluidization velocity, and the results do not reflect the influence of temperature alone. Fluidization velocity effects as discussed in the previous section must also be considered. 


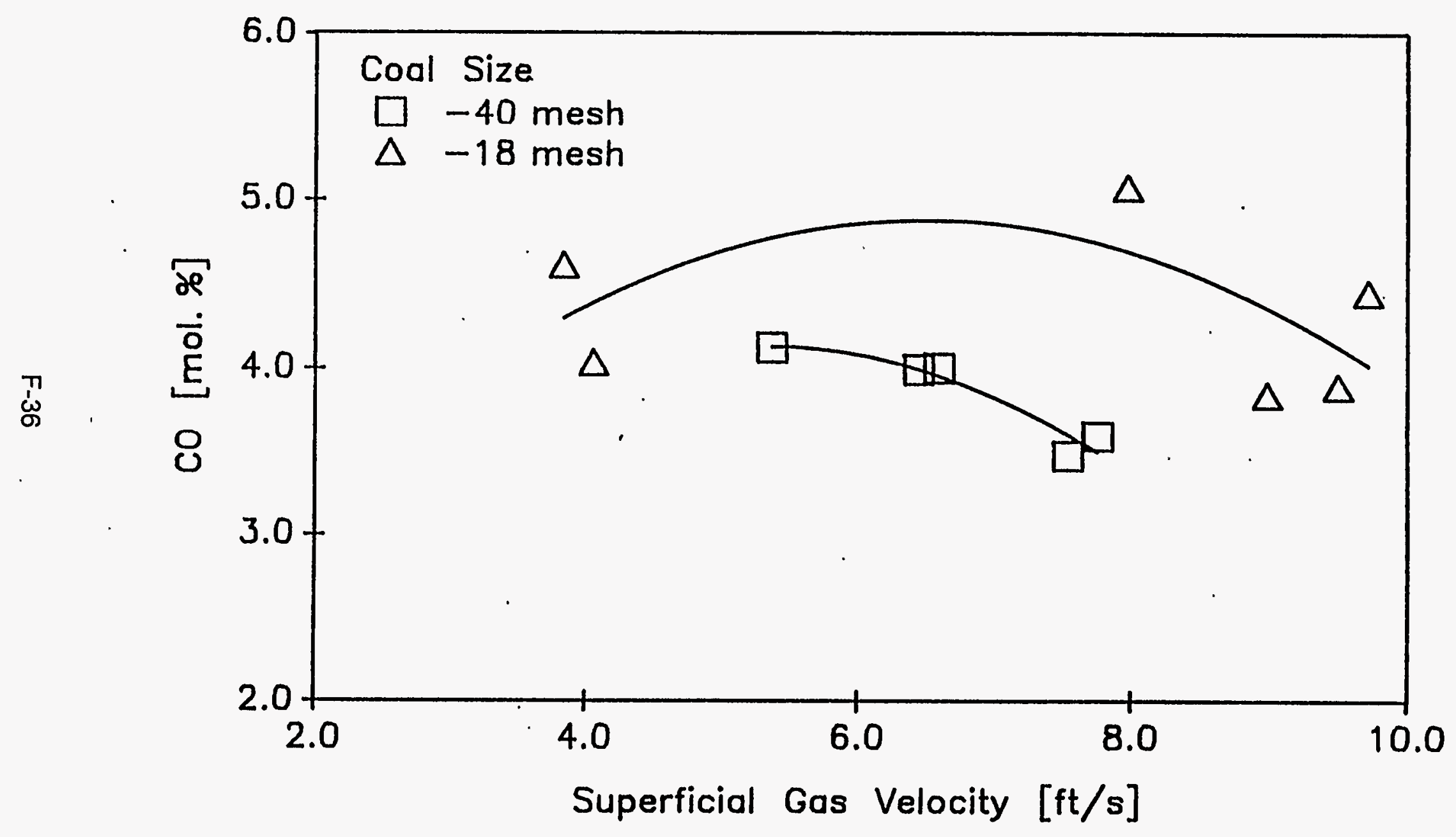

Figure F-23 Influence of Superficial Velocity on Fuel Gas Carbon Monoxide Concentration 


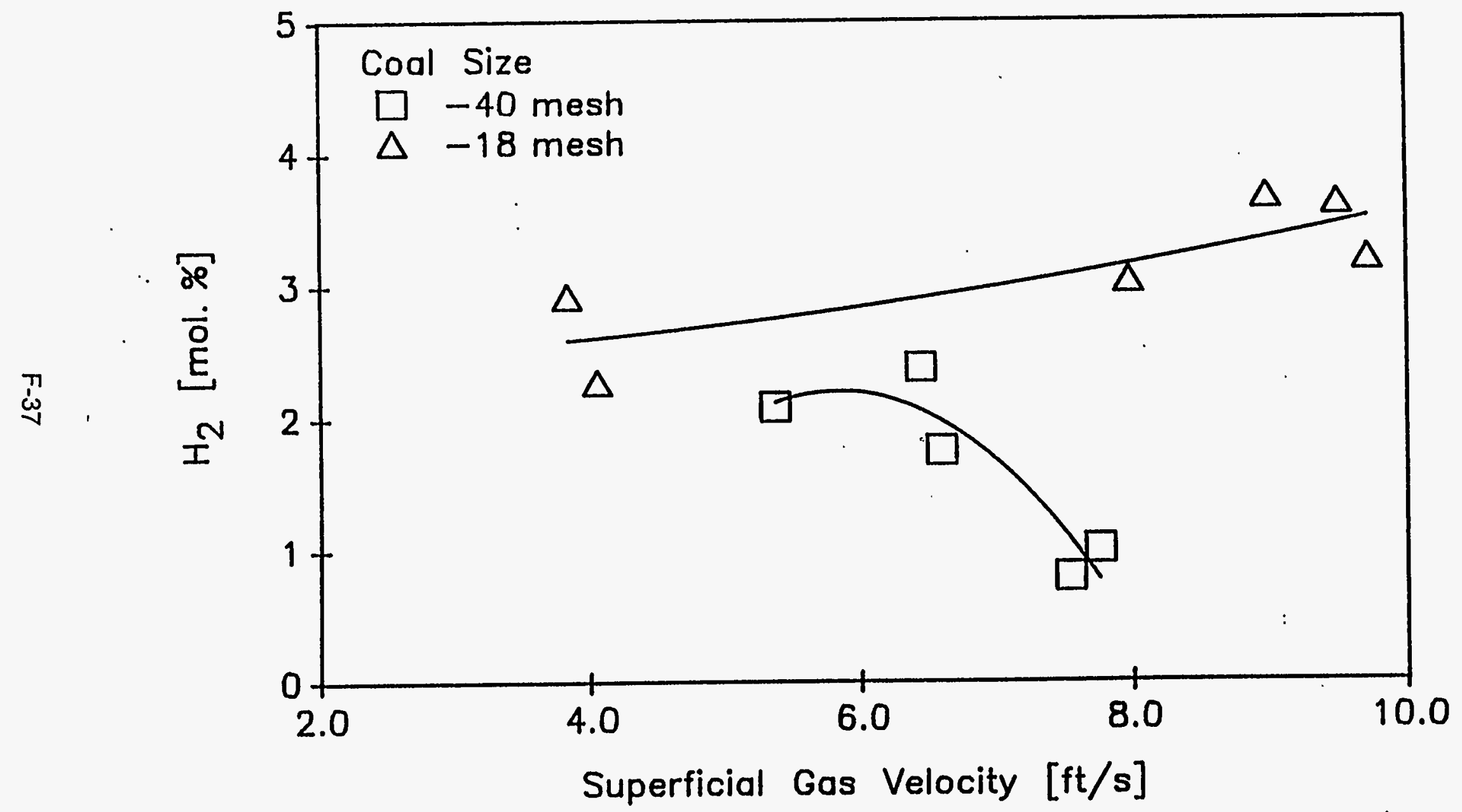

Figure F-24 Influence of Superficial Velocity on Fuel Gas Hydrogen Concentration 


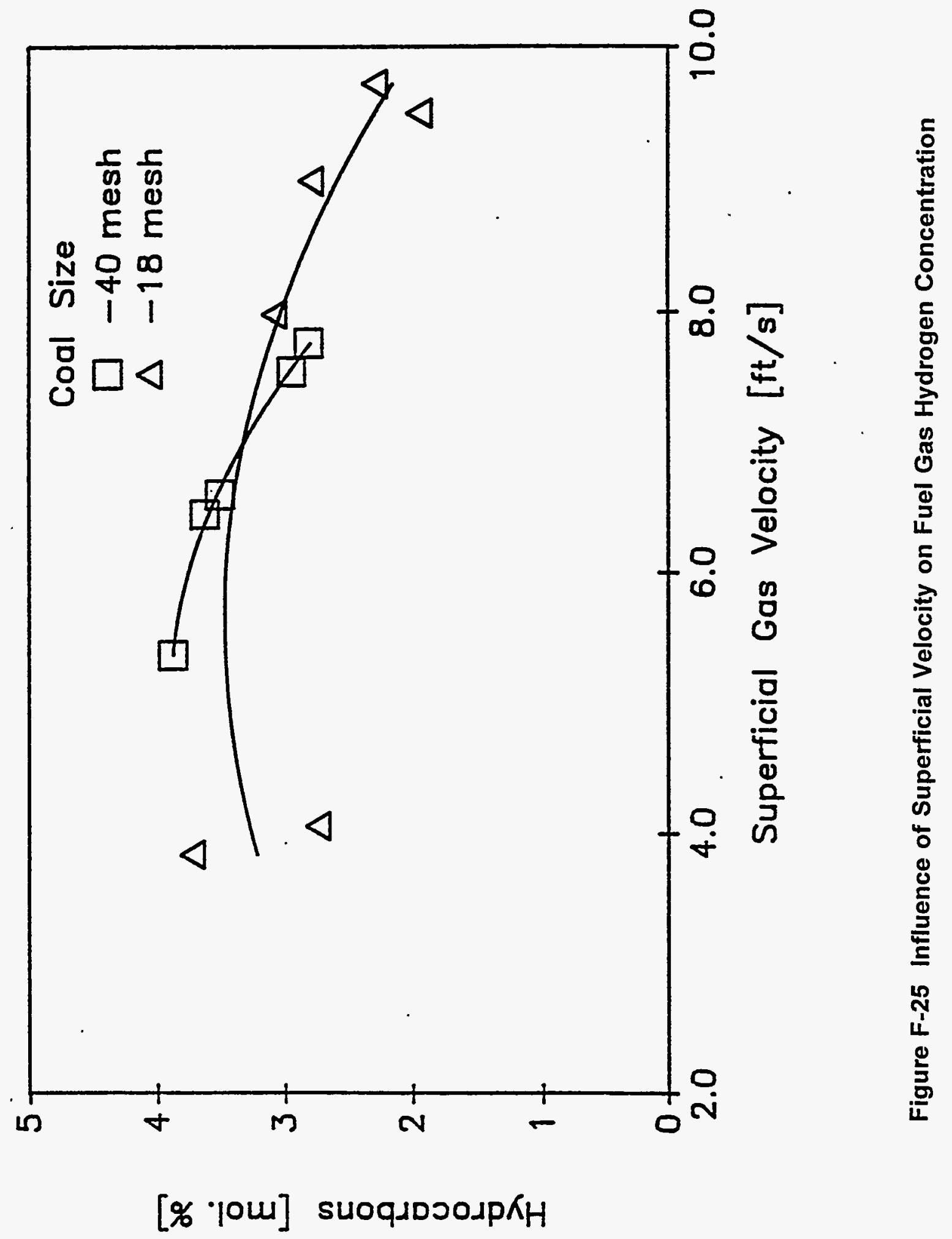

F-38 


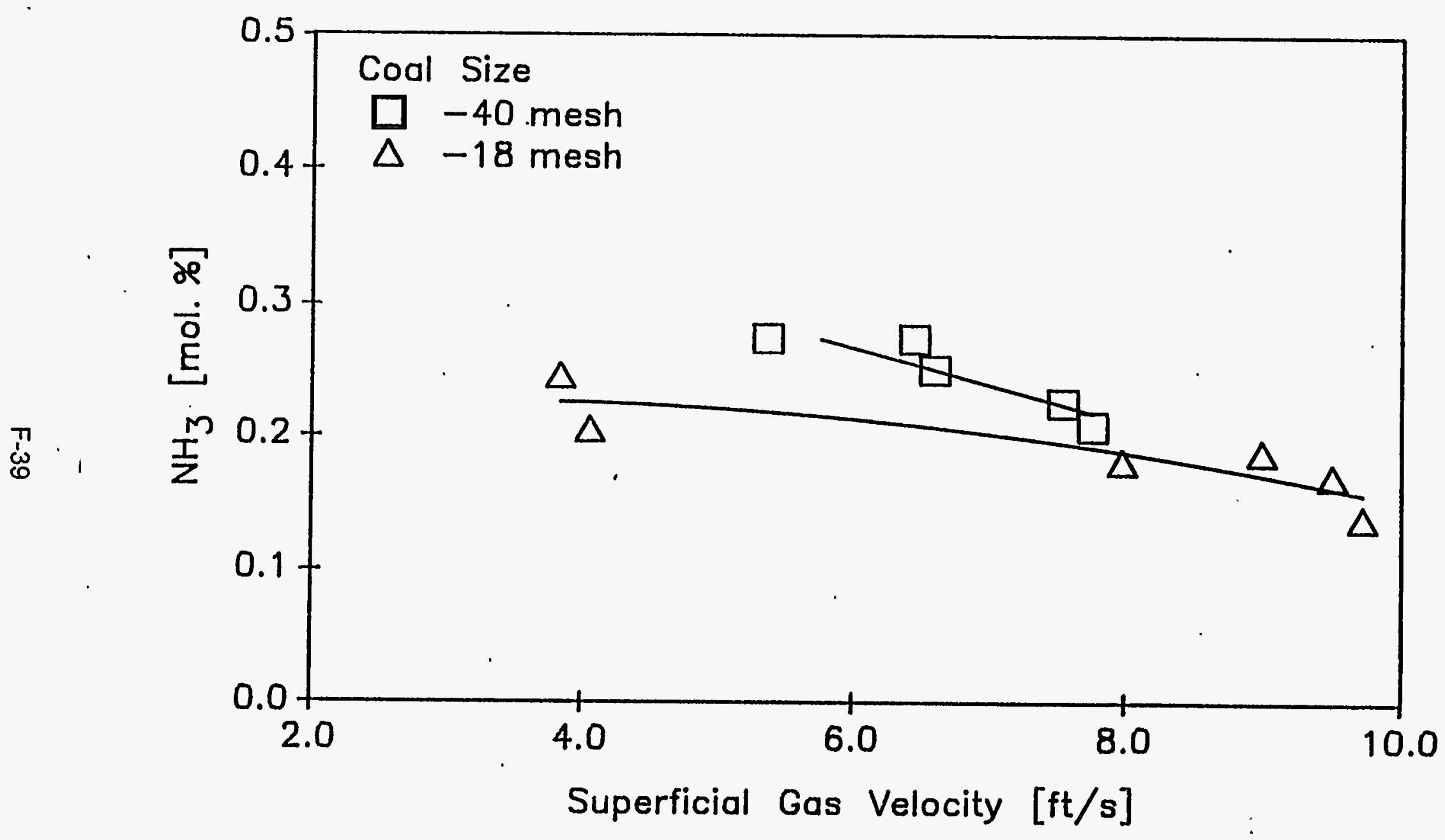

Figure F-26 Influence of Superficial Velocity on Fuel Gas Ammonia Concentration 


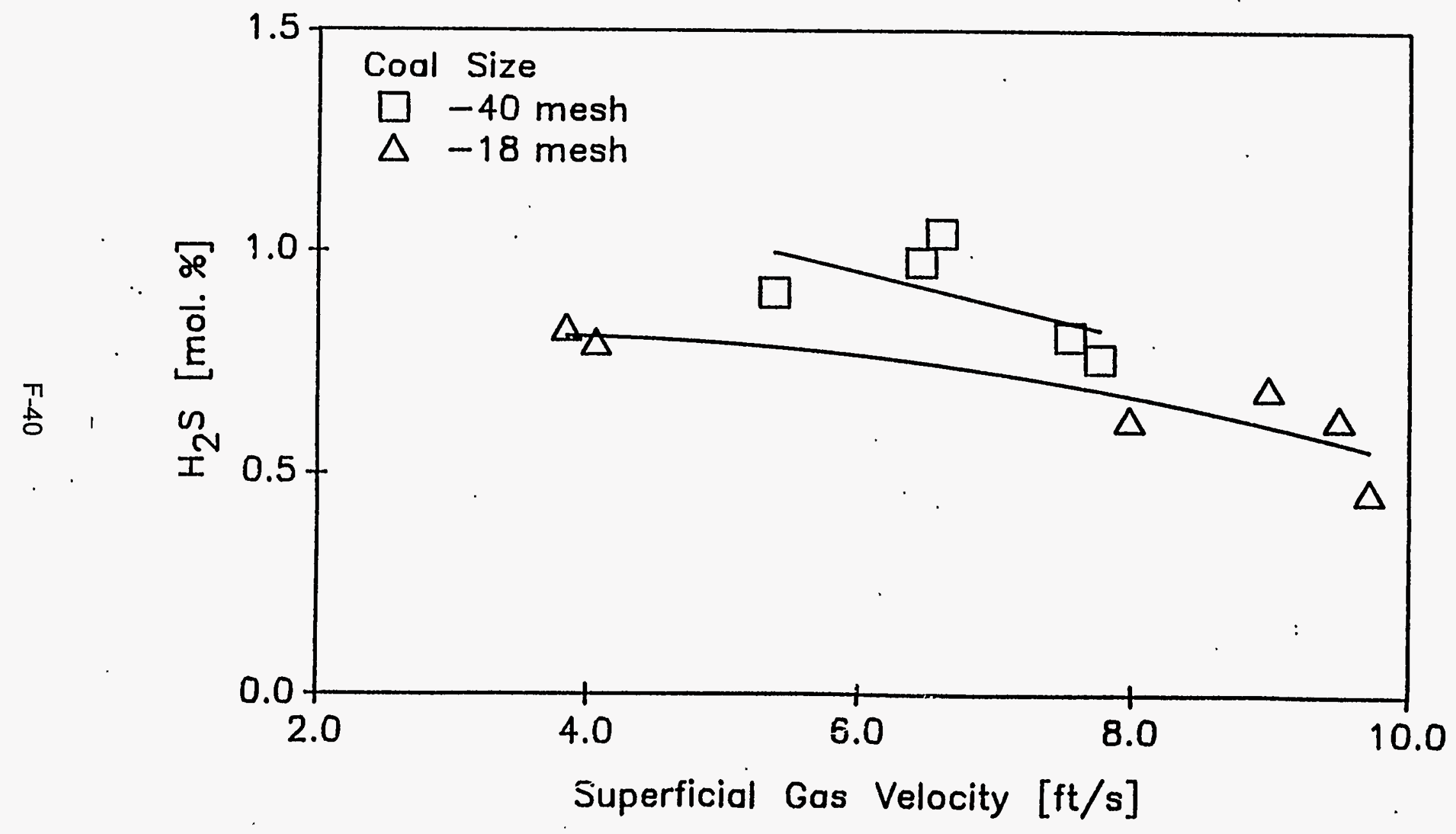

Figure F-27 Influence of Superficial Velocity on Fuel Gas Hydrogen Sulfide Concentration 
Because of these effects, the results of the experiments that are shown in Figures F-28 to F-32 do not show any strong influence of temperature, as the higher reaction rates promoted by the higher temperatures are offset by the influence of lower residence time at the higher velocities. Only the hydrogen concentration appears to show a slight increase.

\section{F.3.4 FUEL GAS HEATING VALUES}

The fuel gas heating values were computed from the measured gas compositions and the enthalpy of reaction for the oxidation reactions of $\mathrm{CO}, \mathrm{H}_{2}$ and the hydrocarbons represented as methane $\mathrm{CH}_{4}$. They are presented as $\mathrm{Btu} / \mathrm{b}$ on a wet gas basis.

Effect of Feed Particle Size and C/A Ratio. Figure F-33 shows the variation of the lower heating value of the fuel gas with feed particle size and C/A ratio. As is to be expected, the heating value increases with CIA ratio. At the fluidization velocity of 6.4 $\mathrm{ft} / \mathrm{sec}$ and $1650^{\circ} \mathrm{F}$ temperature, the heating value increases as more coal is fed to the pyrolyzer and is the result of increased reaction rate based on coal concentration in the bed. The coal concentration in the bed is in turn a function of coal particle size, fluidization velocity and recycle mass. At constant fluidization velocity and recycle mass, as in the case of the present experiments, the coal/char concentration is a function of particle size. This influence of particle size is clearly shown in Figure F-33. The larger -18 mesh size coal experiences a longer residence time in the dense phase portion of the bed and yields gas with the highest heating value, even though the smaller size coal is considered more reactive. The heating value is about $700 \mathrm{Btu} / \mathrm{b}$ at a.C/A ratio of 2.2, on a wet basis. The data also seems to indicate that the higher reactivity of the smallest -40 mesh coal may compensate for the longer residence time of the larger coal under the proper circumstances.

The results presented in Figure F-33 also reflect the influence of pyrolyzer scale. In a tall commercial unit, it is possible that freeboard reactions will contribute more strongly given enough residence time. However, the present results indicate that the mixing and - heat transfer rates in the dense phase do exert a significant influence on gas heating value and the relative importance of freeboard height and bed depth needs to be investigated in optimizing the pyrolyzer design.

Effect of Fluidization Velocity. The effect of fluidization velocity at a constant C/A ratio of 0.22 and a bed temperature of $1650^{\circ} \mathrm{F}$ is shown in Figure F-34. The fuel gas heating value decreases slightly with increasing fluidization velocity. The larger -18 mesh coal gives fuel gas with the highest heating value, especially at higher superficial velocities. The decreased residence time in the dense phase for the smaller -40 mesh coal appears to influence the heating value more strongly at higher velocities. 


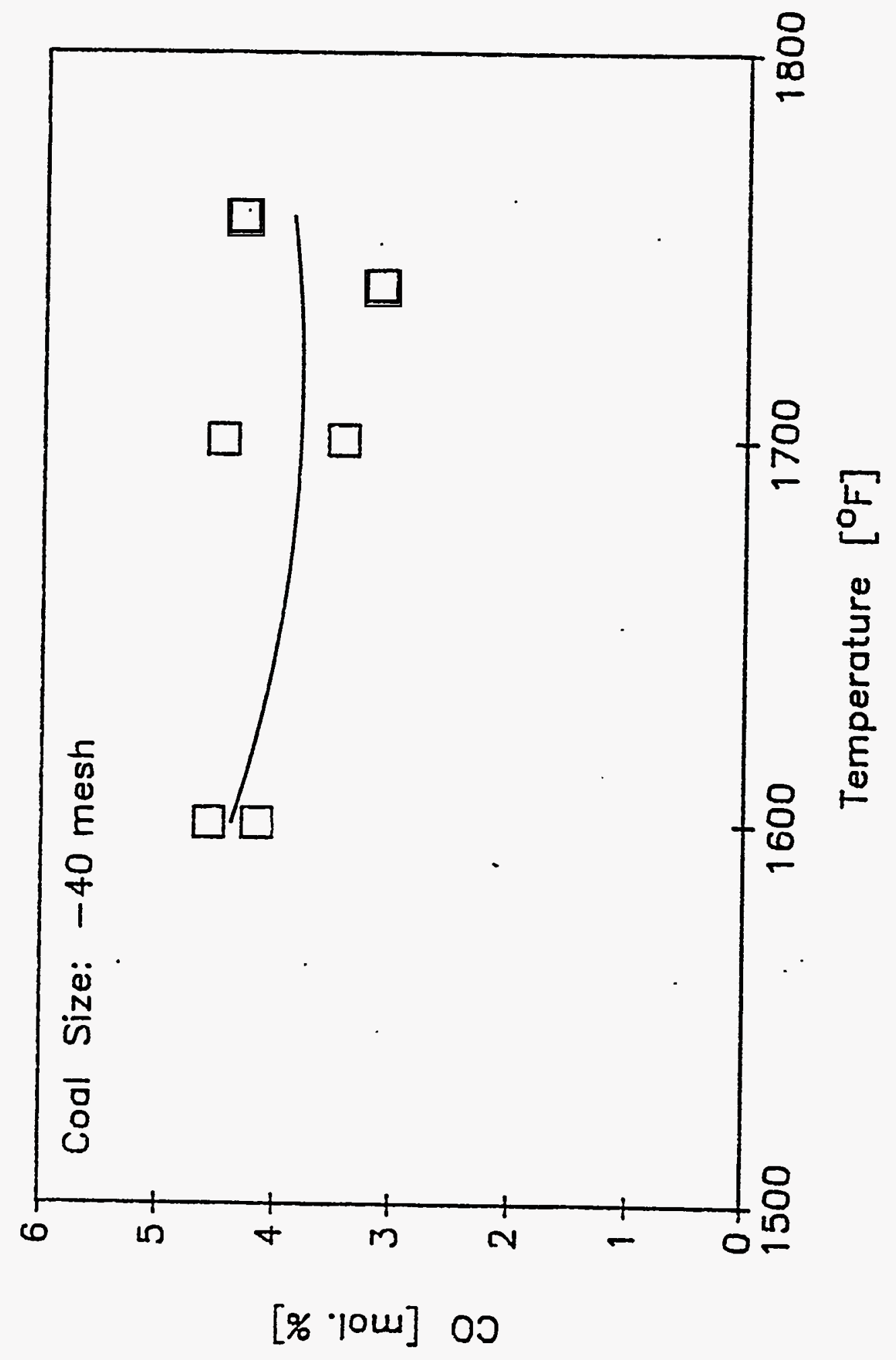

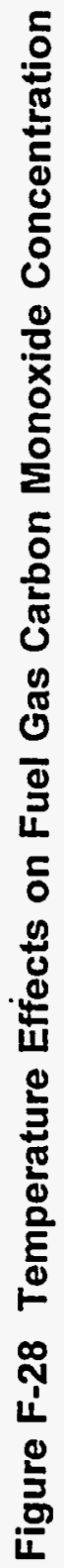

$F-42$ 


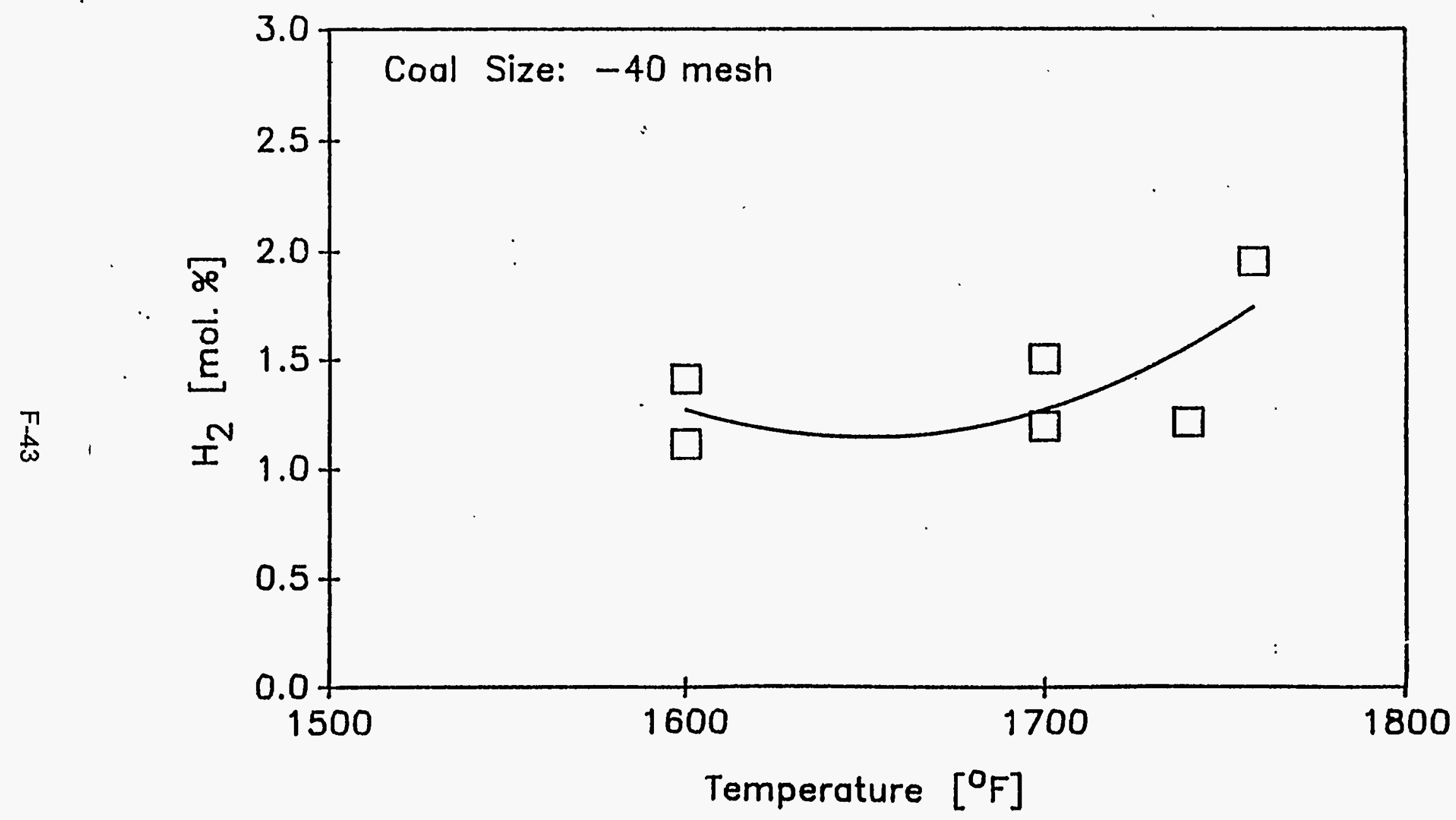

Figure F-29 Temperature Effects on Fuel Gas Hydrogen Concentration 

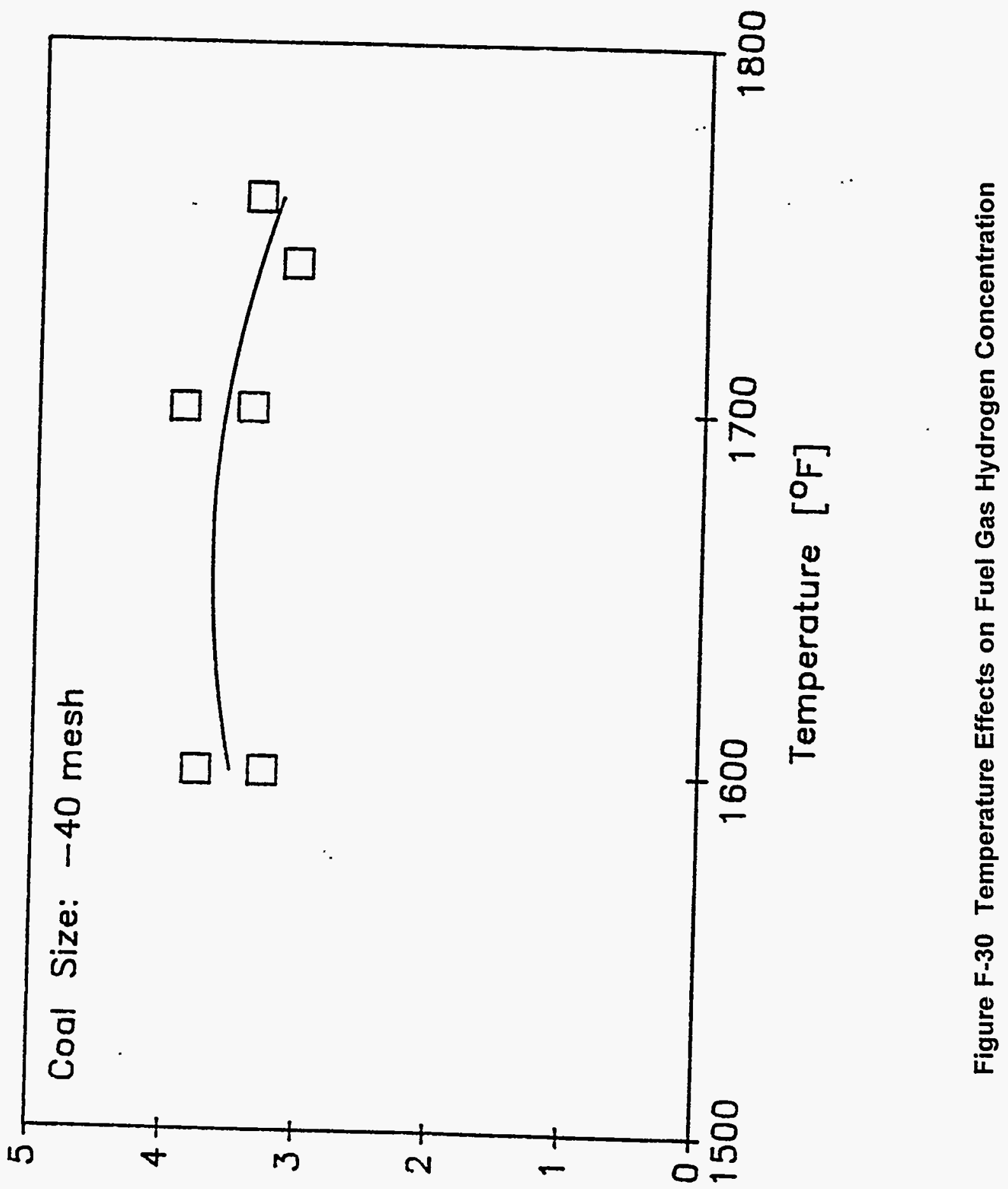

[\% \% 


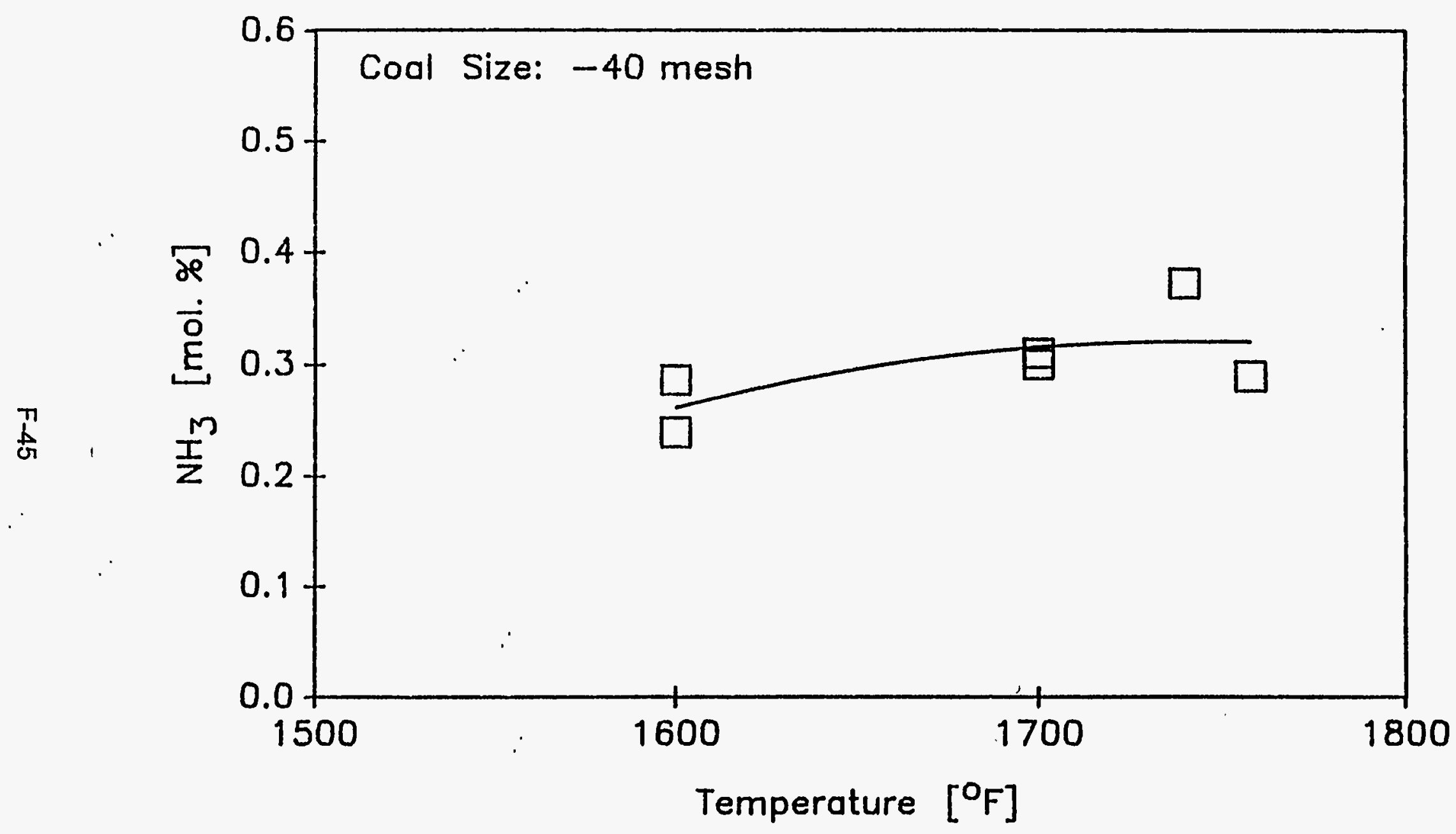

Figure F-31 Temperature Effects on Fuel Gas Ammonia Concentration 


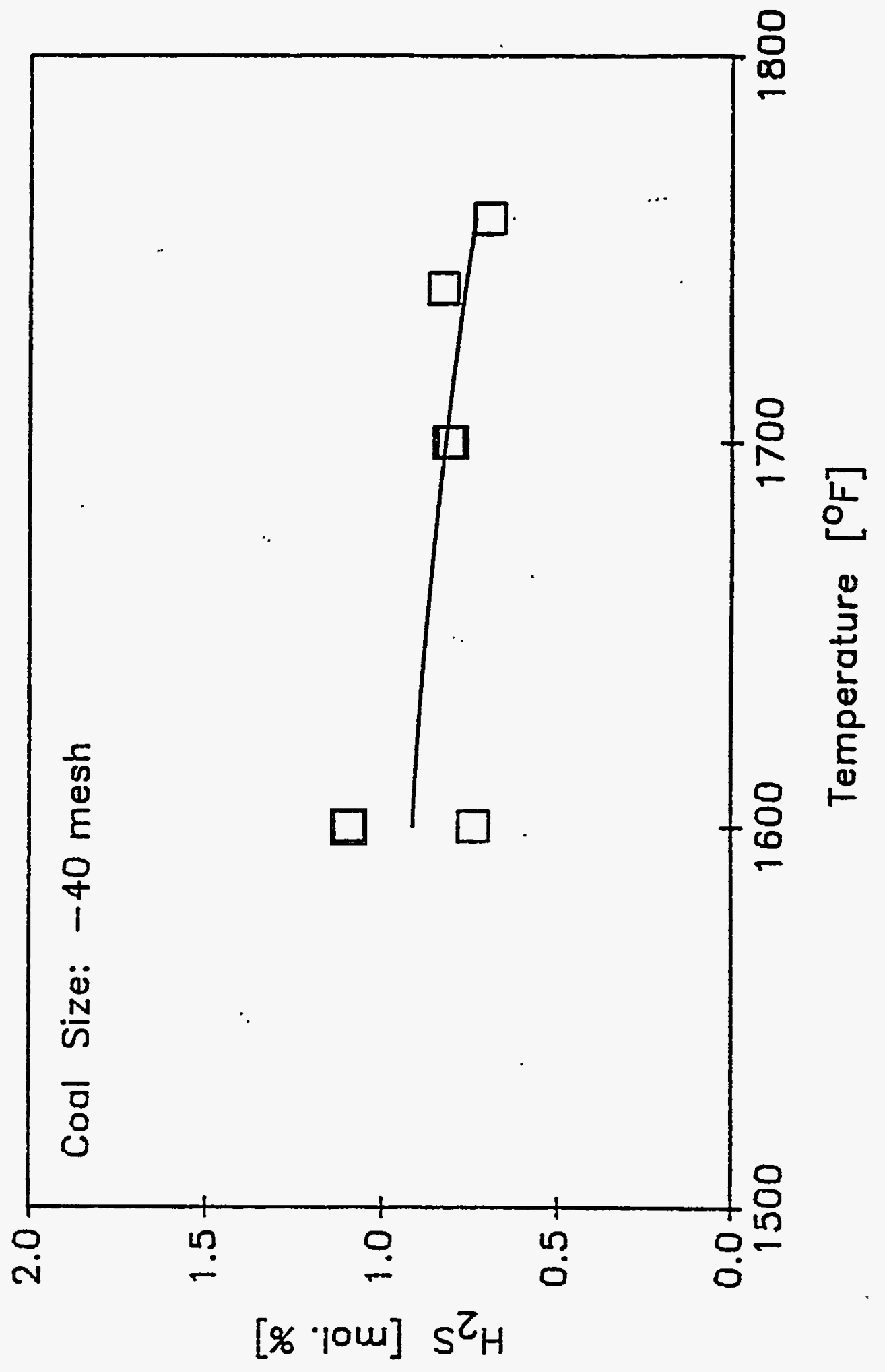

을

$F-46$ 


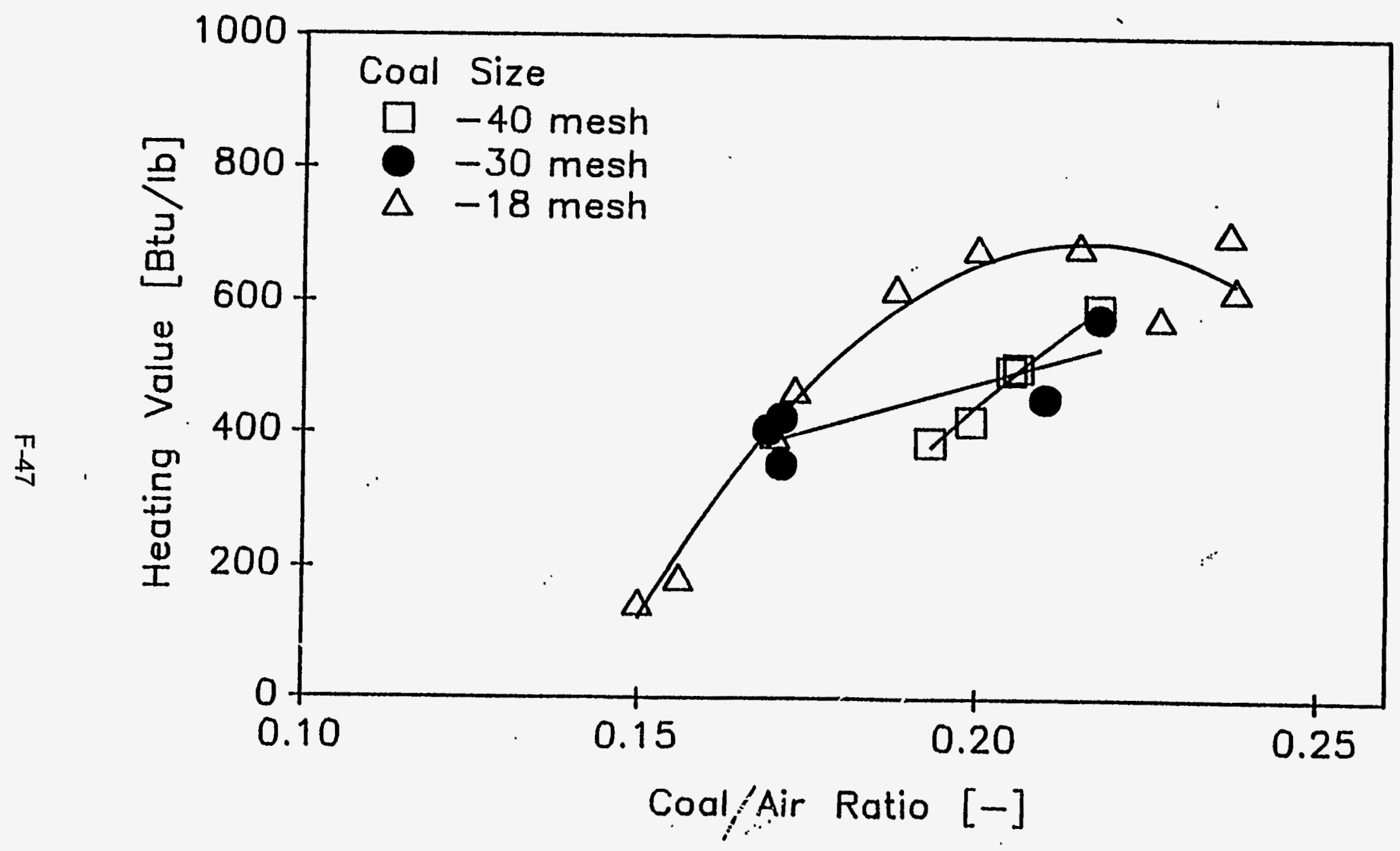

Figure F-33 Fuel Gas Heating Value Variation with Coal/Air Ratio and Particle Size 


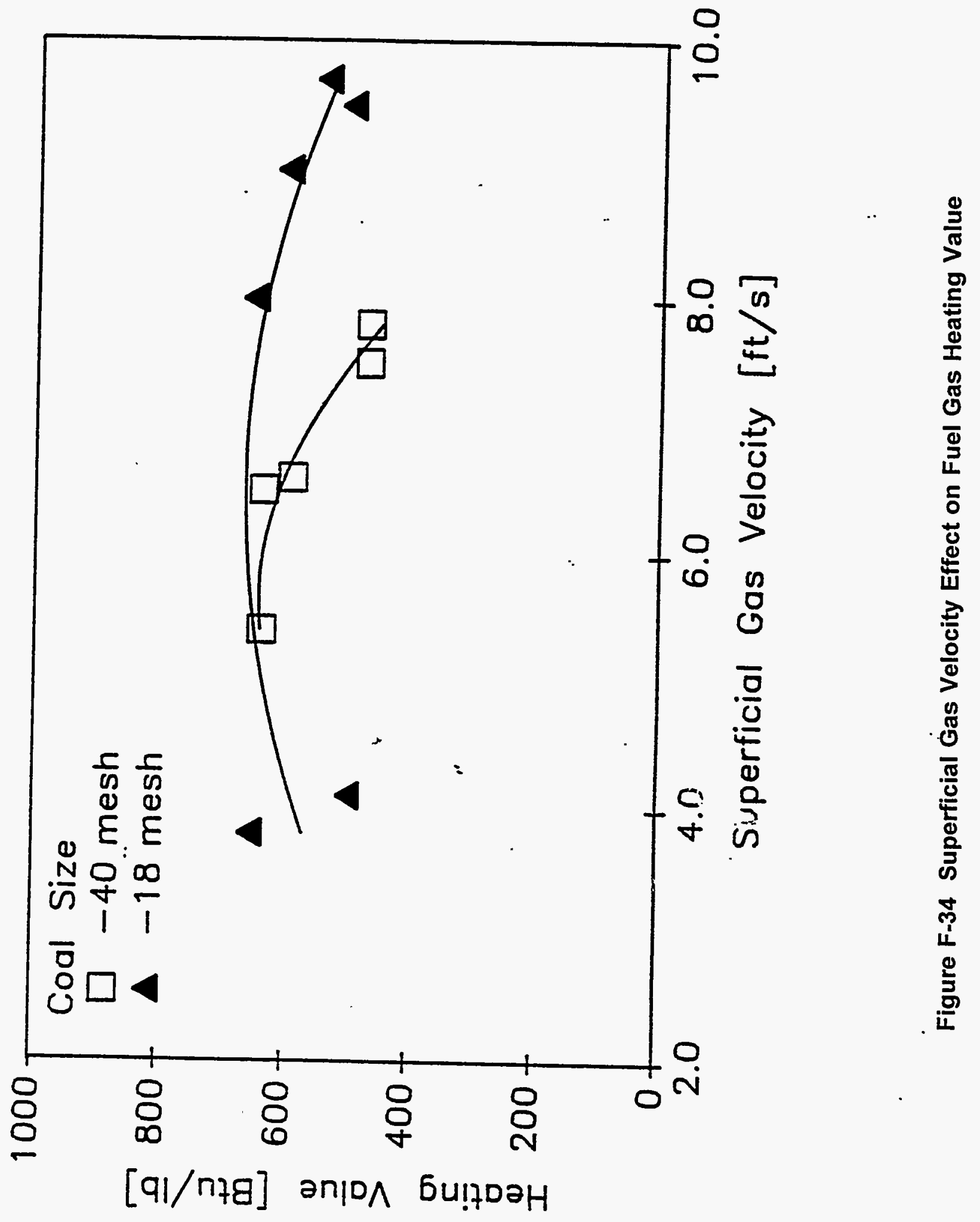

$F-48$ 
Effect of Bed Temperature. Figure F-35 shows the variation of fuel gas heating value for the -40 mesh coal. Because of the conflicting influence of temperature and fluidization velocity as discussed in Section F.3.3, the effect of temperature on heating value is not very pronounced.

\section{F.3.5 CHAR SURFACE MORPHOLOGY}

The char morphology was studied using scanning electron microscopy (SEM) to investigate the influence of feed particle size, fluidization velocity and bed temperature on surface characteristics.

Effect of Coal Feed Particle Size. Representative samples of char taken from test runs where the C/A ratio was 0.22 , the fluidization velocity was $6.4 \mathrm{ft} / \mathrm{sec}$ and the bed temperature was $1650^{\circ} \mathrm{F}$ were observed using SEM. Figures F-36 through F-38 show the surface structural features of the primary char from the $-40,-30$ and -18 mesh coal feed sizes, respectively. The figures show a split image, with the top section at 1500 magnification, while the bottom portion is at 150 magnification. Softening of the surface and blowholes are observed to be common to the chars of all three sizes. Where more reaction has occurred, the particles can be seen to have large holes reaching into the interior of the particle with breakdown of the walls between pores.

Effect of Fluidization Velocity. Figures F-39 and F-40 show the surface features of the -40 mesh coal at a superficial velocity of $7.8 \mathrm{ft} / \mathrm{sec}$ and the -18 mesh coal at a superficial velocity of $9.7 \mathrm{ft} / \mathrm{sec}$, respectively, for the same C/A ratio and bed temperature of $1650^{\circ} \mathrm{F}$. Some of the larger particles are shown in the figures. The bottom half of the photograph is at a low magnification of 150 , while the top half shows a portion of the lower half at 1500 times magnification. The top half of Figure F-39 actually shows the magnified view of a piece of limestone at the middle right of the lower section. The -40 mesh char in Figure $\mathrm{F}-39$ does have some large areas with holes protruding into the interior of the particle. However, the surface of the -18 mesh char is seen to have been subjected to reaction much more than the surface of the -40 mesh char, as seen from the top half of Figure F-40. This is perhaps indicative of the longer times that the -18 mesh coal has been subjected to reaction due to its longer residence times in the dense phase section of the bed as described earlier.

Effect of Temperature. Figure F-41 shows an SEM picture of the -40 mesh char at $1760^{\circ} \mathrm{F}$, at a fluidization velocity of $7 \mathrm{ft} / \mathrm{sec}$ and a C/A ratio of 0.2 . The effect of this higher temperature, in comparison to that of the $1650^{\circ} \mathrm{F}$ char shown in Figure $\mathrm{F}-36$, is that more surface holes can be observed. This is indicative of higher reaction rates.

Figure F-42 shows particles of char collected from the secondary cyclones at $1740^{\circ} \mathrm{F}$ with the -40 mesh coal. From the bottom half of the picture, which is at a magnification of 1000, it can be seen that the secondary particles are much smaller. The top half of Figure $F-42$ shows the section indicated by the box in the lower half magnified 10 times, i.e., at 10,000 magnification, and indicates a organized structure of a dendritic pyrite 


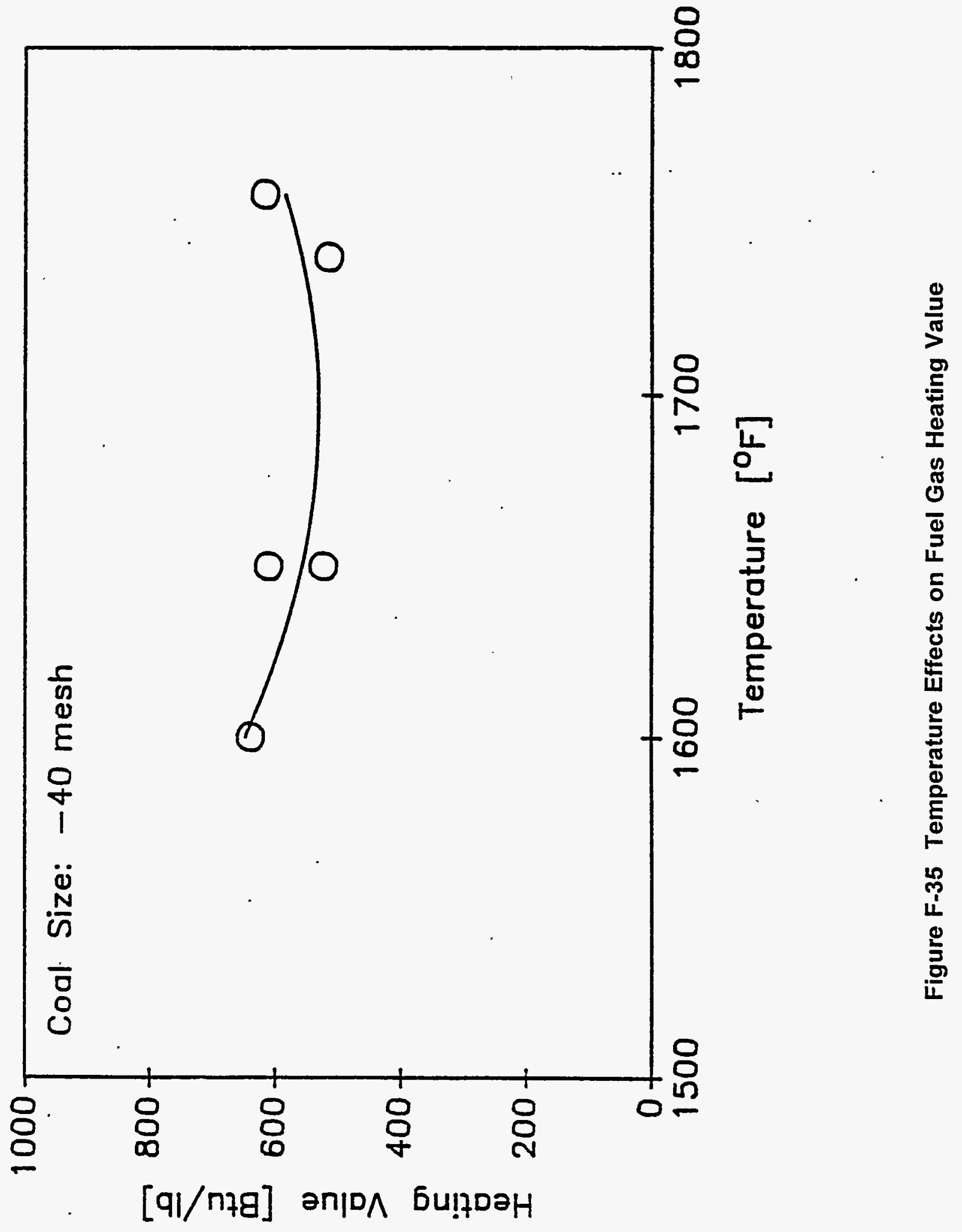




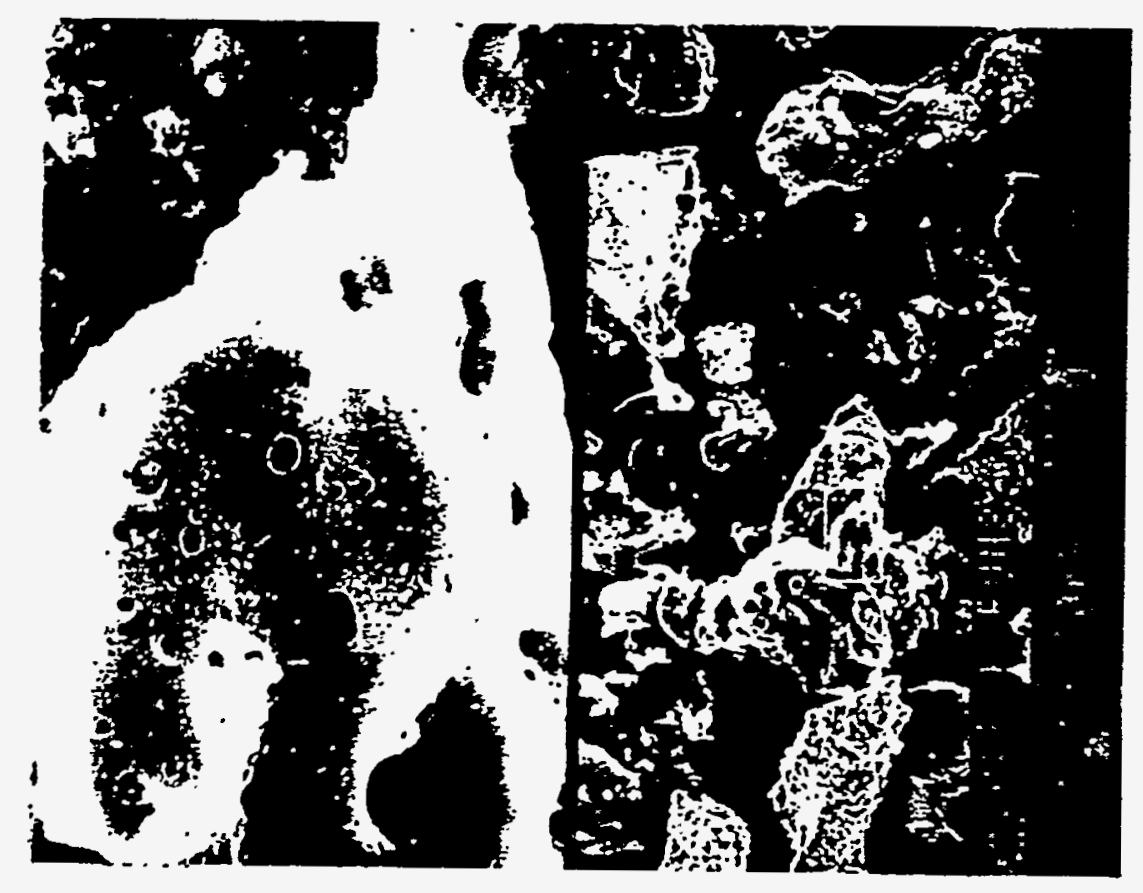

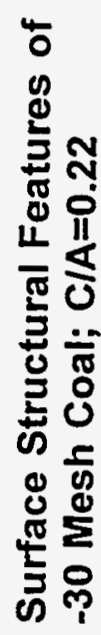

解

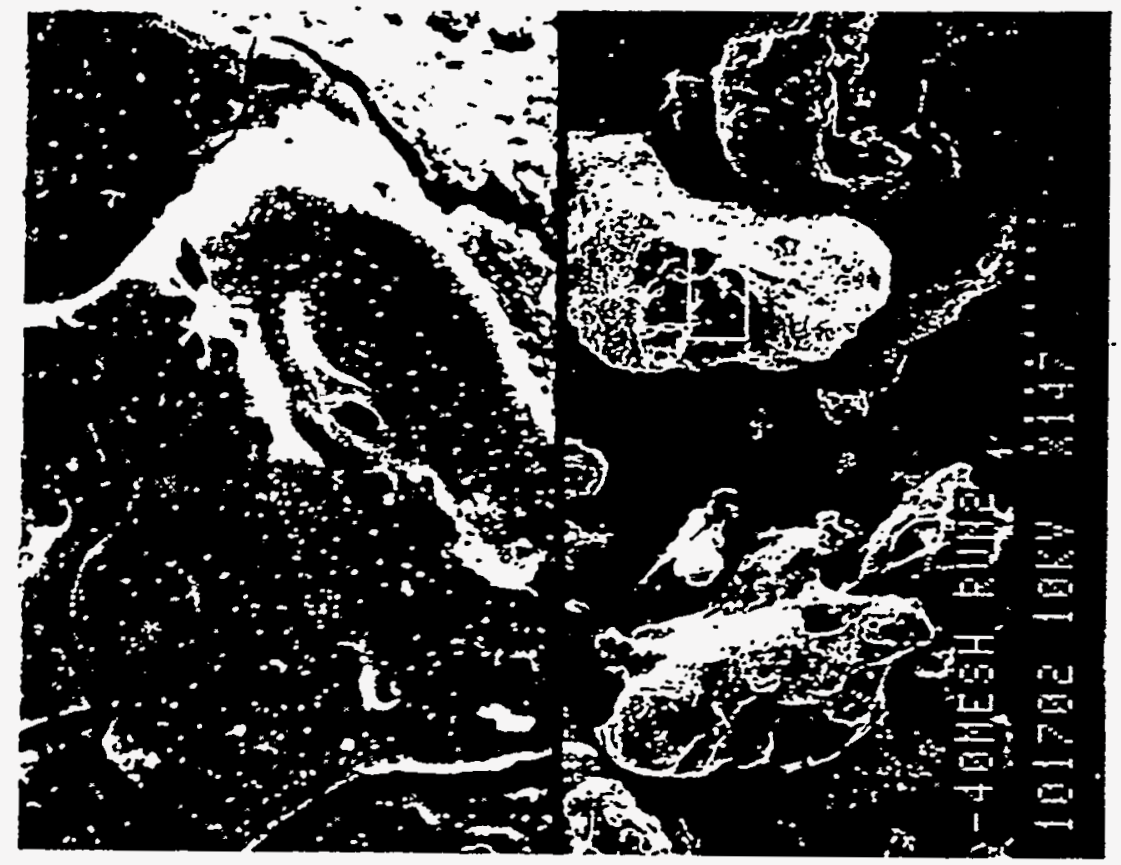

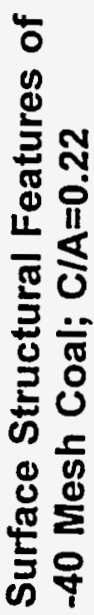

\%
ㄴ.
늘
은 


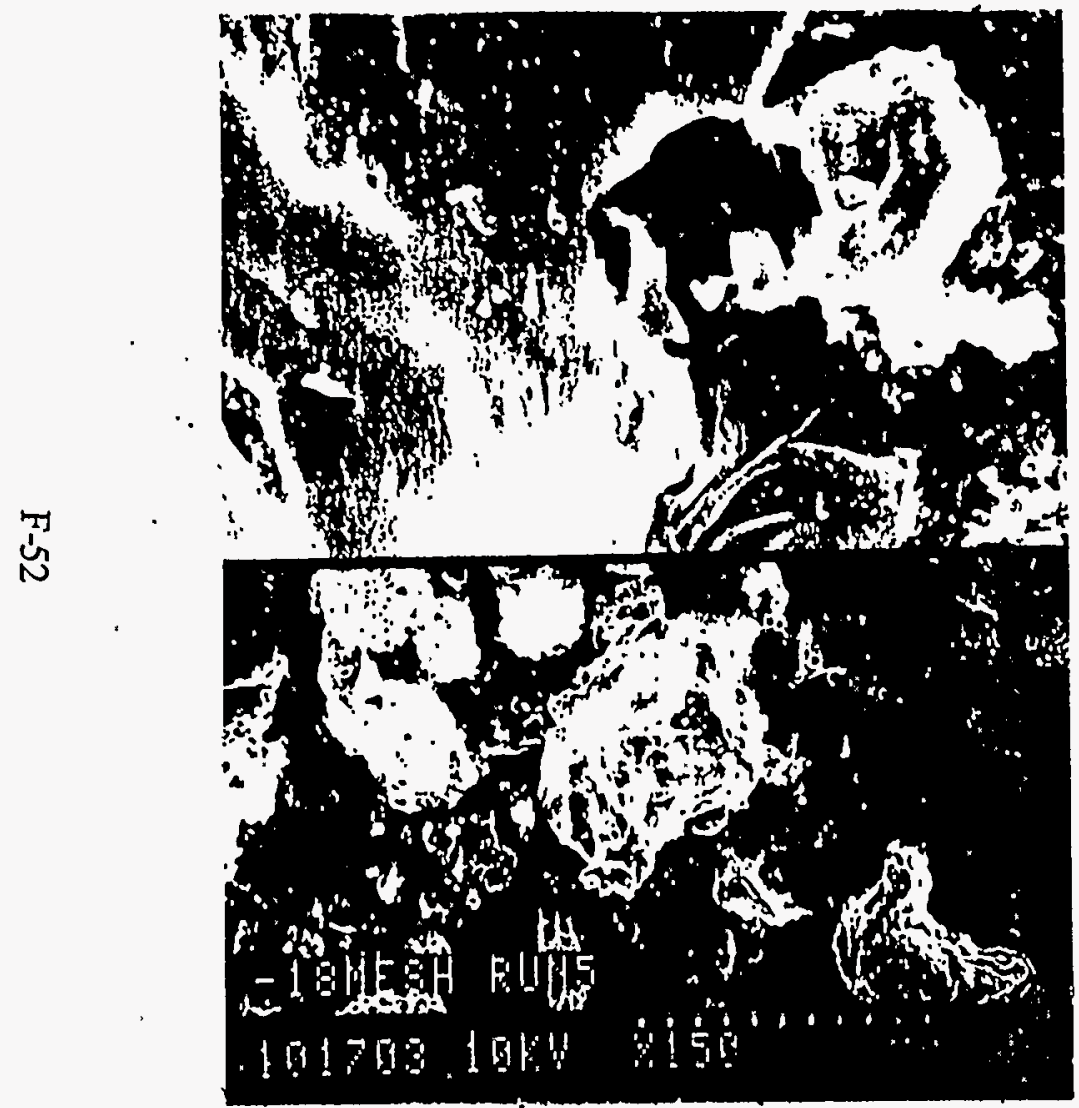

Figure F-38 Surface Features of -18 Mesh Coal; $C / A=0.22$

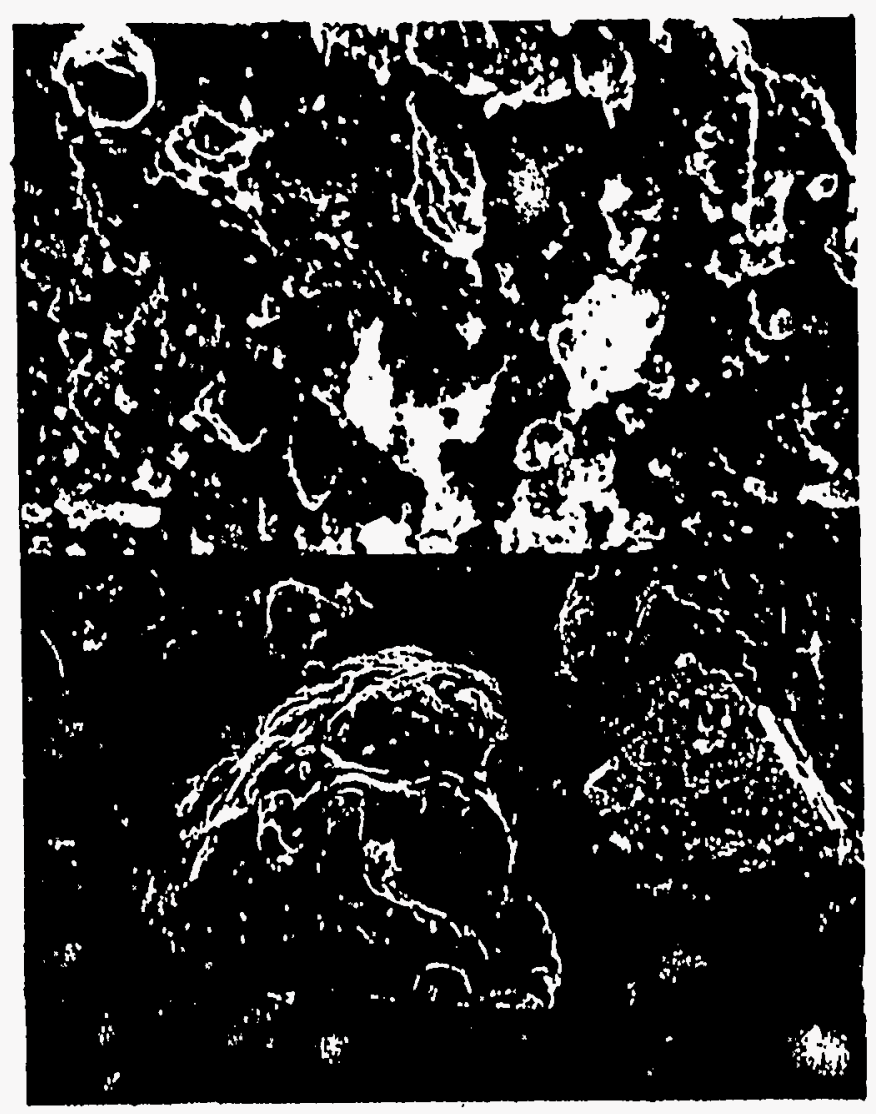

Figure F-39 'Surface Features of -40 Mesh Coal at Higher Superficial Velocity of $7.8 \mathrm{ft} / \mathrm{sec}$ 


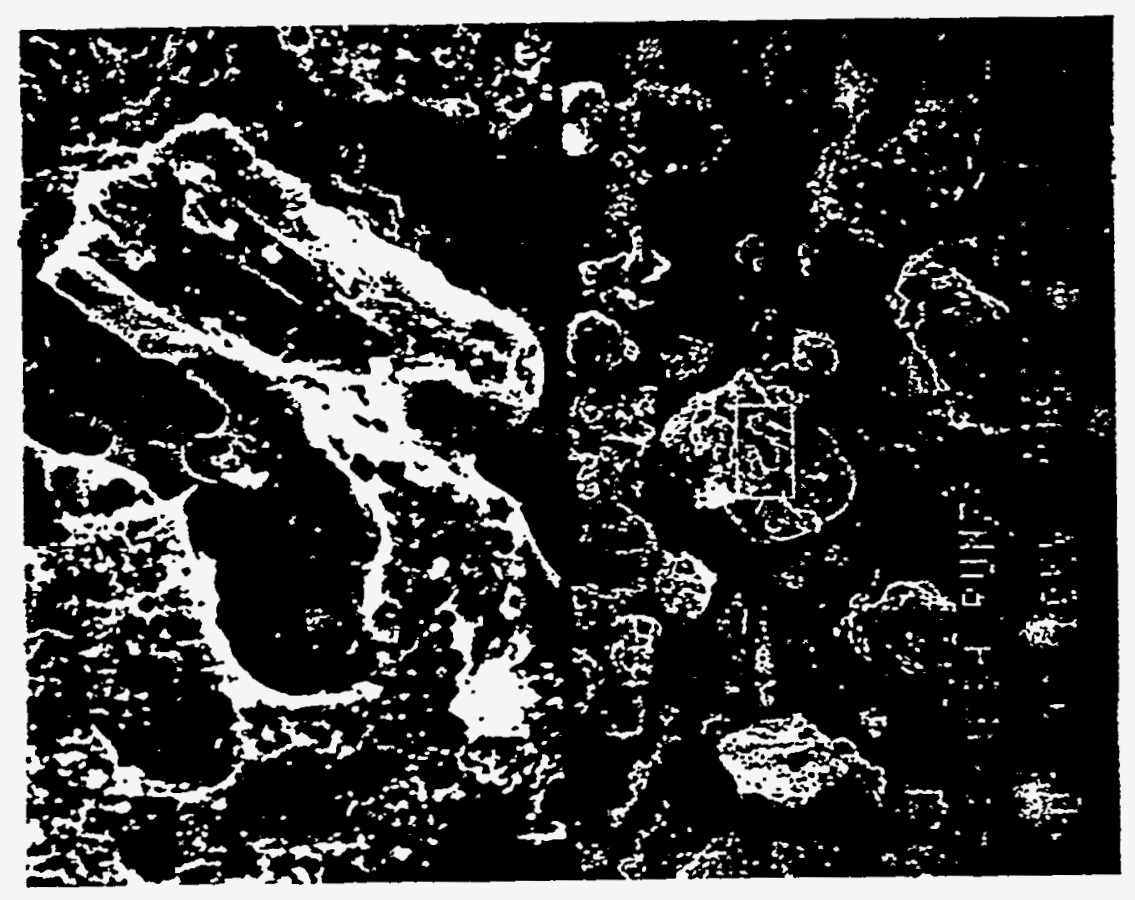

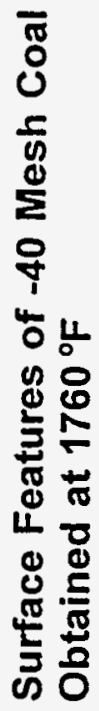

$\frac{5}{4}$

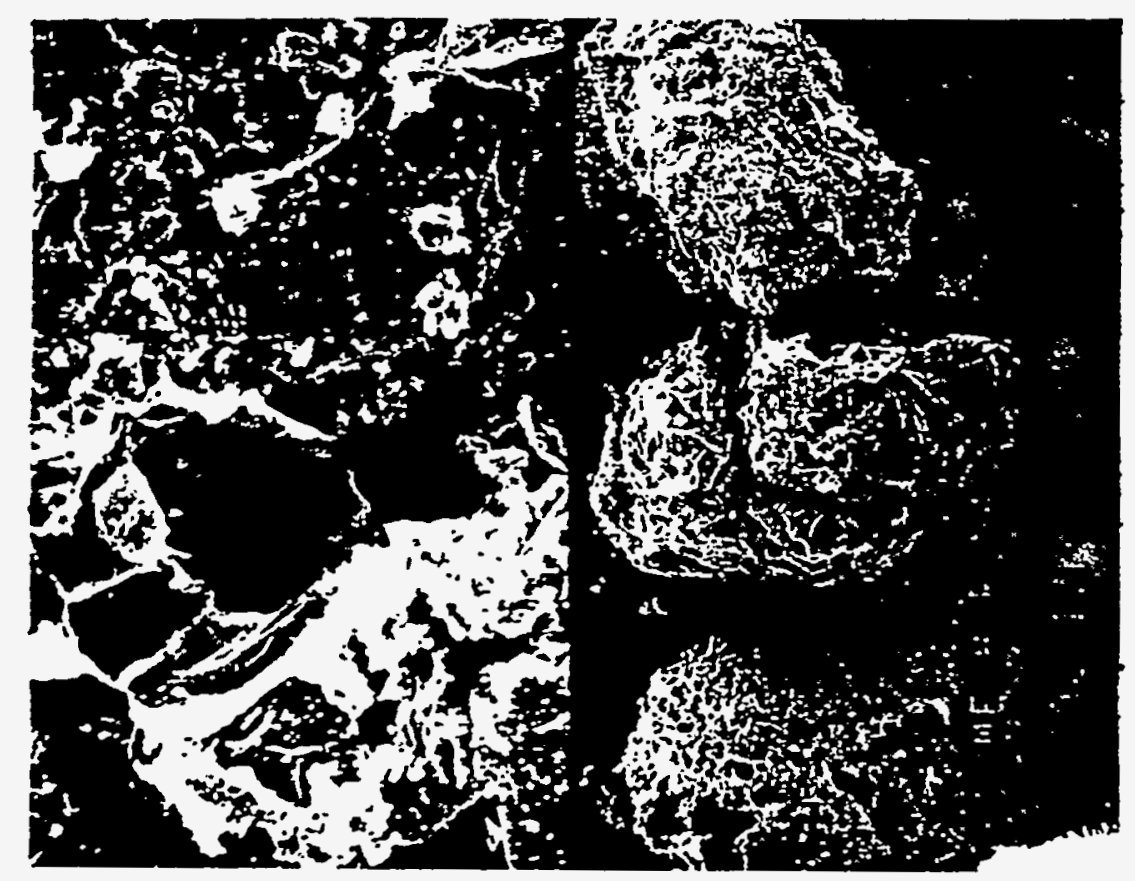

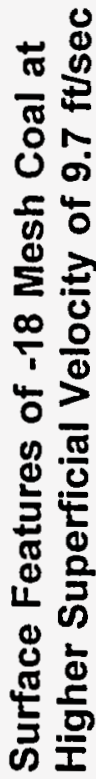

운 

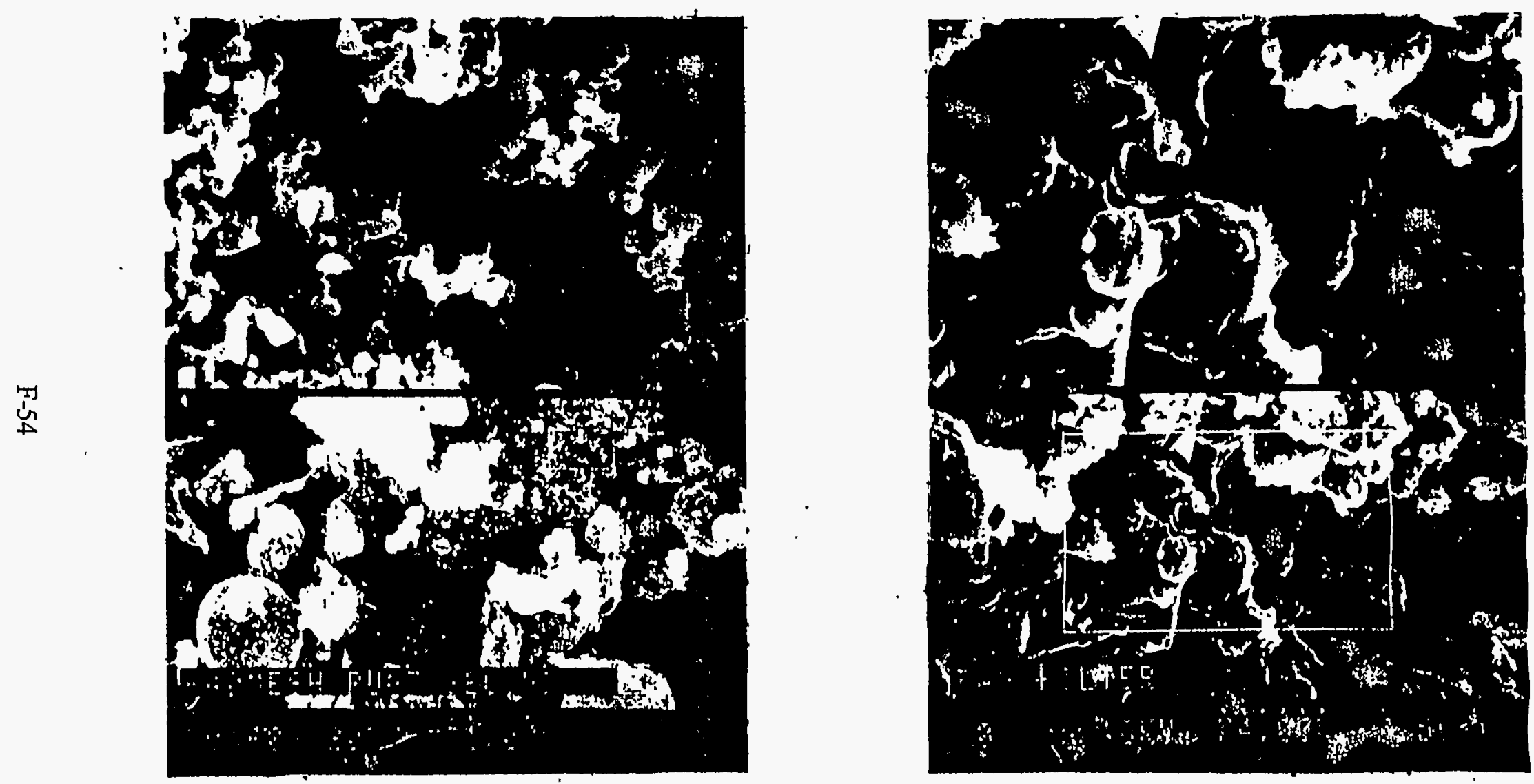

Figure F-42 Surface Features of Secondary Char from -40 Mesh Coal
Figure F-43 Surface Features of Bag Filter Catch; -40 Mesh Coal 
particle. Figure F-43 shows particles collected from a bag filter at the exit of the secondary cyciones at a magnification of 4000 on the bottom half and 8000 in the top half.

\section{F.3.6 CHAR REACTIVITY}

Since the char produced by the pyrolyzer is proposed to be utilized in a slagging furnace, tests were conducted in a Cahn thermogravimetric analyzer (TGA) to measure . the influence of particle size and other factors on char reactivity. The tests were conducted with $0.1 \mathrm{gm}$ samples of the char. Each char was heated in an atmosphere of air starting from a temperature of $100^{\circ} \mathrm{C}$ at a heating rate of $1{ }^{\circ} \mathrm{C} / \mathrm{sec}$ up to $400^{\circ} \mathrm{C}$. It was then heated at the rate of $1.5^{\circ} \mathrm{C} / \mathrm{sec}$ up to a temperature of $1000^{\circ} \mathrm{C}$, at which temperature it was held for 20 minutes. It was then allowed to cool down to $100^{\circ} \mathrm{C}$ at a rate of $4^{\circ} \mathrm{C} / \mathrm{min}$. The flow rate of the air was $30 \mathrm{cc} / \mathrm{min}$.

Effect of Coal Feed Particle Size on Char Reactivity. Figures F-43 through F-46 show the weight loss and the rate of weight loss profiles for the $-40,-30$ and -18 mesh coals, respectively. These chars correspond to the chars discussed in the previous section on char morphology. The fluidization velocity was $6.4 \mathrm{ft} / \mathrm{sec}$, the C/A ratio of 0.2 and the bed temperature was $1650^{\circ} \mathrm{F}$.

From the figures, it is seen that the weight loss curves drop sharply during the initial portion of the weight loss profile in a non-linear manner. Then there is a definite change in slope and the weight loss profile is almost linear till the curve bottoms out. The increase in weight after the curve has reached its lowest level is an artifact of the set temperature. This is because after 32 minutes, the test is over and the furnace begins to cool down.

The rate of weight curve loss exhibits a deep dip indicating a very high rate of weight loss between 12-16 minutes. Since the chars do contain a small portion of volatiles, these high weight loss rates are due to the enhancement of the carbon weight loss from the volatiles combustion. Once these volatiles have been burnt off, the weight loss rate of the remaining char is fairly linear till the maximum weight loss is attained.

Comparative rates of char weight loss were computed for this char combustion region by measuring the decrease in the percentage weight during a given period and dividing

Weight loss rate $\%=\frac{\text { Decrease in weight loss } \%}{\text { time }}$

Weight loss rate $\%=\frac{A B}{B C} \frac{\%}{\min }$ 


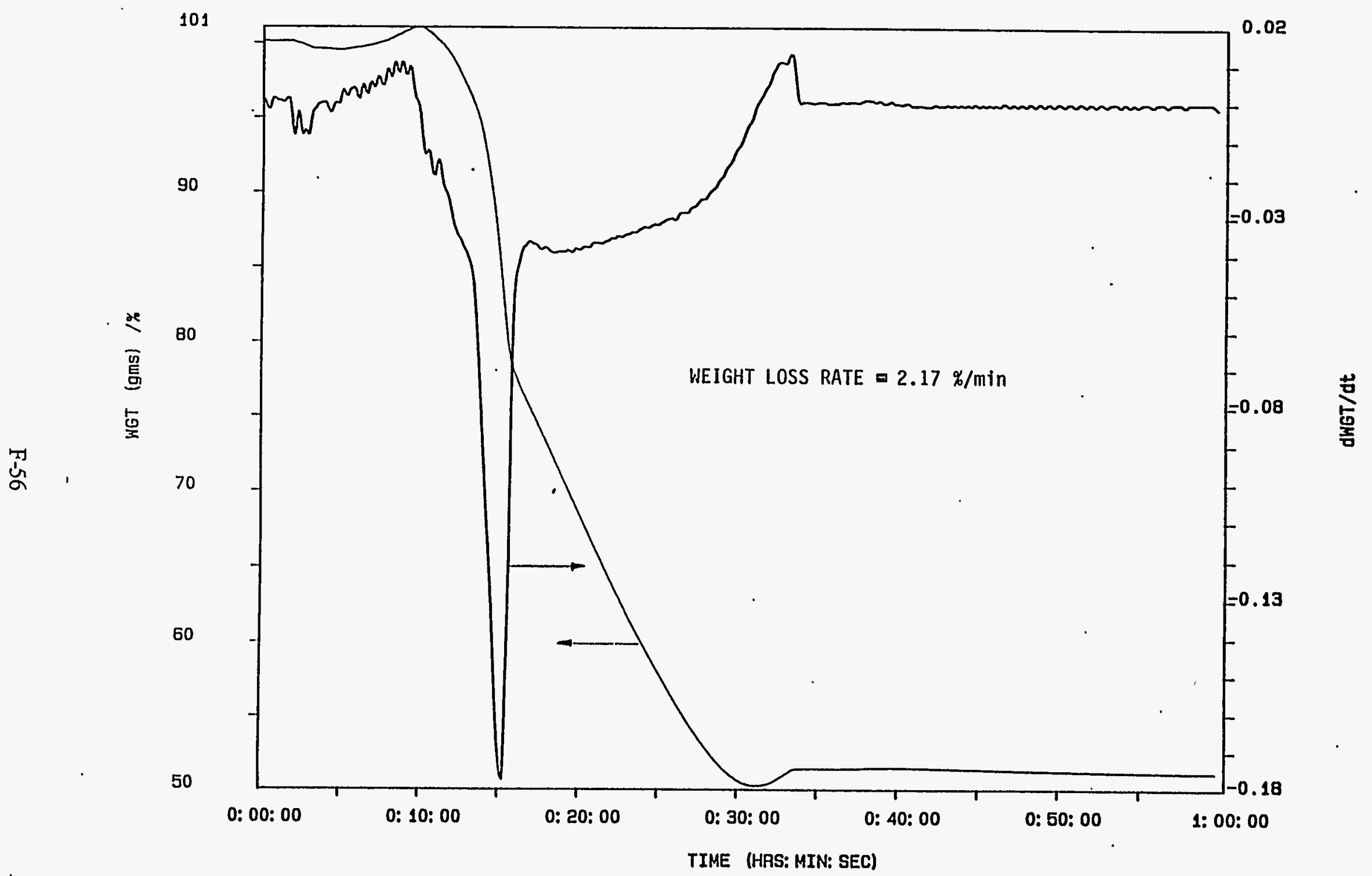

Figure F-44 Weight Loss and Rate of Weight Loss Profiles for -40 Mesh Coal 


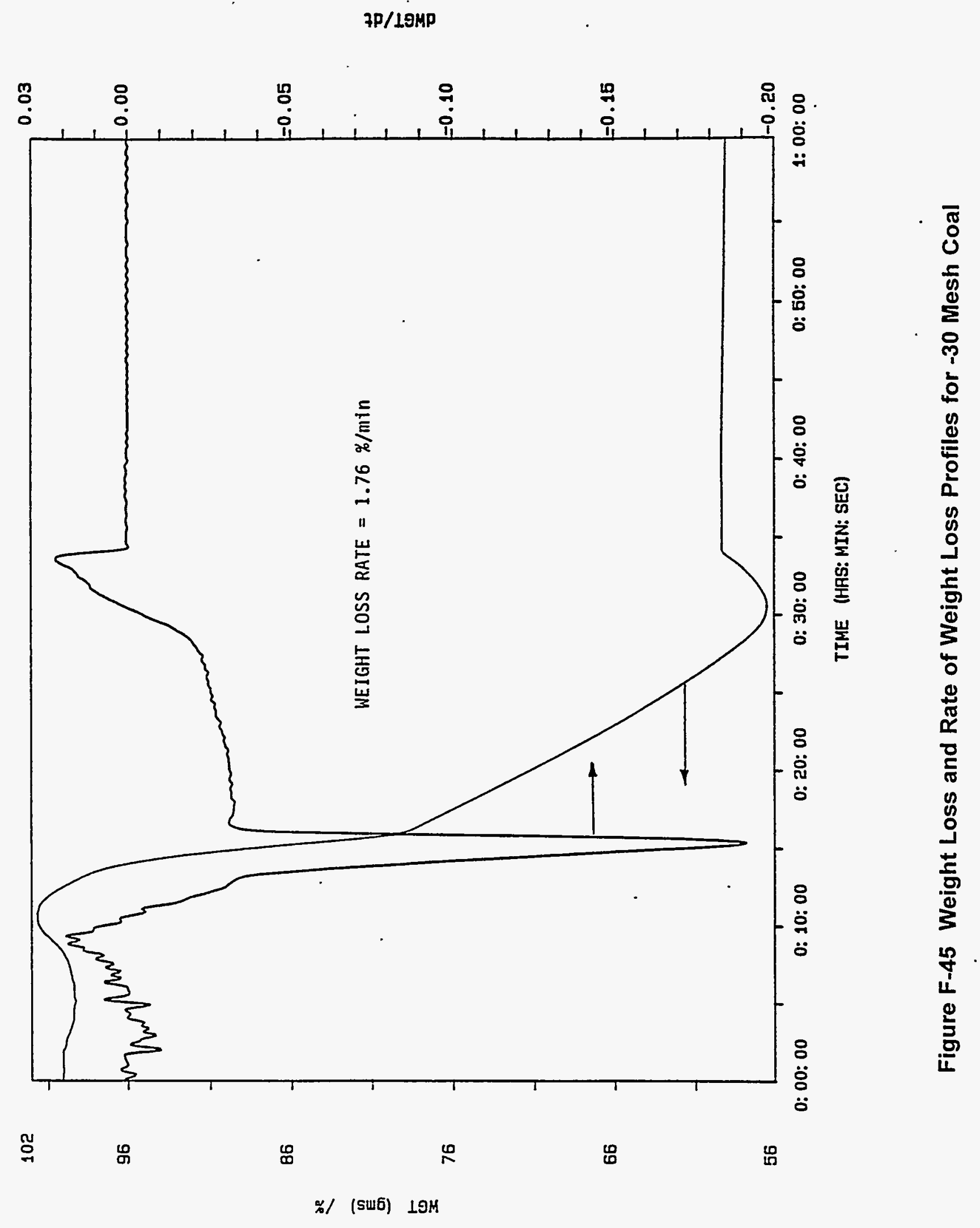




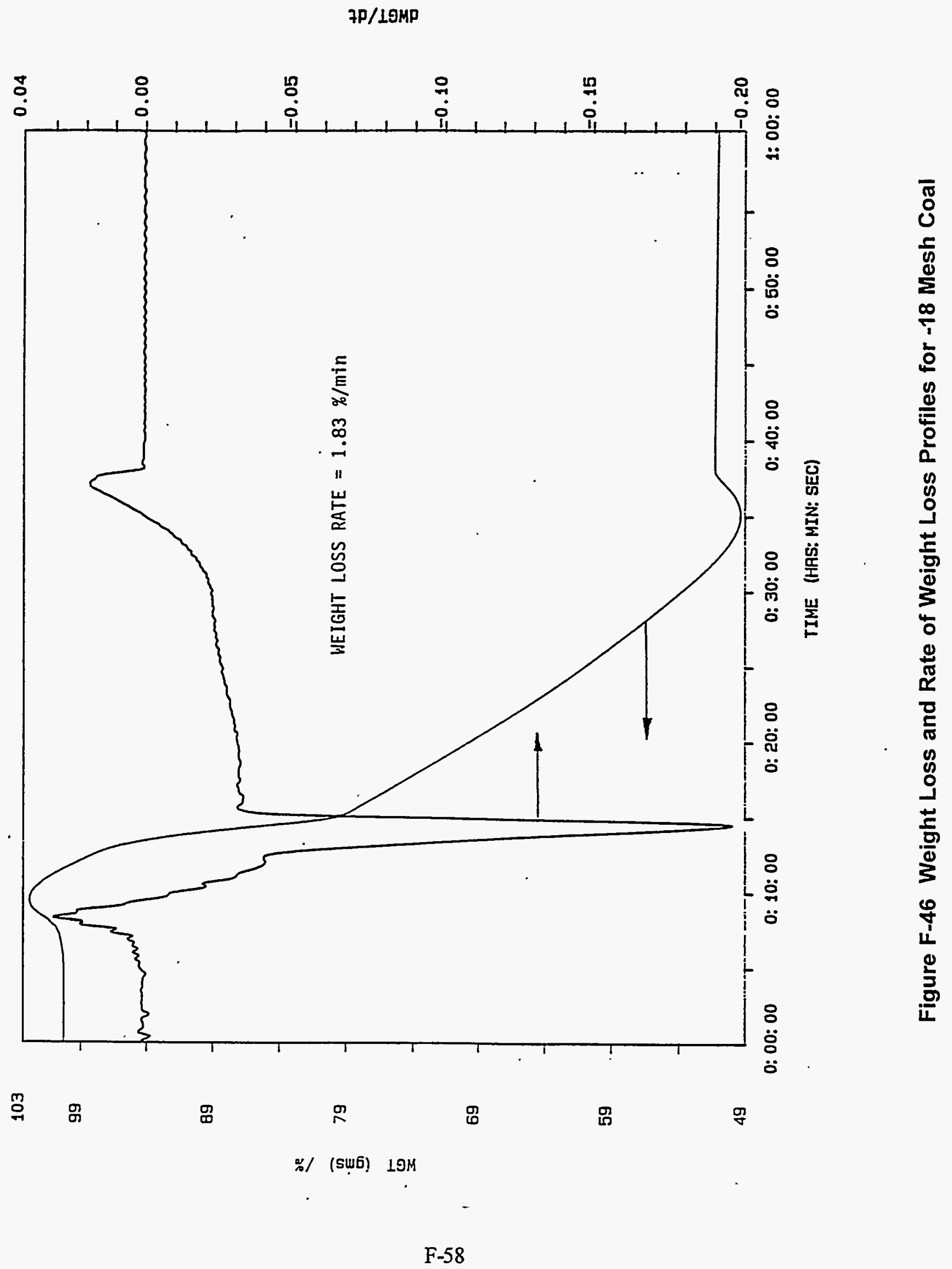


this by the time required to attain this weight loss. For example, in Figure F-48, this is not an absolute measure, but serves to compare the reactivity of the chars. The percent weight loss rate as computed above is referred to here as the reactivity of the char and is shown on each of the figures.

Because of its smaller particle size, the percent reactivity is highest for the char produced from the -40 mesh parent coal, Figure F-44, while the chars produced from the -30 and -18 mesh coals have almost the same reactivity.

Effect of Fluidization Velocity on Char Reactivity: Figures F-47 and F-48 show the TGA results for chars produced from the -40 and -18 mesh coals at a temperature of $1650^{\circ} \mathrm{F}$ and a C/A ratio of 0.2 , but at a higher fluidization velocities. The data for the 40 mesh coal is at a superficial velocity of $7.8 \mathrm{ft} / \mathrm{sec}$ and that for the -18 mesh coal is at $9.7 \mathrm{ft} / \mathrm{sec}$. Comparing Figures $\mathrm{F}-47$ and F-48 with Figures F-44 and F-45, respectively, it is seen that the maximum rate of weight loss occurs slightly earlier in the heating cycle. This indicates a very slight increase in the effect of the residual volatiles on the char combustion rate.

On the other hand, the percent char reaction rate decreases from 2.17 to $1.83 \% / \mathrm{min}$ for the -40 mesh char and from 1.83 to $1.67 \% /$ min for the -18 mesh char. In section F.3.2 above, it was shown that increasing the fluidization velocity increases the primary char particle size. This increased char particle size produces a decrease in the char reactivity at higher fluidization velocities as shown in Figures F-47 and F-48.

Effect of Temperature on Char Reactivity. Figure F-49 shows the weight loss data for the -40 mesh char at a temperature of $1760^{\circ} \mathrm{F}$ at a C/A ratio of 0.2 and a superficial velocity of $7.0 \mathrm{ft} / \mathrm{sec}$. As discussed above, the -40 mesh char is influenced both by the increased temperature and by the secondary effect of increased fluidization velocity when the temperature is increased at constant coal/air mass ratio. Hence, Figure F-49 shows that the percent char reactivity of the -40 mesh coal at $1760^{\circ} \mathrm{F}$ is $1.98 \% / \mathrm{min}$, which is in between the value of $2.17 \% / \mathrm{min}$ at $6.4 \mathrm{ft} / \mathrm{min}, 1650^{\circ} \mathrm{F}$ and the value of 1.83 $\% / \mathrm{min}$ at $7.8 \mathrm{ft} / \mathrm{sec}, 1650^{\circ} \mathrm{F}$. This is because the effect of temperature is to reduce char particle size while the influence of superficial velocity is to increase it. The combined influence of these two factors, therefore, yields an intermediate reactivity for the char from the -40 mesh coal at $7.0 \mathrm{ft} / \mathrm{sec}, 1760^{\circ} \mathrm{F}$.

\section{F.3.7 PRODUCT GAS YIELDS}

The effect of particle size, coal-air mass ratio and other parameters on fuel gas heating value was discussed in Section F.3.4. In this section, the effect of these variables on fuel gas yields will be examined.

Fuel gas yields were computed from a nitrogen balance on the chemical reaction equation utilizing the known coal feed analysis, the measured fuel gas composition and the measured char production rate. Figure F-50 shows the computed fuel gas yields for 


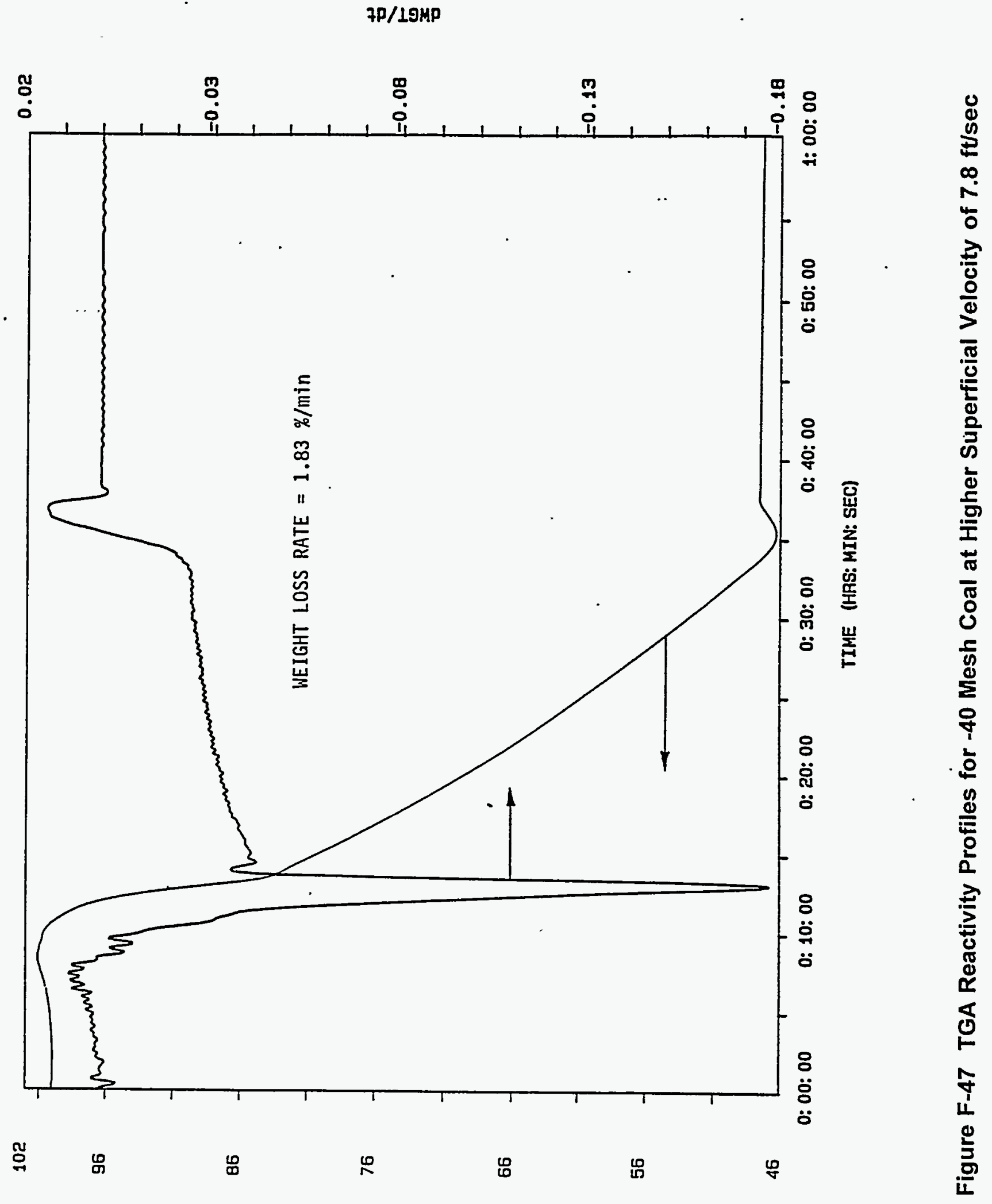

*/ (Sแ6) $19 M$ 


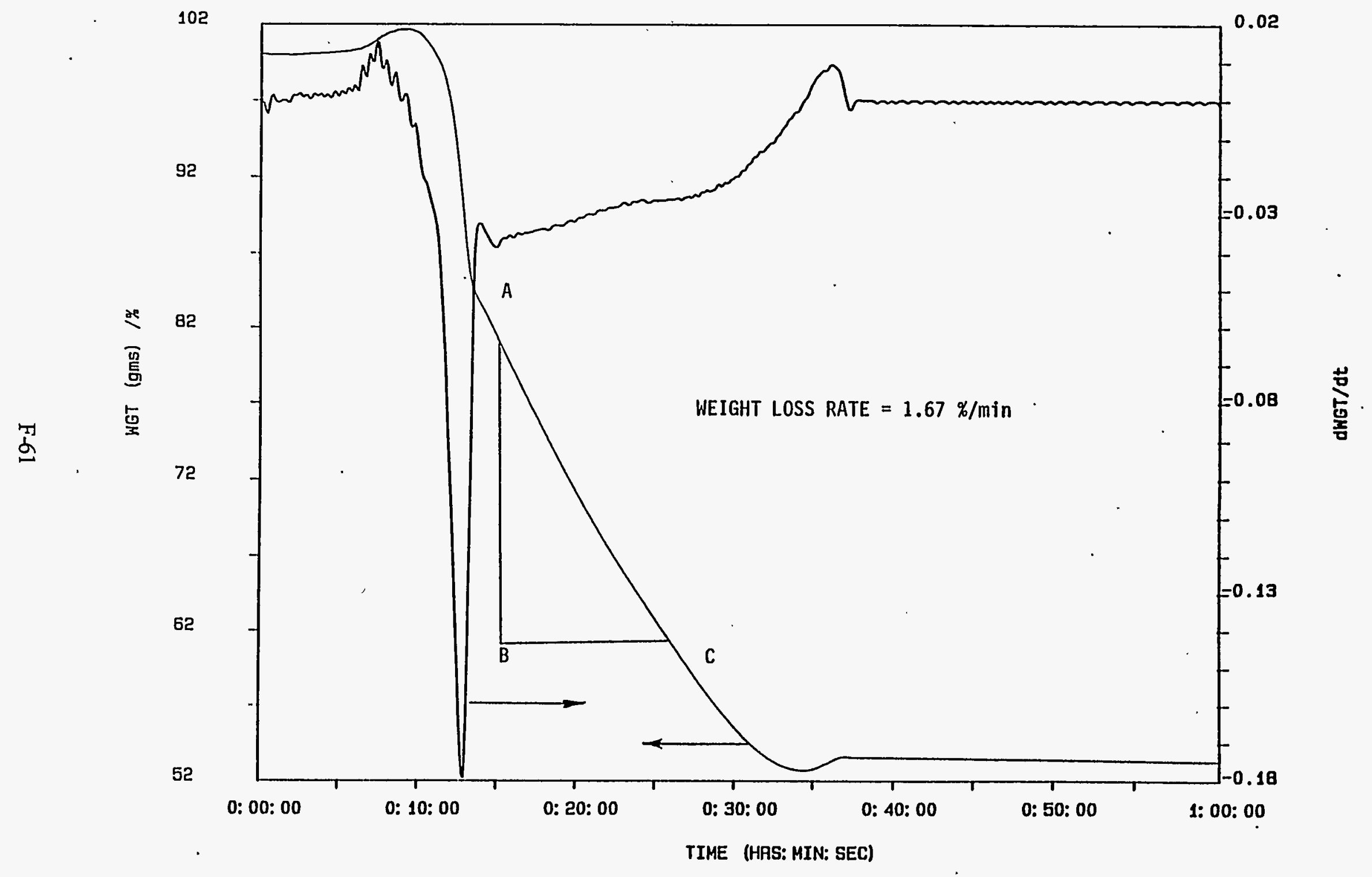

Figure F-48 TGA Reactivity Profiles for -18 Mesh Coal at Higher Superficial Velocity of $9.7 \mathrm{ft} / \mathrm{sec}$ 


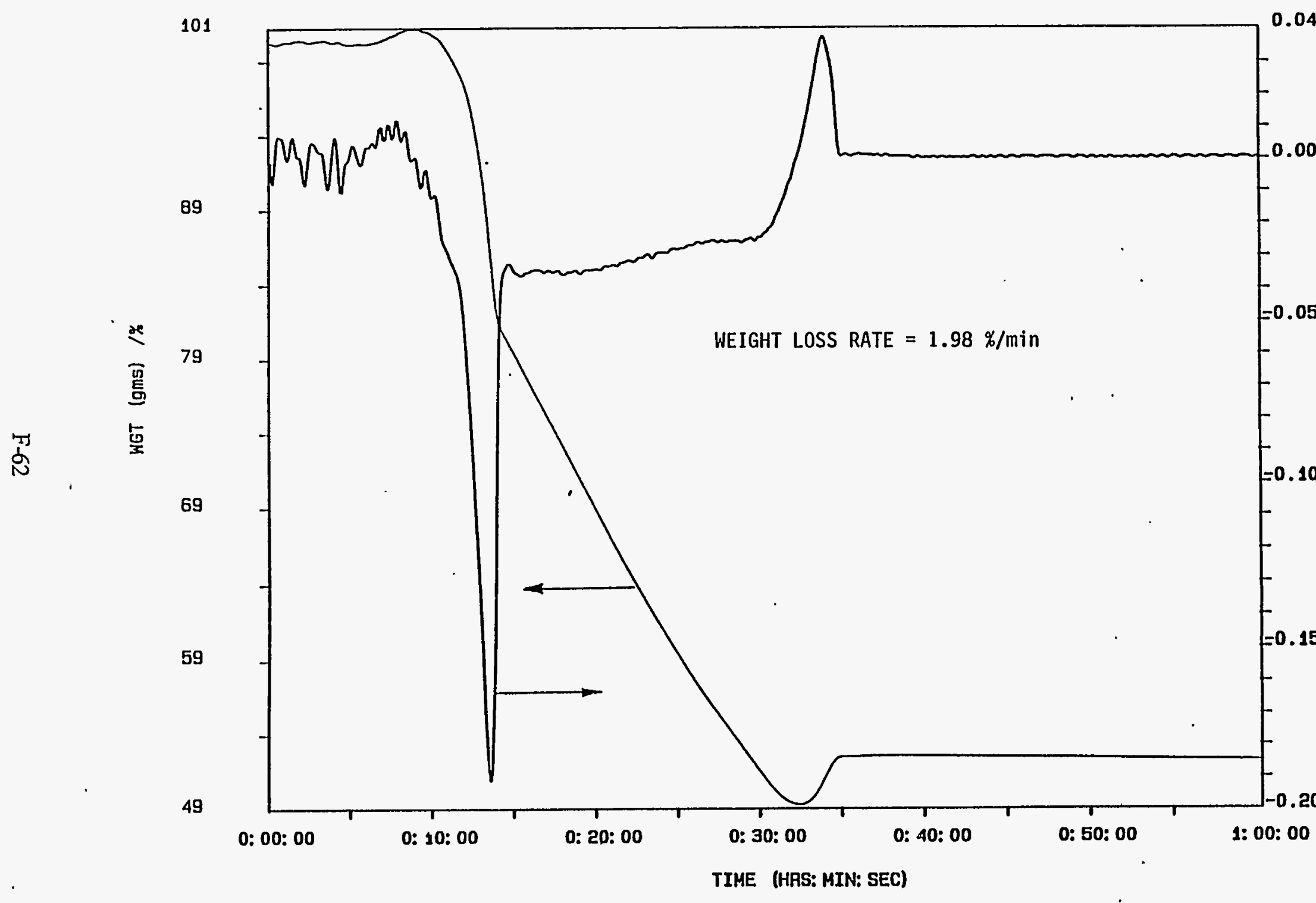

蓬

Figure F-49 TGA Reactivity Profiles for -40 Mesh Coal at Higher Temperature (1760 ${ }^{\circ}$ ) 


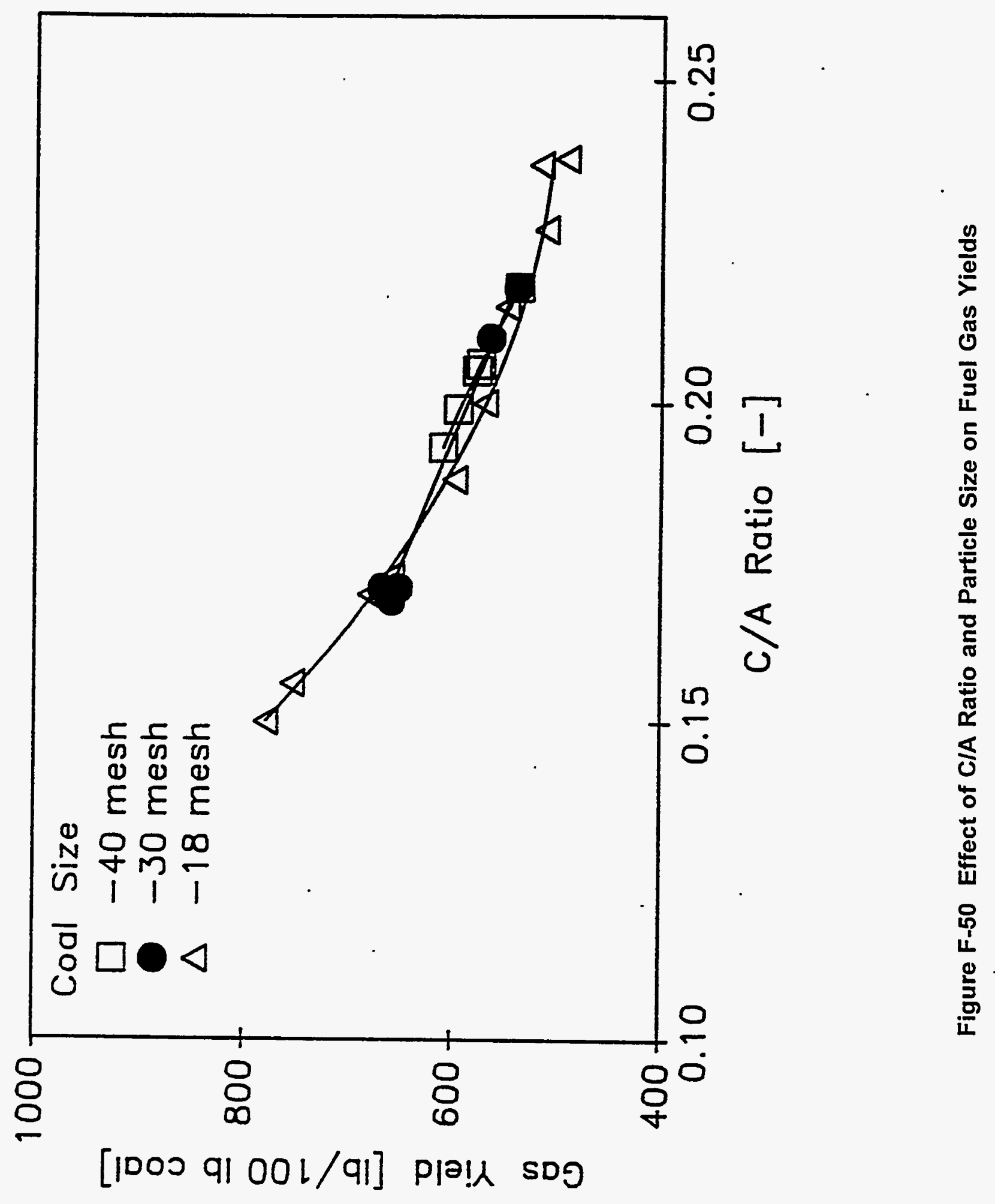


the $-40,-30$ and -18 mesh feed coals as a function of the C/A mass ratio. The fuel gas yields shown are computed for a coal feed of $100 \mathrm{lbs}$. The data indicates that in terms of fuel gas yield, there is no significant effect of particle size. Fuel gas yields, however, do decrease as the coal/air mass ratio is increased. This is because at low coal/air mass ratios, the rate of coal feed is low compared to the rate of air feed and most of the fuel gas is of low quality and heating value. That the fuel gas is of low heating value at the lower C/A ratios is seen from Figure F-33. Thus, as the coal/air mass ratio is increased, the fuel gas yield per $100 \mathrm{lb}$ coal feed decreases, but a fuel of a higher heating value is produced.

Studies conducted in Japan in a two-stage entrained flow pyrolyzer also yielded similar data showing a decrease in fuel gas yields with increasing coal/air mass ratio [4]. Figure F-51 shows that the effect of superficial velocity is to increase the fuel gas yields. This data needs to be considered in conjunction with the data on the heating value in Figure F-33.

Figure $\mathrm{F}-52$ shows the equilibrium constant $\mathrm{K}_{\mathrm{p}}$ for the water gas shift reaction

$$
\mathrm{CO}+\mathrm{H}_{2} \mathrm{O} \Leftrightarrow \mathrm{CO}_{2}+\mathrm{H}_{2}
$$

where the equilibrium constant

$$
\mathrm{K}_{\mathrm{p}}=\frac{\left[\mathrm{CO}_{2}\right]\left[\mathrm{H}_{2}\right]}{[\mathrm{CO}]\left[\mathrm{H}_{2} \mathrm{O}\right]}
$$

The measured concentrations of $\mathrm{CO}_{2}, \mathrm{H}_{2}$ and $\mathrm{CO}$ were used along with computed values for $\mathrm{H}_{2} \mathrm{O}$ in the calculation. The equilibrium constant $\mathrm{K}_{\mathrm{p}}$ is shown plotted against $\mathrm{C} / \mathrm{A}$ ration for the three feed sizes. Also shown is the theoretical equilibrium thermodynamic value of $\mathrm{Kp}$ calculated at the test temperature of $1650^{\circ} \mathrm{F}$. The data shows that as the C/A ratio is increased, the equilibrium constant increases and at the . standard test conditions of the present experiments, i.e., at a C/A ratio of $0.22,1650^{\circ} \mathrm{F}$, the measured and theoretical $\mathrm{Kp}$ values agree very well, especially for the -18 mesh coal. This indicates that the $\mathrm{CO}, \mathrm{H}_{2}, \mathrm{CO}_{2}$ and $\mathrm{H}_{2} \mathrm{O}$ concentrations measured during the present experiments are indeed those that can be expected under the test conditions.

\section{F.3.8 CHAR-SORBENT ANALYSIS}

The elemental analysis for selected primary cycione chars was performed to get an idea of the carbon and ash content of these char-sorbent mixtures. Table F-4 gives the results of this analysis. Generally, the carbon content of the chars ranged from 44 to $68 \%$, and the sulfur content was about $3 \%$. Roughly $50 \%$ of the char was ash. The heating values of the chars varied in a narrow range from 6780 to $7780 \mathrm{Btu} / \mathrm{b}$. 


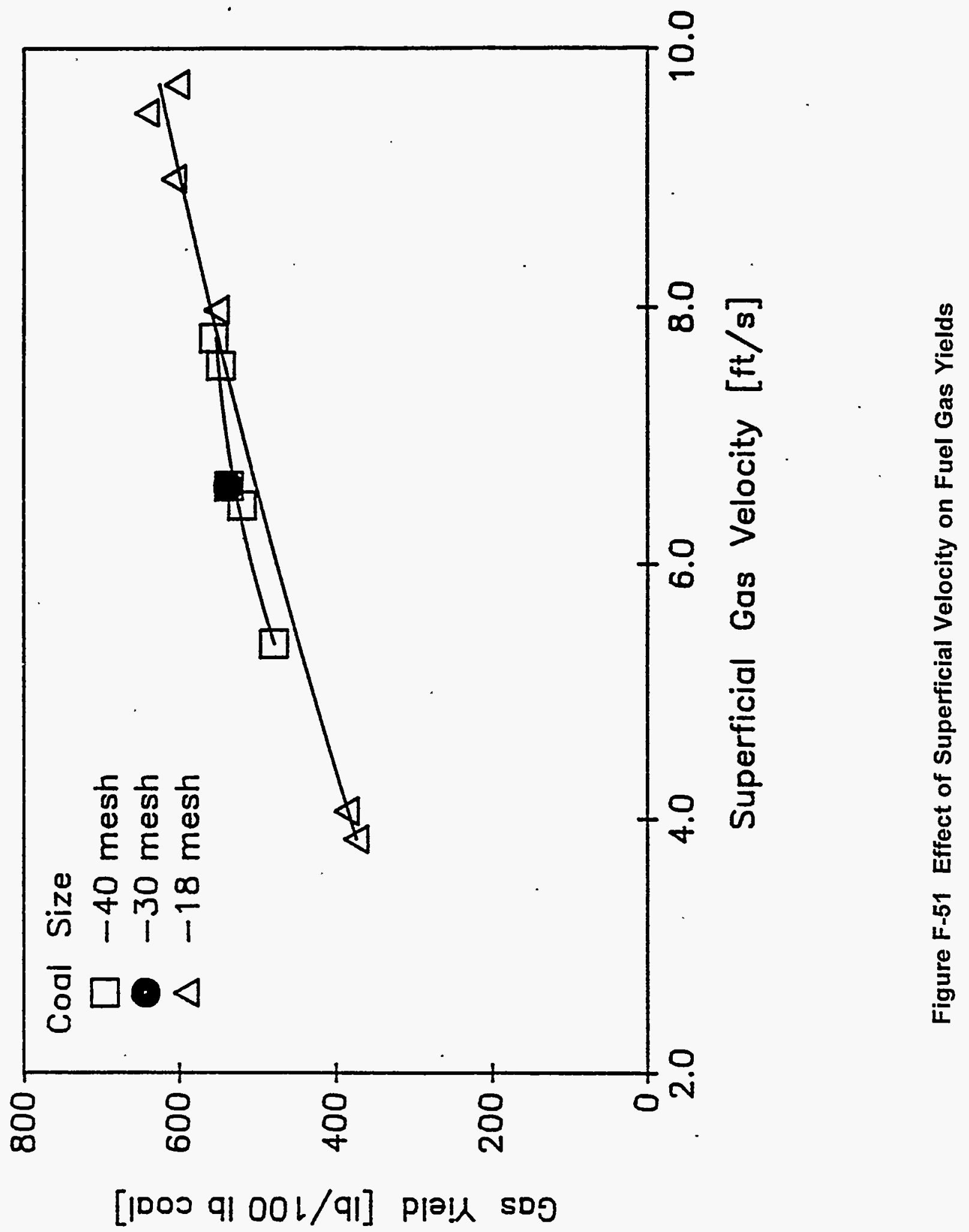




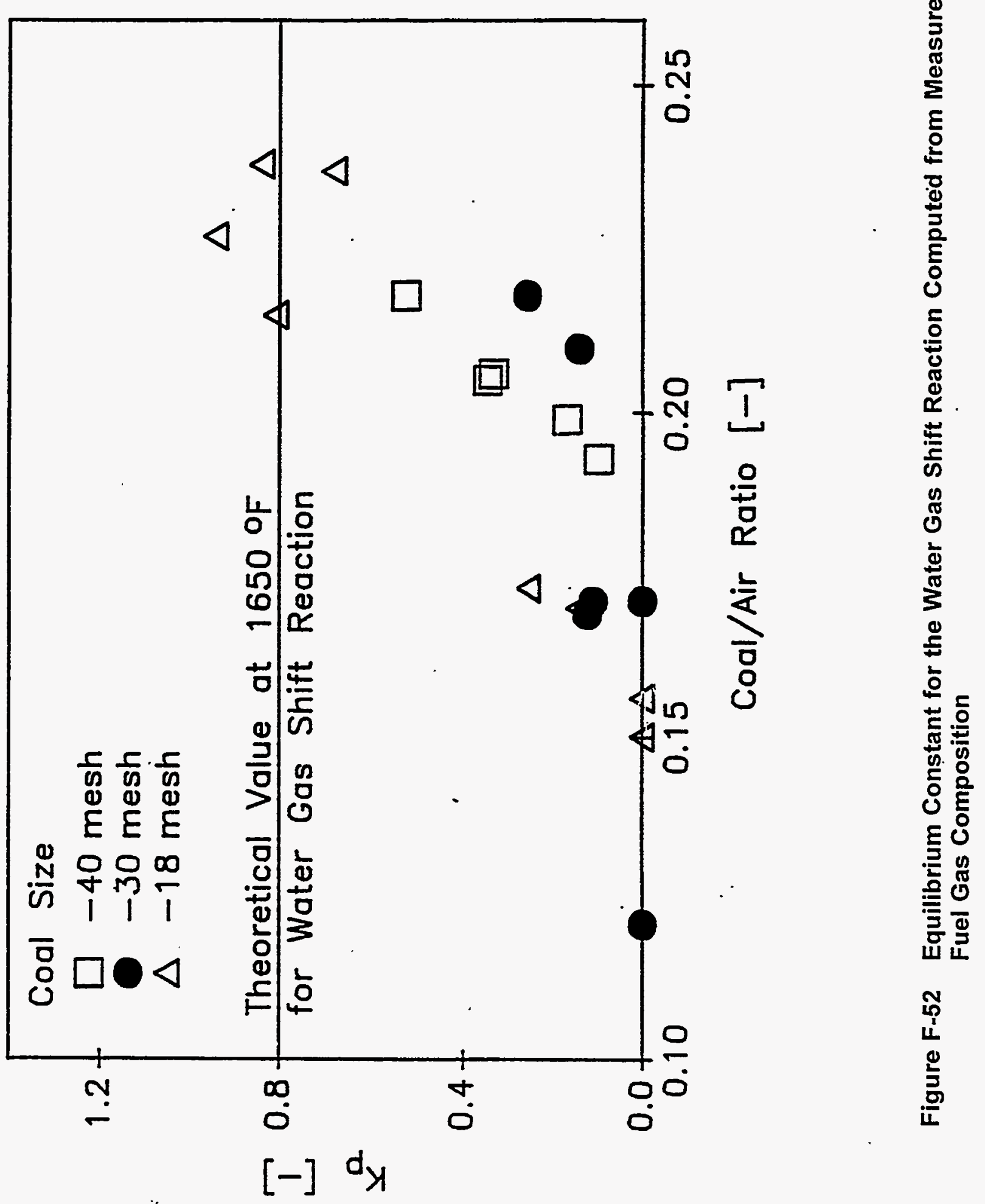


Table F-4 Elemental Analysis of Selected Chars

\begin{tabular}{|c|c|c|c|c|c|c|c|}
\hline & \multicolumn{7}{|c|}{ Coal Size and Test Number } \\
\hline Component & $\begin{array}{c}-40 \text { Mesh } \\
4-2\end{array}$ & $\begin{array}{c}-30 \text { Mesh } \\
1-6\end{array}$ & $\begin{array}{c}-18 \text { Mesh } \\
2-5 a\end{array}$ & $\begin{array}{c}-18 \text { Mesh } \\
3-3\end{array}$ & $\begin{array}{c}-40 \text { Mesh } \\
5-4 b\end{array}$ & $\begin{array}{c}-40 \text { Mesh } \\
4-3 a\end{array}$ & $\begin{array}{c}-40 \text { Mesh } \\
5-4 b \\
\text { Secondary }\end{array}$ \\
\hline Carbon & 63.92 & 54.43 & 54.66 & 54.97 & 67.76 & 65.18 & 43.49 \\
\hline Hydrogen & 0.133 & 0.212 & 0.29 & 0.13 & 0.0 & 0.24 & 0.208 \\
\hline Oxygen & & & & & & & \\
\hline Nitrogen & 1.33 & 1.05 & 0.91 & 1.16 & 1.17 & 1.18 & 0.69 \\
\hline Sulfur & 3.45 & 3.20 & 3.04 & 3.12 & 3.25 & 3.15 & 3.12 \\
\hline Ash & 52.01 & 50.49 & 51.68 & 50.15 & 53.78 & 51.66 & 50.40 \\
\hline Moisture & 0.88 & 0.99 & 0.45 & 0.76 & 0.65 & 0.93 & 1.78 \\
\hline $\begin{array}{l}\text { Heating } \\
\text { Value } \\
\text { Btu/lb }\end{array}$ & 7068.1 & 6933.7 & 6783.0 & 7886.1 & 6999.2 & 7135 & 6868.1 \\
\hline
\end{tabular}

\section{F.3.9 MATERIAL BALANCES}

Material balances were computed for the pyrolyzer test data by employing the measured values of the fuel gas composition, the char accumulation rate (C-D) and the known coal elemental composition. A check on the calculation was made by verifying whether the oxygen values on the reactant and product sides of the reaction equation were in agreement. In most cases, this check on the oxygen values was very good. Details of the method of calculation are given in Section F.5. Figures F-53 through F55 show typical material flow data for the $-40-30$ and -18 mesh coal sizes, respectively. In general, the material balance calculations were in error by less than $5 \%$, although the error in the oxygen balance check was $10-12 \%$. This indicates that the data is reasonable within the limits of experimental error.

In the tables of data presented in Section 5 , the result of the oxygen value check for the chemical reaction equation is indicated by means of a letter designation as $B$ (bad), $F$ (fair), $G$ (good) or VG (very good). In general, the agreement is good or very good. Material balances given in Figures F-53 through F-55 are presented on a $10 \mathrm{lbs} / \mathrm{hr}$ coal feed basis. However, the Section 5 data contain the actual coal feed rates. 
Product Gas

Flow rate $=53.6 \mathrm{lb} / \mathrm{hr}$

Mol\%

co

$\mathrm{CO} 2$

$\mathrm{O} 2$

H2

H2S

$\mathrm{CH} 4$

NH3

$\mathrm{H} 20$

N2
3.56

13.18

1.56

0.93

3.11

0.22

11.01

66.43

LHV wet $=590.6 \mathrm{Btu} / \mathrm{lb}$

Molecular $w t=28.3$

Nitrogen $\quad 0.06$

Sulfur $\quad 0.14$

Ash $\quad 2.11$

Air 150 deg. $F$

Flow rate $=39.5 \mathrm{lb} / \mathrm{hr}$
Coal

Flow rate $=10 \mathrm{lbs} / \mathrm{hr}$

Carbon

Hydrogen

Nitrogen

Sulfur

Ash

Moisture

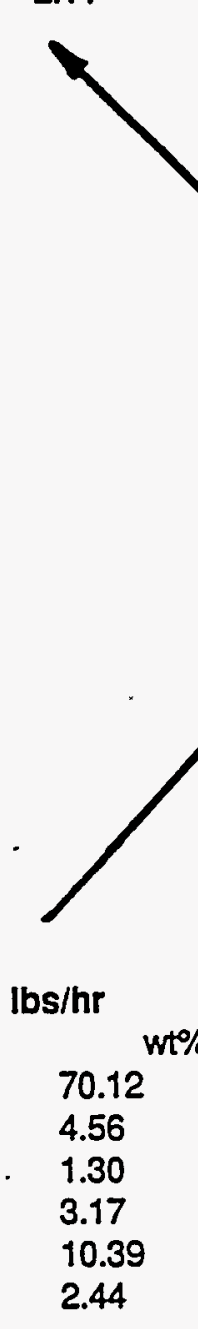

Limestone

$\mathrm{Ca} / \mathrm{S}=2.0$

Flow rate $=0.8 \mathrm{lb} / \mathrm{hr}$
350 deg. F Steam

Flow Rate $=2.43 \mathrm{lb} / \mathrm{hr}$

$w+\%$

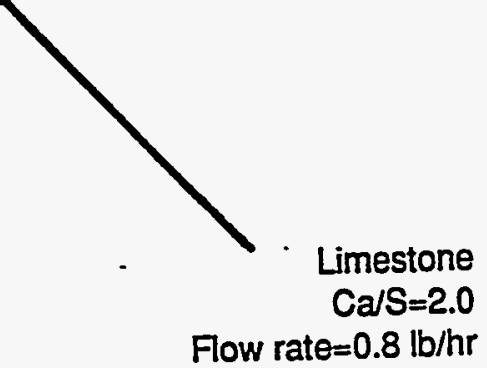

Figure F-53 Material Balance Sheet for -40 Mesh Coal Test (Run No. 4-2) 
Product Gas

Flow rate $=60.2 \mathrm{lb} / \mathrm{hr}$

$\begin{array}{lrr} & \text { Mol\% } \\ \text { CO } & 3.78 \\ \text { CO2 } & 1265 \\ \mathrm{O} 2 & 0 \\ \text { H2 } & 1.05 \\ \text { H2S } & 0.25 \\ \text { CH4 } & . . & 3.03 \\ \text { NH3 } & 0.27 \\ \text { H20 } & 13.54 \\ \text { N2 } & 65.44 \\ & \text { LHV wet }=575.4 \text { Btu/lb } \\ & \text { Molecular wt }=28.3\end{array}$

Char-Sorbent

Flow rate $=5.06 \mathrm{lb} / \mathrm{hr}$

Carbon 2.50

Hydrogen 0.01

Oxygen $\quad 0.00$

Nitrogen $\quad 0.05$

Sulfur $\quad 0.15$

Ash $\quad 2.35$

Molecular wt $=28.3$

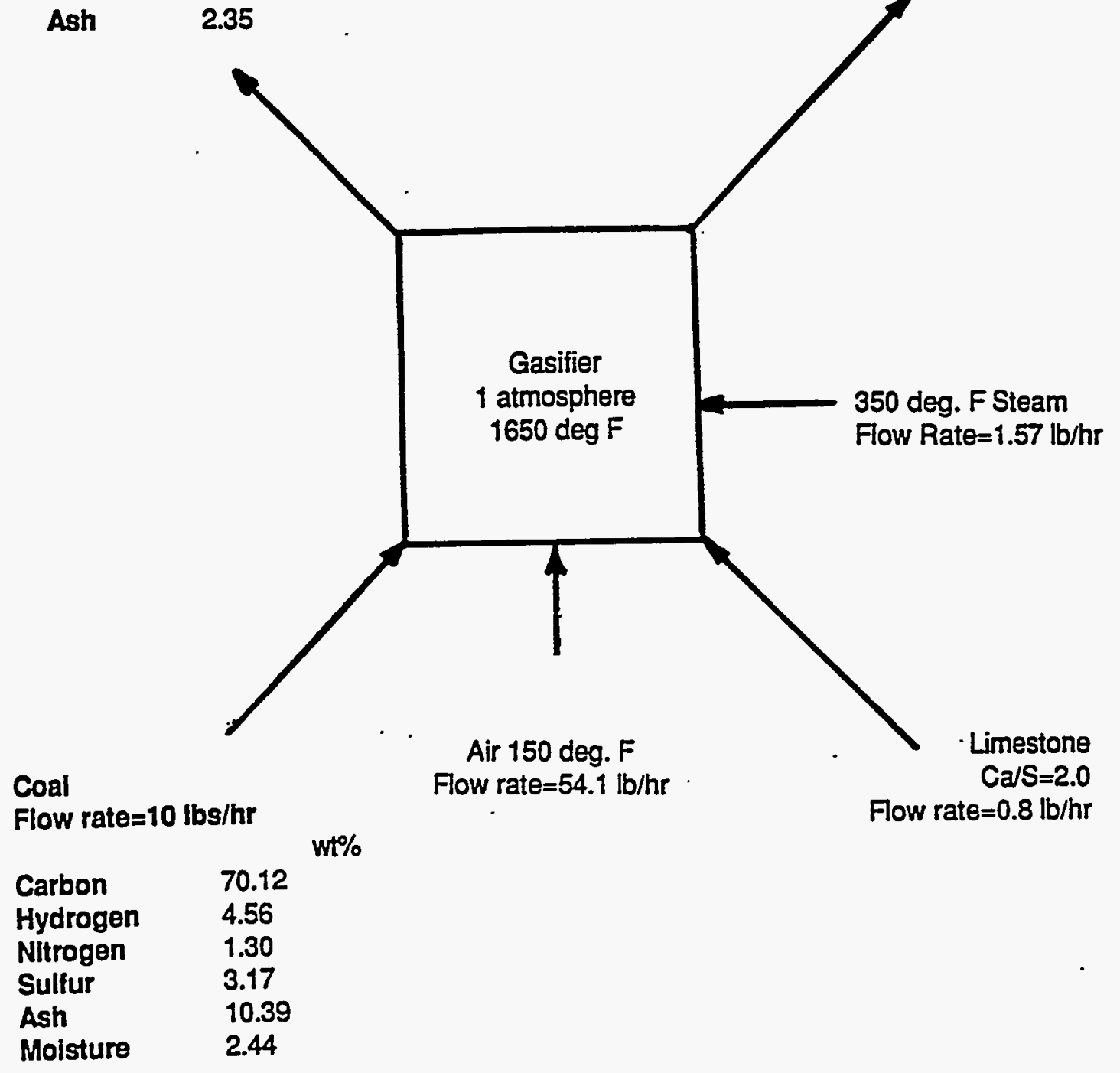

Figure F-54 Material Balanice Sheet for -30 Mesh Coal Test (Run No. 1-6) 


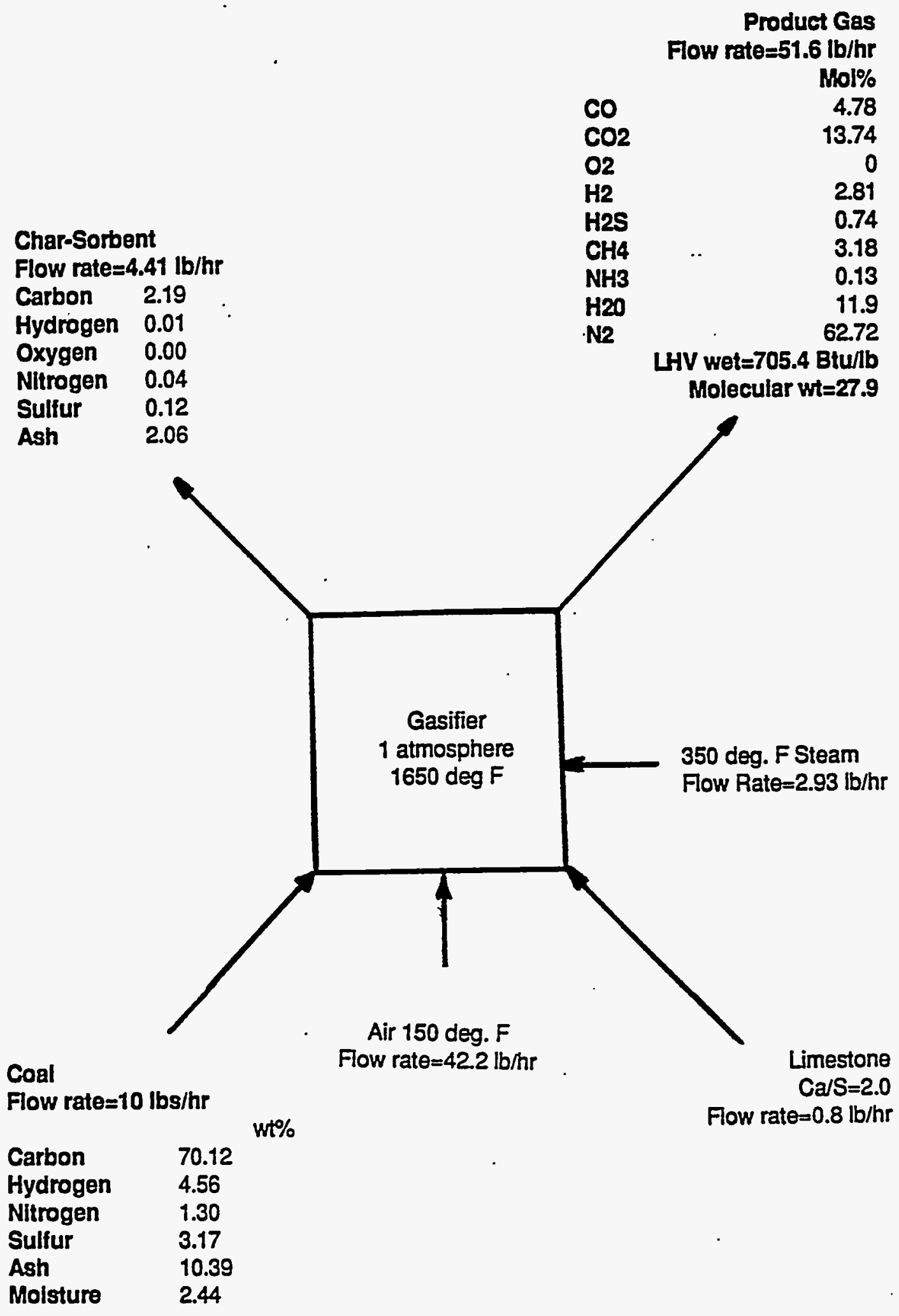

Figure F-55 Material Balançe Sheet for -18 Mesh Coal Test (Run No. 2-5a) 


\section{F.3.10 ENERGY BALANCE CONSIDERATIONS}

An estimate of the various components of the energy inputs and outputs was performed for a random test case for the -40 mesh coal. The test number selected is 4-2 in the data tables of Section F.5. This energy balance is performed using the actual coal, air, fuel gas and char masses, as the computations are influenced by the actual heat flows for the particular size of pyrolyzer used. Details of the calculation are given in Section 6 . Figure F-56 shows the results.

$42.13 \%$

Product Gas

Calorific Value

and Sensible Heat $\quad 28.7 \%$

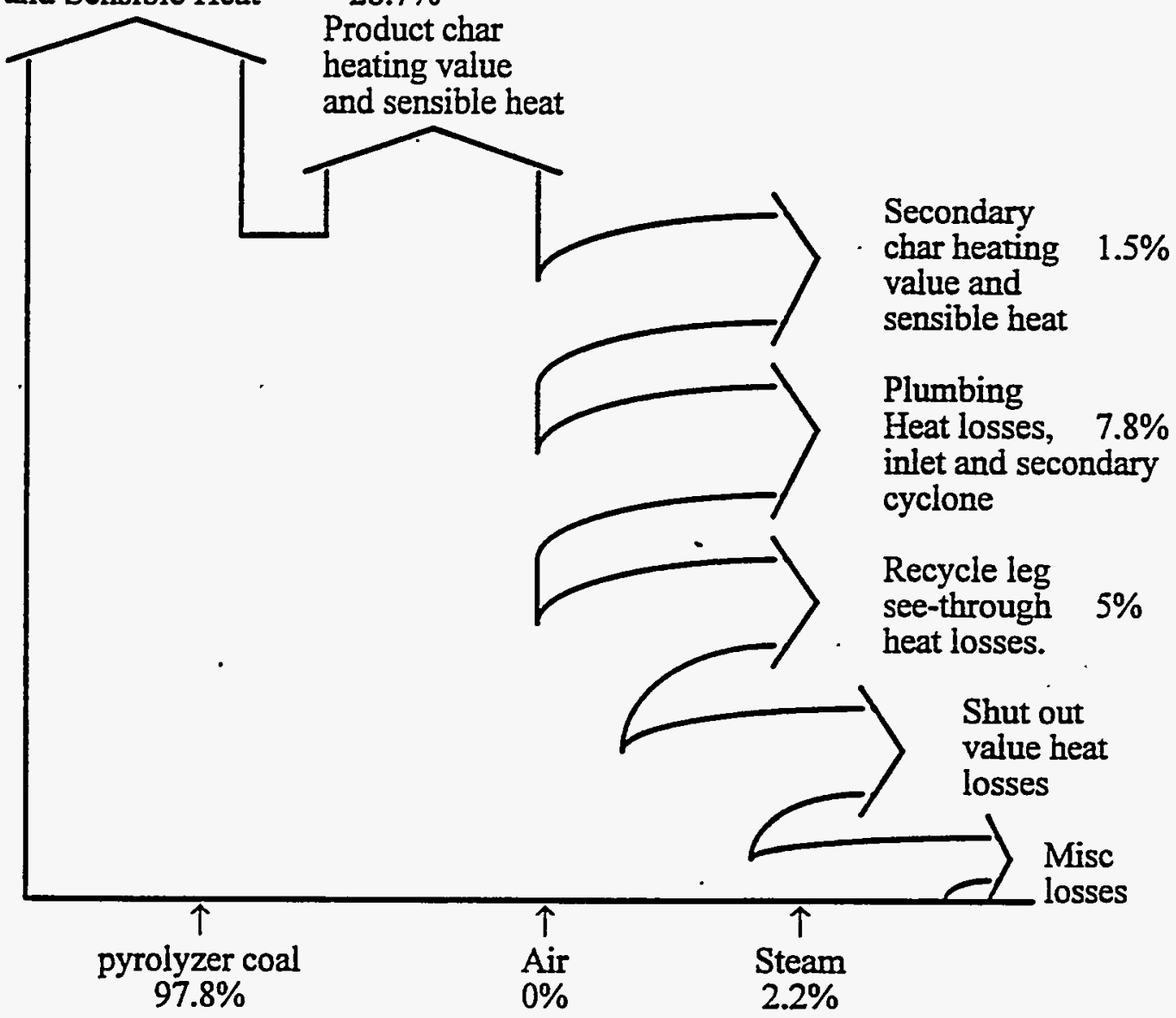

Figure F-56 Pyrolyzer Heat Balance for a Typical Case (Run 4-2) 
In the tests, no air preheat was used; hence, the energy inputs are from the coal and steam alone. The product gas heating value and sensible heat account for $42.13 \%$ of the total energy input. An additional $28.7 \%$ of input energy is located in the primary char-sorbent product, mostly as heating value, with a small portion as sensible heat. The energy content of the secondary char is minimal being only about $1.5 \%$. The rest of the energy input is accounted for as losses occurring in various segments of the pyrolyzer. These losses equal $27.8 \%$ of energy input.

For the purposes of this energy audit, it is to be noted that the heat losses from the main column of the pyrolyzer are neutralized by external heat provided by electrical resistance heaters wrapped around the pyrolyzer column. The primary cyclone and applicable portions of the recycle leg are also wrapped with heaters and insulated. For the main pyrolyzer column, controllers maintain the wall temperature equal to the process temperature. The heat provided by these external electric heaters was calculated previously by operating the pyrolyzer as a combustor and conducting an energy audit similar to the one performed here in Section F.6. The heat input provided by the electric resistance heaters was computed to be $118 \mathrm{Btu} / \mathrm{min}$ for this particular combustor. 


\section{F.4 SUMMARY AND DISCUSSION}

\section{F.4.1 Summary}

A wide range of tests have been performed in a $10 \mathrm{lb} / \mathrm{hr}$ laboratory circulating fluidized bed pyrolyzer in support of Foster Wheeler Development Corporation's larger effort for the Department of Energy. Specifically, the influence of coal feed particle size on char product particle size, gas composition, gas yields, heating value and other parameters have been studied. The influence of fluidization velocity, temperature and coal-air mass ratios have been investigated.

A summary of the findings is given below.

\section{Particle Size Effects}

1. Larger coal feed particle size produces char with a larger overall particle size. The reduction in char particle size, compared to the feed coal size, brought about by attrition and reaction is more pronounced for the larger feed size of -18 mesh in the present experiments compared to the -40 mesh feed size.

2. The effect of higher superficial velocity is in general to increase the primary char particle size.

3. Increasing the coal-air ratio does influence the char particle size. This effect is a synergistic one involving the combined effect of reaction rate, residence time and temperature

4. Higher temperatures in general tend to produce smaller primary char particles.

5. Primary char recycling reduces the product char particle size due to increased attrition and reaction.

6. Secondary cyclone chars for the feed coal sizes used in the present tests were found to be smaller in size, with $50 \%$ being less than 10 microns in size, and $90 \%$ less than 100 microns.

7. Similarly, bag filters particles collected from the product fuel gas were even smaller in size with $50 \%$ being less than 10 microns and fully 90 being less than 30 microns.

\section{Fuel Gas Composition}

8. For the scale of apparatus being used fuel gas composition is controlled by feed particle size in a definite manner. The larger -18 mesh coal gave the highest yields of carbon monoxide, hydrogen and hydrocarbons. As coal feed rate is increased, i.e., at higher $\mathrm{C} / \mathrm{A}$ ratios, the yields of these components increase.

9. Residence time in the dense phase portion of the fluidized bed is important, depending upon the scale of the apparatus. Hence, increased fluidization velocities tend to decrease the $\mathrm{CO}, \mathrm{H}_{2}$ and $\mathrm{HC}$ gas yields, especially for the smaller particle sizes. 


\section{Gas Heating Values}

10. Fuel gas heating values increased with both $C / A$ ratio and particle size in the present experiments. Maximum values measured were on the order of $705 \mathrm{Btu} / \mathrm{lb}$, wet basis.

11. Increase in superficial velocity tends to decrease the fuel gas heating value. Temperature changes in the range of $1640-1740^{\circ} \mathrm{F}$ did not produce a marked increase in heating value of the fuel gas.

\section{Char Morphology}

12. Char surface morphology is influenced by feed particle size, superficial velocity and temperature. Reaction and attrition are the two main factors influencing char surface features. Pores, blowholes and breakdown of pore walls are easily observed on the primary char particles. Secondary chars and bag filters catch are much smaller in size.

\section{Char TGA Reactivity}

13. Smaller char particle sizes yield higher TGA reactivity rates. Surface structure plays a secondary part in reactivity.

14. Increasing the superficial velocity increases the primary char particle size and tends to reduce char reactivity.

\section{Product Gas Yields}

15. Product gas yields were found to decrease with coal-air ratio. This is in agreement with the results of other experiments conducted in a two-stage entrained flow pyrolyzer. Product gas yields, however, must be considered in conjunction with gas heating values. Heating values increase as product gas yields decrease with increasing coal-air ratios.

.16. The influence of particle size on product gas yields is not. very pronounced.

17. Higher superficial gas velocities produce higher product gas yields on a $100 \mathrm{lb} / \mathrm{hr}$ coal feed basis.

18. As a measure of expected product gas composition yields and heating values, it was found that the equilibrium constant for the water gas shift reaction computed from measured gas compositions at a coal-air mass ratio of 0.22 agreed very well with the theoretical value at $1650^{\circ} \mathrm{F}$, the test temperature.

\section{Product Char Analysis}

19. The product chars typically contained about $50 \%$ ash. Their heating values ranged from 6800 to $7800 \mathrm{Btu} / \mathrm{lb}$. 
20. In keeping with the rest of the data, product char heating value decreased with increased particle size.

21. Higher superficial velocities increases char heating value.

\section{Material Balances}

22. Material balances show very good agreement generally within $5 \%$ for the present tests.

\section{Energy Balance}

23. Energy balance calculations performed for a typical case show that about $42 \%$ of the input energy appears in the product gas with another $28 \%$ being in the char product. About $28 \%$ of the energy input is lost in the present case. These energy losses have to do with the small scale of the apparatus used. In a large size commercial unit, these energy losses will be considerably less.

\section{F.4.2 Discussion}

In applying the results of the present experiments to large scale units, a number of factors need to be considered. Large scale units with a large freeboard length to bed depth ratio could provide a long residence time for heterogeneous reaction to occur in the freeboard. However, attrition rates will be lower during the freeboard passage of the coal, char and other reactants. Heat transfer and gas phase diffusion will be controlling factors. These factors must be kept in mind in applying the results of the present study to large scale units.

There is a balance between coal feed particle size and conversion rates. While smaller. particles are generally considered to react faster, heat transfer to smaller particles can be influenced by their relative residence time in the dense phase and dilute phase. This will affect product gas composition and yield and char particle sizes depending on coal feed size.

It would, therefore, be beneficial to the optimum design of the pyrolyzer to investigate the influence of coal feed particle size distribution and its relationship to ratio of dense bed height to freeboard height. This will result in a more compact pyrolyzer and yield overall cost savings. 


\section{REFERENCES}

1. Shenker, J. And Grove, A., "Char Combustor Considerations for a PartialGasification-Based Combined-Cycle Power Generation System," Paper 93-JPGCPWR-2, American Society of Mechanical Engineers, 1993.

2. Rajan, S., "Combustion and Emissions of Gasification Chars," Final Report, Illinois Clean Coal Institute, Carterville, IL, November 1994.

3. Rajan, S., "Combustion of Char-Coal Waste Pellets for High Efficiency and Low No," Final Report, Illinois Clean Coal Institute, Carterville, IL, September 1995.

4. Inumaru, J. et al., "Characteristics of a 2T/D Pressurized Two-Stage Entrained Bed Gasifier -- Results of Operational Study and Gasification Tests," Yokosuko Research Laboratory, Japan, Report No. EW89002, 1990. 


\section{F.5 TABLES OF EXPERIMENTAL DATA VALUES}

The attached tables give the actual mass flow rates for the coal, air, limestone and steam. The measured values of bed temperature, the fuel gas composition on a dry basis, and the primary char accumulation rate, i.e., the quantity (C-D), referred to in section 4.2(d), are tabulated. This char accumulation rate is referred to as "Primary Char" in the tables, and is recalculated on a $100 \mathrm{lb}$ coal feed basis.

The coal-air ratio listed in the tables is obtained by balancing the reaction equation for the test using the measured values for (1) the dry gas composition, (2) the char accumulated (C-D), and (3) the elemental analysis of the coal used in the tests. For this purpose, the carbon content of the accumulated char was taken to be an average value of $50 \%$. For the tests conducted, the carbon contents of a limited number of chars were determined and ranged in value from 42 to $55 \%$. Hence, an average value of $50 \%$ was used in the calculations throughout. This was not found to influence the computed coal/air ratios significantly.

In addition to determining the coal/air ratio, the chemical reaction equation was utilized to calculate the water concentration in the fuel gas. The dry fuel gas composition was then converted to volumetric concentrations on a wet basis. This wet basis fuel composition was then used to determine the fuel gas heating value based on standard enthalpy of reaction values from the thermodynamic tables. The tables listed here include the molecular weight of the wet fuel gas.

The data tables also show the calculated values for the equilibrium constant as described in the text. The carbon conversion data listed in the tables is the ratio defined as

$$
\text { carbon conversion }=\frac{\text { moles carbon in fuel gas }}{\text { moles carbon in coal feed }}
$$

In addition, the tables list the average superficial velocity, the recycle ratio, $\mathrm{lb}$ gas $/ 100 \mathrm{lb}$ coal, Ibs of input coal, air and steam per $100 \mathrm{lbs}$ coal and the mean particle diameter of the primary cyclone char-sorbent solids.

A quick mass balance for each test may be made by adding the lbs char $/ 100 \mathrm{lbs}$ coal and the $\mathrm{lbs}$ gas $/ 100 \mathrm{lbs}$ coal and verifying how close this sum comes to the lbs input solids $/ 100 \mathrm{lbs}$ coal. Generally, the agreement is within $5 \%$.

Another check on the data was performed by verifying the oxygen balance on the reactant and product sides of the chemical reaction equation. The result of this calculation is indicated in the tables as F (fair), $G$ (good), VG (very good) and B (bad). In general, this check on the data is in the range of fair to good with fair indicating that the oxygen balance was off by $10-12 \%$. 
Due to the large number of test points for which data was taken, in a few instances, the primary char samples were either mislabelled or misplaced. In these few cases, the table indicates that the char samples were lost. 
COAL MESH SIZE: -30

TEST NUMBER: 1

COMMENTS:

RUN \#

Temperature deg. F

input Coal (g/min)

input Steam (g/min)

Input Air (g/min)

Input LImestone (g/min)

Dry Gas Composition
Variable Coal to Air Ratio Test

Average Superficial Velocity: $6.4 \mathrm{ft} / \mathrm{s}$

Average Bed Temperature: 1650 deg. F

$\begin{array}{rrrrrr}1-1 & 1-2 & 1-3 & 1-4 & 1-5 & 1-6 \\ 1650 & 1660 & 1650 & 1650 & 1670 & 1650 \\ 18.51 & 26.66 & 29.39 & 32.1 & 34.82 & 38.55 \\ 4.3 & 4.3 & 5.9 & 11.3 & 11.3 & 11.3 \\ & 155.9 & 173.9 & 187.7 & 165.8 & 176.8 \\ 1.4 & 2.1 & 2.3 & 2.5 & 2.7 & 3.0 \\ & & & & & \\ 1.95 & 3.62 & 3.88 & 4.12 & 4.23 & 4.37 \\ 16.4 & 14.47 & 14.17 & 14.21 & 14.97 & 14.63 \\ 0 & 0 & 0 & 0 & 0 & 0 \\ 0 & 0 & 0.4 & 0.5 & 0.73 & 1.21 \\ 0.212 & 0.231 & 0.23 & 0.247 & 0.222 & 0.288 \\ 0.59 & 2.03 & 2.27 & 2.4 & 2.65 & 3.5 \\ 0.081 & 0.215 & 0.245 & 0.247 & 0.259 & 0.318 \\ & & & & & \\ \text { Char } & 11.35 & 11.74 & 12.32 & 17.79 & 19.49 \\ \text { Samples } & 42.6 & 39.9 & 38.4 & 51.1 & 50.6 \\ \text { Lost. } & 0.96 & 0.96 & 0.96 & 0.96 & 0.96 \\ & 0.171 & 0.169 & 0.171 & 0.21 & 0.218 \\ & 28.8 & 28.6 & 28.2 & 28 & 28 \\ & 354.1 & 405.1 & 422.8 & 453.4 & 575.4 \\ & 0 & 0.123 & 0.11 & 0.14 & 0.259 \\ & G & G & F & V G & \text { G } \\ & 0.231 & 0.236 & 0.243 & 0.241 & 0.249 \\ & 5.8 & 6.5 & 7.0 & 6.2 & 6.6 \\ & 59.6 & 58.8 & 57.6 & 48.5 & 46.2 \\ & 651.3 & 658.5 & 668.5 & 564 & 537.9 \\ & 709.6 & 719.2 & 727.4 & 617 & 595.2 \\ & 161.7 & & 192.9 & 167.2 & 203.2\end{array}$


COAL MESH SIZE: -18

TEST NUMBER: 2

COMMENTS:

RUN

Temperature deg.F

input Coal (g/min)

Input Steam (g/min)

Input Air ( $g / \mathrm{m} / \mathrm{n})$

Dry Gas Composilion
Input Lmestone (g/min)

Variable C/A Ratio Test

Average Superfictal Velocity: $5.9 \mathrm{ft} / \mathrm{s}$

Average Test Temperature: 1647 deg.F

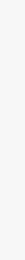

$\begin{array}{rr}\text { CO } & 1.65 \\ \text { CO2 } & 15.4 \\ \text { O2 } & 0 \\ \text { H2 } & 0 \\ \text { H2S } & 0.49 \\ \text { CH4 } & 0.88 \\ \text { NH3 } & 0.1178\end{array}$

Primary Char (g/min)

lb Char/100 Ib Coal

Secondary Char $(\mathrm{g} / \mathrm{mln})$

Coal/Air Fallo

Mol. Welght (lb/lbmol)

Hoating Valuo (BTU//b)

$\mathrm{Kp}$

O2 Balance

Carbon Conversion

Bed Velocity (ft/s)

Recycle Ratio

Ib gas/100 lb coal

lb Input 100 lb coal

mean part. dla. $\left(m^{*} 10 E-6\right)$

\begin{tabular}{rr}
$15.4 \quad 13.66$ \\
\hline
\end{tabular}

0

0
0.83

0.332
1.12

0.55

2.08

8.06

0.071

10.09

42.13

43.54

0.96
0.156

0.96
0.17

0.15

. 27.9

27.9

$\begin{array}{rr}9 & 9 \\ 0.205 & 0.212\end{array}$

9
0.229

777.6

836.1

752.2
809

809
194.9

679.9

742
194.8

$\begin{array}{rrr}2-1 \mathrm{a} & 2-1 \mathrm{~b} & 2-2 \\ 1650 & 1650 & 1665 \\ 18.51 & 18.51 & 23.95 \\ 11.3 & 11.3 & 11.3 \\ 123.4 & 1.18 .7 & 140.9 \\ 1.4 & 1.4 & 1.9\end{array}$

$2-3$
1650
29.39
11.3
169.9
2.3

$2-4 a$
1650
34.82
11.3
2.7

$4.413 \quad 4.33$

12.9

0
1.43

0.635

2.29

0.093

12.77

43.45

0.96

0.173
27.9

$\begin{array}{llll}145.7 & 183.6 & 396.5 & 465.1\end{array}$

$\begin{array}{rrrr}0 & 0 & 0.142 & 0.255 \\ \mathrm{~g} & \mathrm{~g} & \mathrm{~g} & \mathrm{f}\end{array}$

0.226

$\begin{array}{llll}4.6 & 4.4 & 5.2 & 6.3\end{array}$

$\begin{array}{llll}67.5 & 67.5 & 52.4 & 56.7\end{array}$

656.7
725

202.9

$2-4 b$
1650
34.82
11.3

$2-5 \mathrm{a}$
1625
38.55
11.3
162.7
3.0

$2-5 b$
1625
38.55
11.3
179.3
3.0

$\begin{array}{rr}2-6 \mathrm{a} & 2-6 \mathrm{~b} \\ 1650 & 1650 \\ 34.82 & 34.82 \\ 7.5 & 7.5 \\ 146.3 & 153.4 \\ 2.7 & 2.7\end{array}$

2-7a

1650

38.55

7.5

3.0

$(34$

5.42

13.28

13.34

2.19

2.25

$\begin{array}{rrr}5.04 & 4.55 & 4.18 \\ 14.38 & 14.45 & 14.21 \\ 0 & 0 & 0 \\ 3.37 & 3.39 & 3.44 \\ 0.831 & 0.692 & 0.726 \\ 3.41 & 3.02 & 2.73 \\ 0.15 & 0.184 & 0.172 \\ & & \\ 16.98 & 20.05 & 20.05 \\ 44.05 & 57.58 & 57.58 \\ 0.96 & 0.96 & 0.96 \\ 0.215 & 0.238 & 0.227 \\ 27.9 & 27.8 & 27.9 \\ 685.9 & 620.2 & 576.8 \\ 0.807 & 0.838 & 0.941 \\ 1 & 99 & \\ 0.26 & 0.236 & 0.227 \\ 6.7 & 5.4 & 5.7 \\ 49.7 & 45.5 & 45.5 \\ 547.6 & 491.1 & 510.5 \\ 602.8 & 549.3 & 572 . \\ 178.3 & 184.6 & 184.6\end{array}$

178.3

184.6
$>$

2-7b

1650

38.55
7.5

3.0

$4.34 \quad 4.19$

$14.6 \quad 14.12$

14.12

3.31

0.754

3.17

2.95
0.149

0.149

Char Samples Lost

16.98
$\mathbf{4 4 . 0 5}$

0.96

0.237

$$
705.4
$$$$
\begin{array}{r}
705.4 \\
0.68
\end{array}
$$$$
\begin{array}{r}
\mathrm{vg} \\
0.281
\end{array}
$$

49.7

515.8
559

178.3

3.72
0.852

3.33

0.165

$15.39 \quad 15.39$

$39.92 \quad 39.92$

$0.96 \quad 0.96$

0.20 .188

$28.3 \quad 28.3$

$680.8 \quad 620.3$

$1.724 \quad 1.458$

0.259

0.248

7.6

$52.1 \quad 52.1$

$568.7 \quad 597.1$

$626.3 \quad 659.6$

$171.3 \quad 171.3$ 
COAL MESH SIZE: -18

TEST NUMBER: 3

COMMENTS:

RUN \#

Temperature deg. $F$

Input Coal ( $g / \mathbf{m i n})$

Input Steam (g/min)

Input Air (g/mln)

Input Limestone (g/miln)

Dry Gas Composition

Primary Char (g/min)

Ib Char/100 lb Coal

Secondary Char (g/min)

Coal/Air Ratio

Mol. Weight (lb/lbmol)

Heating Value (BTU/hb)

$\mathrm{Kp}$

O2 Balance

Carbon Conversion

Bed Velocity (ft/s)

Recycle Ratio

Ib gas $/ 100$ lb coal

lb input/100 lb coal

mean part. dla. $\left(m^{*} 10 E-6\right)$
Variable Superficial Velocity Test

Average C/A Ratio: 0.231

Average Test Temperature: 1636

$\begin{array}{rrrrrr}3-1 \mathrm{a} & 3-1 \mathrm{~b} & 3-2 & 3-3 & 3-4 \mathrm{a} & 3-4 \mathrm{~b} \\ 1650 & 1650 & 1665 & 1650 & 1600 & 1600 \\ 43.13 & 43.13 & 43.13 & 48.06 & 34.82 & 34.82 \\ 7.5 & 7.5 & 7.5 & 7.5 & 7.5 & 7.5 \\ 242.3 & 255.2 & 213.5 & 259.8 & 103.0 & 109.5 \\ 3.4 & 3.4 & 3.4 & 3.7 & 2.7 & 2.7\end{array}$

CO

$3.84 \quad 3.89$

$\mathrm{CO2}$

13.001

0

12.91

$\mathrm{H} 2$
$\mathrm{H} 2 \mathrm{~S}$

3.66

0.693

2.78

$\mathrm{CH} 4$

NH3

0.188

19.46

45.12

0.96

0.178

28.1

601.7

1.848

b

0.223

9.0

46.3

606.4

683.7

200

\subsection{1}

0.625

1.94

0.17

19.46

45.12

0.96

0.169

28.1

500.7

0.1543

b

0.213

9.5

46.3

641

717.7

200
3.4

3.7

2.7

2.7

$\begin{array}{rrrr}5.07 & 4.45 & 4.61 & 4.03 \\ 12.9 & 13.83 & 14.04 & 14.76 \\ 0 & 0 & 0 & 0 \\ 3.03 & 3.19 & 2.92 & 2.27 \\ 0.622 & 0.461 & 0.826 & 0.794 \\ 3.075 & 2.28 & 3.72 & 2.73 \\ 0.181 & 0.139 & 0.245 & 0.204\end{array}$

21.1

48.92

0.96

0.202

28

653.1

0.878

$f$
0.235

0.235
8.0

44.3

551.5

620.1

232.9

20.77

43.22

0.96

0.185

28.3

541.7

1.181

1

0.235

9.7
44.6

602.2

665.4

193.4

28.17

28.17

$80.9 \quad 80.9$

$0.96 \quad 0.96$

$0.338 \quad 0.318$

$27.1 \quad 27.3$

$652.6 \quad 496.8$

$0.417 \quad 0.365$

$\begin{array}{rr}\text { vg } & g \\ 0.218 & 0.21\end{array}$

0.21
4.1

37.3

37.3

373.2

434.3

385.6

443.7

187.8 
COAL MESH SIZE: -40

TEST NUMBER: 4

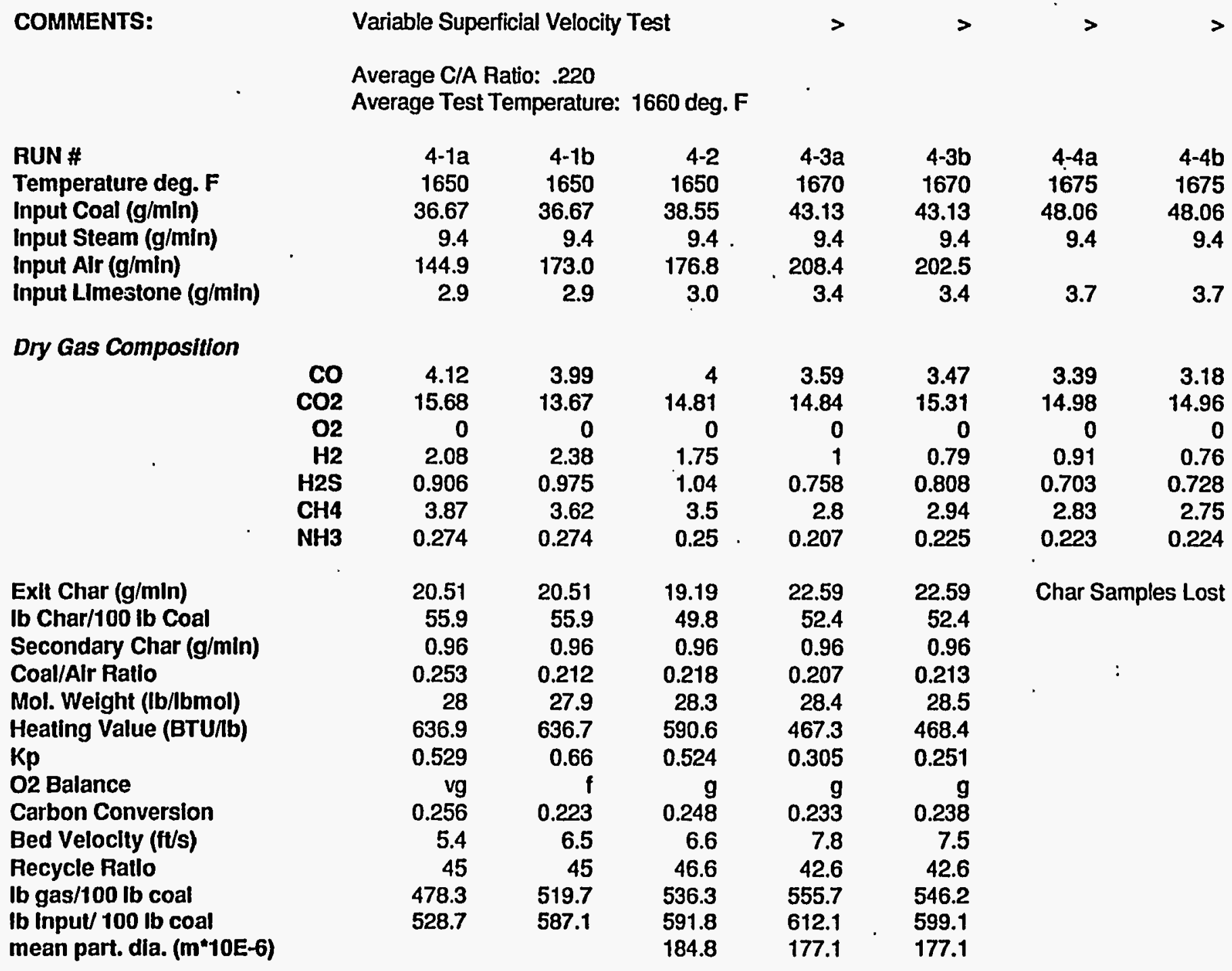


COAL MESH SIZE: -40

TEST NUMBER: 5

COMMENTS:

RUN \#

Temperature deg. $F$

Input Coal ( $\mathrm{g} / \mathrm{min})$

Input Steam (g/min)

Calculated Input Alr (g/min)

Input LImestone (g/min)

Dry Gas Composition

政

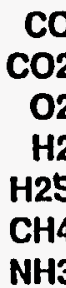

Primary Char (g/min)

Ib Char/100 lb Coal

Secondary Char (g/min)

Coal/Air Ratlo

Mol. Weight (lb/lbmol)

Heating Value (BTU//b)

Kp

02 Balance

Carbon Conversion

Bed Veloclty (ft/s)

Recycle Ratlo

ib gas/100 lb coal

Ib Input/ $100 \mathrm{lb}$ coal

mean part. dia. $\left(m^{*} 10 E-6\right)$
Variable Bed Temperature Test

Average Superficial Velocity: 6.4

Average C/A Ratio: .241

$\begin{array}{rrrrrr}5-1 & 5-2 & 5-3 a & 5-3 b & 5-4 a & 5-4 b \\ 1600 & 1600 & 1700 & 1700 & 1740 & 1758 \\ 38.55 & 38.55 & 38.55 & 38.55 & 38.55 & 38.55 \\ 9.4 & 9.4 & 9.4 & 9.4 & 9.4 & 9.4 \\ 114.1 & 152.4 & & & 229.5 & 189.0 \\ 3.0 & 3.0 & 3.0 & 3.0 & 3.0 & 3.0 \\ & & & & & \\ 4.15 & 4.56 & 4.46 & 3.43 & 3.12 & 4.31 \\ 15.18 & 16.6 & 14.64 & 14.56 & 13.09 & 14.61 \\ 0 & 0 & 0 & 0 & 0 & 0 \\ 1.11 & 1.41 & 1.5 & 1.19 & 1.21 & 1.95 \\ 0.735 & 1.09 & 0.807 & 0.798 & 0.823 & 0.691 \\ 3.27 & 3.77 & 3.91 & 3.4 & 3.09 & 3.37 \\ 0.239 & 0.286 & 0.3 & 0.31 & 0.372 & 0.289 \\ & & & & . & \\ 31.49 & 19.38 & \text { Char Samples Lost } & 16.93 & 16.93 \\ 81.68 & 50.3 & & & 43.9 & 43.9 \\ 0.96 & 0.96 & & & 0.96 & 0.96 \\ 0.338 & 0.253 & & & 0.168 & 0.204 \\ 27.3 & 28.3 & & & 28.4 & 28.3 \\ 506.5 & 615 & & & 504.2 & 600.1 \\ 0.154 & 0.346 & & & 0.525 & 0.582 \\ 1 & \mathrm{~g} & & & b & \mathrm{~g} \\ 0.22 & 0.276 & & & 0.22 & 0.254 \\ 4.2 & 5.7 & & & 8.6 & 7.0 \\ 34.7 & 46.3 & & & 49.7 & 49.7 \\ & & & & & \\ 171.9 & 171.9 & & . & 162.4 & 162.4 \\ & & & & & \end{array}$


COAL MESH SIZE: -40

TEST NUMBER: 6

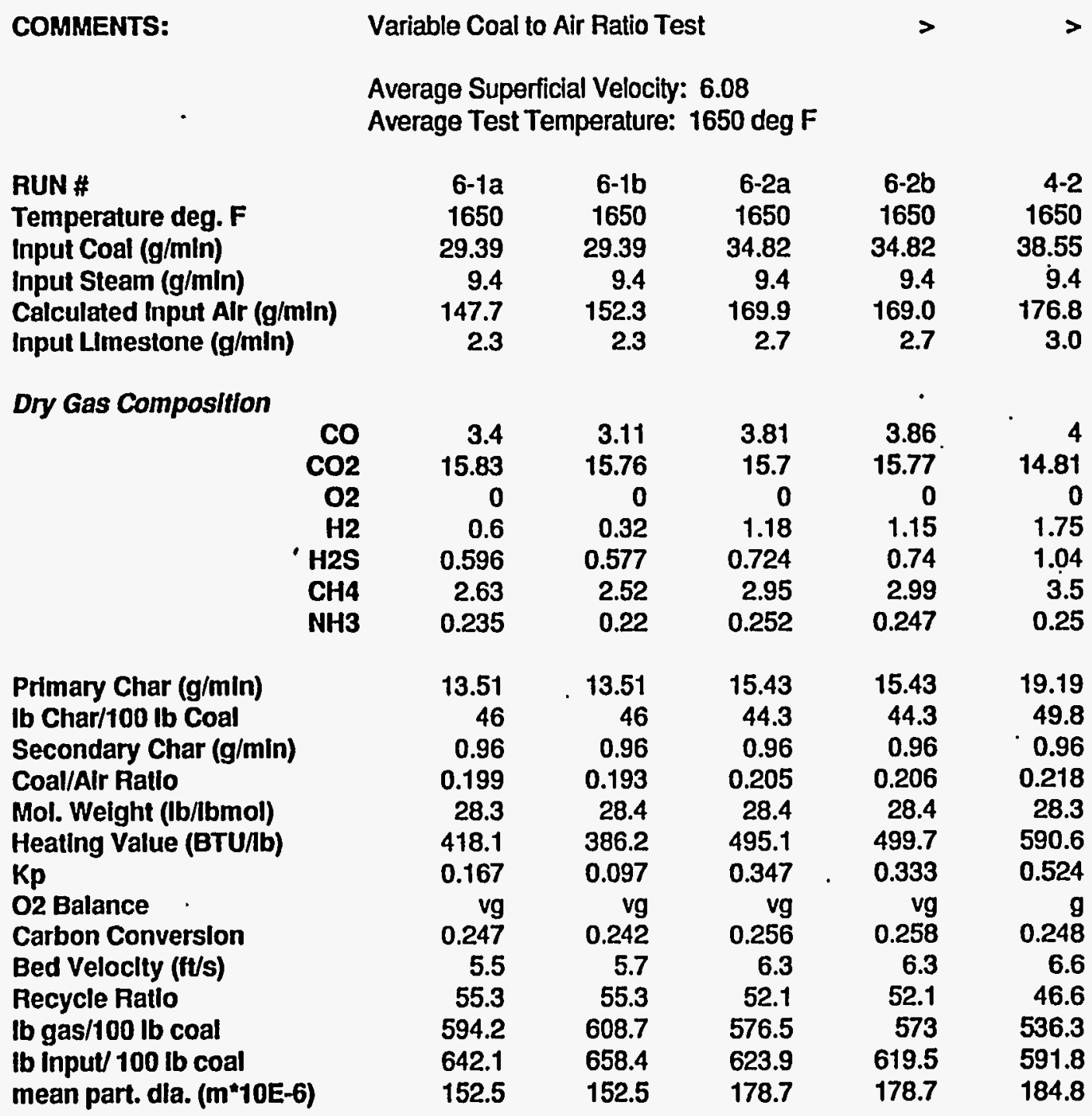


COAL MESH SIZE: -30

TEST NUMBER: 7

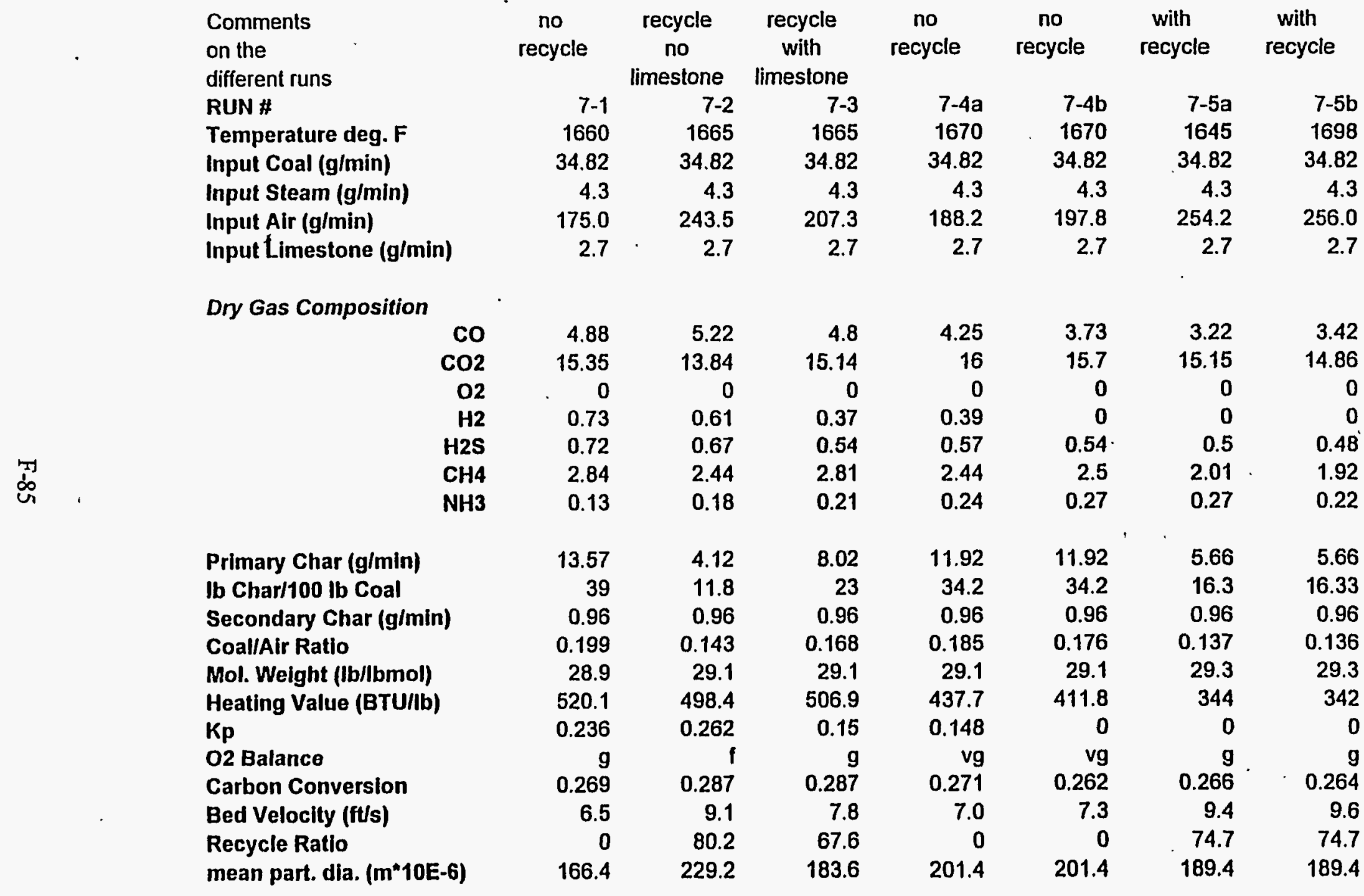




\section{F.6 ENERGY BALANCE CALCULATIONS}

The energy inputs into the pyrolyzer are

(a) the heating value of the coal

(b) the sensible enthalpy of the air

(c) the enthalpy of the steam

To account for the scale of the pyrolyzer, the energy audit must be performed with the actual mass flows.

Sample case. The following energy audit computations are for the case of Test

Number 4-2 of Appendix 1.

Coal size: -40 mesh

Superficial velocity: $6.4 \mathrm{ft} / \mathrm{sec}$

Temperature: $1650^{\circ} \mathrm{F}$

Air inlet temperature $=300^{\circ} \mathrm{F}$ ambient

Steam inlet temperature $=300^{\circ} \mathrm{F}$

Coal mass flow $=38.55 \mathrm{gms} / \mathrm{min}=0.0851 \mathrm{lbs} / \mathrm{min}$

Air mass flow $=176.83 \mathrm{gms} / \mathrm{min}=0.39 \mathrm{lbs} / \mathrm{min}$

Steam mass flow $=9.4 \mathrm{gms} / \mathrm{min}=0.0208 \mathrm{lbs} / \mathrm{min}$

Coal Heating value $=12765 \mathrm{Btu} / \mathrm{lb}$

- Air Specific heat $=0.24 \mathrm{Btu} / \mathrm{lb}^{\circ} \mathrm{F}$.

Steam enthalpy at $300^{\circ} \mathrm{F}, 1 \mathrm{~atm}=1192.6 \mathrm{Btu} / \mathrm{lb}$

Energy input in coal $=0.0851 \times 12765 \mathrm{Btu}=1086 \mathrm{Btu} / \mathrm{min}$

Energy input in air $=0.0$

Energy input in steam $=0.0208 \times 1192.6=24.81 \mathrm{Btu} / \mathrm{min}$

Total inputs

$=1110.8 \mathrm{Btu} / \mathrm{min}$ 


\section{Energy outputs from pyrolyzer}

The energy outputs from pyrolyzer are

(a) the heating value of the fuel gas

(b) the sensible enthalpy of the fuel gas

(c) the heating value of the primary and secondary char-sorbent product

(d) the sensible enthalpy of the char sorbent product

(e) heat losses

The heat output in fuel gas=mass $\times$ calorific value

$$
=\frac{536.3}{100} \times 0.0851 \times 590.6=269.5 \mathrm{Btu} / \mathrm{min}
$$

The specific heat of the fuel gas was calculated using the fuel gas molar composition and was found to be 0.29 .

Sensible enthalpy of fuel gas at the exit temperature of $1600^{\circ} \mathrm{F}$

$$
\begin{aligned}
& =\text { mass } \times \text { specific heat } \times \text { temperature difference } \\
& =(5.363 \times 0.0851) \times 0.29(1600-100) \\
& =198.5 \mathrm{Btu} / \mathrm{min}
\end{aligned}
$$

Heating value of char product=mass $\times$ calorific value

$$
=\frac{49.8}{100} \times 0.0851 \times(0.3) \times(1600-100)=299.5 \mathrm{Btu} / \mathrm{min}
$$

The calorific value of the char was taken from Table 4.8.1. With the char specific heat taken as $0.3 \mathrm{Btu} / \mathrm{lb}{ }^{\circ} \mathrm{F}$, the char sensible heat is calculated as .

$$
\frac{49.8}{100} \times 0.0851 \times 0.3 \times(1600-100)=19.1 \mathrm{Btu} / \mathrm{min}
$$

The char mass escaping from the primary cyclone is approximately $1 \mathrm{gm} / \mathrm{min}$ and its heating value is taken to be the same as that of the primary char.

Hence, energy lost via secondary char $=\frac{0.0851}{38.55} \frac{\mathrm{lb}}{\mathrm{min}} \times 7068 \frac{\mathrm{Btu}}{\mathrm{lb}}$

$=15.6 \mathrm{Btu} / \mathrm{min}$ 


\section{Heat losses from plumbing and other areas}

The shut-out value at the exit of the primary char collection hopper has to be kept within $300^{\circ} \mathrm{F}$ for proper operation and represents an area of energy loss.

Forced convection heat transfer coefficient from literature $=0.188 \frac{B t u}{\min f t^{2 \circ} F}$

Heat transfer loss from shut-out valve $=\frac{0.188}{144} \frac{B t u}{\mathrm{in}^{2}{ }^{\circ} \mathrm{F} \min } \times 56 \mathrm{in}^{2} \times\left(1600-300^{\circ} \mathrm{F}\right)$

$$
=96 \mathrm{Btu} / \mathrm{min}
$$

Heat transfer from inlet air plumbing $=\frac{0.082}{144} \frac{B t u}{\mathrm{in}^{2 \circ} \mathrm{F} \min } \times 56.55 \times(1600-100)$

$$
=48.3 \mathrm{Btu} / \mathrm{min}
$$

Heat transfer from plumbing at exit cyclone $=\frac{0.082}{144} \frac{B t u}{{i n^{2} \circ \mathrm{F} \min }^{2}} \times 48 i^{2} \times(1500-100)$

$$
=38.27 \mathrm{Btu} / \mathrm{min}
$$

Heat transfer from see-through section of recycie leg

$$
\begin{aligned}
& =\frac{0.082}{144} \frac{\mathrm{Btu}}{\mathrm{in}^{2} \circ \mathrm{F} \min } \times 6 \sin ^{2} \times(1600-100)^{\circ} \mathrm{F} \\
& =55.5 \mathrm{Btu} / \mathrm{min}
\end{aligned}
$$

Total of energy outputs and

losses $=269.5+198.5+299.5+19.1+15.6+96+48.3+38.3+55.5$

$$
=1040.3 \mathrm{Btu} / \mathrm{min}
$$

Heat unaccounted for=input-output

$$
=1110.8-1040.3=70.5 \mathrm{Btu} / \mathrm{min}
$$

In percentages, the above values are as follows:

Inputs: coal $(1086 / 1110.8) 100=97.8 \%$

$$
\text { Air } \quad=0.0 \%
$$

Steam $(24.81 / 1110) 100=2.2 \%$

Qutputs as percentage of total input

.. Product gas calorific value and sensible heat $=(269.5+198.5) \times 100 / 1110.8$

$$
=42.13 \%
$$


Primary char product heating value and sensible heat $=(299.5+19.1) \times 100 / 1110.8=28.7 \%$

Secondary char product heating value and sensible heat $=(15.6+1.0) \times 100 / 1110.8=1.5 \%$

Plumbing heat losses at air inlet and secondary cyclone

outlet $=(48.3+38.29) \times 100 / 1110.8=7.8 \%$

Heat loss from see-through section in recycle leg $=55.5 \times 100 / 1110.8=5 \%$

Heat loss from cooled shut-out valve in recycle leg $=96 \times 100 / 1110.8=8.6 \%$

Miscellaneous losses $=70.5 \times 100 / 1110.8=6.3 \%$

These values are shown in Figure 4.10.1 in the text.

It is to be mentioned here that heat losses from the main column of the fluidized bed pyrolyzer, the primary and secondary cyclones, and portions of the primary cyclone downcomer are not included in the above computations. The vertical portion of the main pyrolyzer column is equipped with electric heaters that come on periodically to ensure that the process temperature in the column is the same as the bed temperature in the dense phase bottom section. The primary cyclone, is also wrapped with heating tape and insulated, although the wall temperature here is less than the gas temperature. The secondary cyclone is not heated, but insulated.

An estimate of the heat provided by the electrical resistance heaters was made by operating the pyrolyzer as a combustor at the test temperature of $1650^{\circ} \mathrm{F}$. The coal and air mass flows were measured, and an energy audit was performed. The computations showed the heat losses to be about $118 \mathrm{Btu} / \mathrm{min}$ when no electrical heaters were employed.

Thus, the miscellaneous heat losses listed above of $6.3 \%$ are considered to occur

(a) in the secondary cyclone

(b) partly in the primary cyclone

(c) and partly in the downcomer from the primary cyclone 
This will account for $100 \%$ of the heat input. However, it is to be noted that approximately $80-100 \mathrm{Btu} / \mathrm{min}$ of heat input are provided by the electrical resistance heaters on the main column of the pyrolyzer and the primary cyclone.

The total heat losses from this small scale pyrolyzer is the sum of (a) plumbing loss, (b) see-through section loss, (c) shut-out value loss, and (d) miscellaneous loss.

This is $(48.3+38.29+55.5+96+70.5) \times 100 / 1110.8=22.8 \%$ of input energy. 